\title{
Dimorfismo alélico na proteína de superfície MSP-6 de merozoítos de Plasmodium falciparum
}

Dissertação apresentada ao Programa de Pós-Graduação em Biologia da Relação Patógeno-Hospedeiro do Instituto de Ciências Biomédicas da Universidade de São Paulo, para obtenção do Título de Mestre em Ciências Biológicas. 


\section{Dimorfismo alélico na proteína de superfície MSP-6 de merozoítos de Plasmodium falciparum}

Dissertação apresentada ao Programa de Pós-Graduação em Biologia da Relação Patógeno-Hospedeiro do Instituto de Ciências Biomédicas da Universidade de São Paulo, para obtenção do Título de Mestre em Ciências Biológicas.

Área de Concentração: Parasitologia

Orientador: Prof. Dr. Marcelo Urbano Ferreira 
DADOS DE CATALOGAÇÃO NA PUBLICAÇÃO (CIP)

Serviço de Biblioteca e Informação Biomédica do

Instituto de Ciências Biomédicas da Universidade de São Paulo

(c) reprodução total

Silva, Rogério Lauria da.

Dimorfismo alélico na proteína de superfície MSP-6 de merozoítos de Plasmodium falciparum / Rogério Lauria da Silva. -- São Paulo, 2008.

Orientador: Marcelo Urbano Ferreira.

Dissertação (Mestrado) - Universidade de São Paulo. Instituto de Ciências Biomédicas. Departamento de Parasitologia. Área de concentração: Biologia da Relação Patógeno-Hospedeiro. Linha de pesquisa: Epidemiologia molecular da malária.

Versão do título para o inglês: Allelic dimorphism in Plasmodium falciparum merozoite surface protein-6 (MSP-6).

Descritores: 1. Malária 2. Plasmodium falciparum 3. Proteínas da membrana 4. Dimorfismo alélico 5. MSP-6 I. Ferreira, Marcelo Urbano II. Universidade de São Paulo. Instituto de Ciências Biomédicas. Programa de Pós-Graduação em Biologia da Relação Patógeno-Hospedeiro III. Título. 
Candidato(a):

Título da Dissertação:
Rogério Lauria da Silva.

Dimorfismo alélico na proteína de superfície MSP-6 de merozoítos de Plasmodium falciparum.

Orientador(a): $\quad$ Marcelo Urbano Ferreira.

A Comissão Julgadora dos trabalhos de Defesa da Dissertação de Mestrado, em sessão pública realizada a ...................,
( ) Aprovado(a)
( ) Reprovado(a)

Examinador(a): Assinatura:

Nome:

Instituição:

Examinador(a): Assinatura:

Nome:

Instituição:

Presidente: Assinatura:

Nome:

Instituição: 


\section{DEDICATÓRIA}

Aos meus pais, Alberto Lauria da Silva e Maria Edina da Rocha, por estarem sempre presentes, mesmo à distância, e por terem sempre me apoiado quando tomei as decisões mais difíceis.

Ao meu irmão Reinaldo, meu mais antigo amigo.

Ao meu irmão Renan, inspiração constante para que eu tente sempre ser alguém melhor. 


\section{AGRADECIMENTOS}

Ao meu orientador, Professor Marcelo Urbano Ferreira, por ter me aceitado como aluno de mestrado, por ter me apresentado a coisas tão novas e distintas, e pelas constantes demonstrações de conhecimento que o tornam um exemplo a ser seguido. Muito obrigado.

Aos meus amigos de laboratório:

Mari (Mariana Tenedini), minha querida aluna de Iniciação Científica, por ter ficado ao meu lado esse tempo todo, sem nunca desistir. Muito obrigado por sua amizade, paciência e companhia.

Zezé (Maria José Menezes), fonte inesgotável de sabedoria (sei que ela vai achar isso irônico, mas não é). Teoricamente a técnica do laboratório, na prática minha grande amiga, incentivadora e conselheira.

Pam (Pámela Orjuela), nossa flor da Colômbia, por sua amizade, seu bom humor e seu sorriso, sempre presentes, seja pipetando um sequenciamento, seja sob ataque dos borrachudos.

Simonete (Simone Ladeia), Princesa do Jaú, cujo sorriso afasta tudo de ruim, de mau-humor a mau-olhado. Saudosos tempos em que eu ia te dar boa noite no laboratório e você pulava de susto.

Scott W. Roy, por todas as conversas filosóficas sobre a vida e dimorfismo alélico, por todas as perguntas e e-mails respondidos, pelas noites na Casa do Norte, pela cafeteira, pelo violão e pela amizade.

Tatiana Havryliuk, pela alegria e energia incomparáveis, inimitáveis e inesgotáveis.

Mônica da Silva Nunes, por fazer minha "entrevista" de admissão no laboratório, e ser minha primeira colega de trabalho.

Natal, caboclo acreano, pelas dicas dadas nos momentos críticos.

... e Kézia Scopel, por muitas coisas, mas principalmente por ter tentado. 
Aos meus companheiros de lar:

Cristiane Gonçalves (Cris) e Alan Rosendo (Normal), irmãos que a vida me deu.

Clodoaldo Teixeira (Bode), pela paciência e amizade inabaláveis, e pela presença constante nos momentos mais críticos da minha vida.

Mauricio Esteves, Carol Sanchez, Bruno Canettieri, Luciana Sanchez, Álvaro, Aninha (a tartaruga), Henrique (Peba), Cristopher Pereira e Cláudia Nóbrega, pelas cervejas, almoços, risadas, amizade, passeios de bicicleta, companhia, enfim, por terem tornado tão agradável, para um jovem interiorano recém-chegado, a vida na cidade grande.

Aos meus amigos da faculdade:

Mauro e Zé, por todas as viagens, especialmente pra Pedra, especialmente "aquela"...

Alex Hubble, por jamais ter desistido de me chamar pra bandejar.

Bininha, Marilia, Liló, Carol do Zé, Lelê, Japonês, Carol do Japonês, Joana (a essas duas últimas, obrigado por EmbrioMol), Vitão, Ninja, Renato Recoder, Thiago Rasta, Solange, e todos os que acidentalmente não estejam nessa lista, por todos os bons (e maus) momentos vividos durante a graduação.

Aos meus companheiros de laboratório durante minha Iniciação Científica: Cleber, Foca (Arthur Neri), Kátia Yuahasi, Kátia Neves, Henrique, Janaína, Karla, Rodrigo Resende, Paromita Majunder e, especial e carinhosamente, Henning Ulrich, meu primeiro orientador.

À Professora Terezinha Schumaker e seus alunos (Guilherme, Flávia, Eliana, Elinor, Gazeta, Gustavo, Thaís e Antônio), pelo agradável convívio ao longo desses dois anos.

Ao Professor Gerhard Wunderlich e seus alunos por toda a ajuda gentilmente cedida em vários momentos.

Aos funcionários do Departamento de Parasitologia: Márcio Yamamoto, José Mário, Valnice Peres, Manoel Peres e Wolfgang Fischer, por todo o auxílio prestado em vários momentos.

À Fundação de Amparo à Pesquisa do Estado de São Paulo (FAPESP) e ao Conselho Nacional de Desenvolvimento Científico e Tecnólgico (CNPq) pelo financiamento concedido ao longo desse projeto. 
"Toda a sua vida estudara o universo, mas passara-lhe despercebida a sua mensagem mais clara: para pequenas criaturas como nós, a imensidão só é suportável através do amor".

Carl Sagan 


\section{RESUMO}

Silva RL. Dimorfismo alélico na proteína de superfície MSP-6 de merozoítos de Plasmodium falciparum [Dissertação]. São Paulo: Instituto de Ciências Biomédicas da Universidade de São Paulo; 2008.

O desenvolvimento de uma vacina contra a malária causada por $P$. falciparum é prejudicado pelo extenso polimorfismo apresentado pelos antígenos desse parasito. O dimorfismo alélico é um tipo particular de polimorfismo no qual os todos os alelos observados de um gene se encontram claramente divididos em duas famílias. A proteína dimórfica MSP-6 se associa à proteína MSP-1 (também dimórfica) na superfície do merozoíto, participando da formação de um complexo que, acredita-se, esteja envolvido no processo de invasão de hemácias. Genes de msp-6 de 21 isolados obtidos de pacientes do Brasil, mais 2 isolados da Tanzânia, África, foram seqüenciados para estudo da diversidade nucleotídica e distribuição geográfica dos alelos. As duas famílias alélicas possuem distribuição global. Não foi verificada associação entre o dimorfismo de MSP-1 e MSP-6 na montagem do complexo proteico. O gene ortólogo de $m s p-6$ em $P$. reichenowi, grupo irmão de $P$. falciparum, foi seqüenciado para estudos evolutivos. Os alelos dimórficos de MSP-6 aparentam ter surgido de uma população ancestral polimórfica, tendo sido mantidos no presente por seleção balanceada. O alto grau de conservação encontrado dentro de cada família alélica torna MSP-6 um potencial alvo de uma vacina contra a malária.

Palavras-chave: Malária; Plasmodium falciparum; Proteína de superfície do merozoíto-6 (MSP-6); Dimorfismo alélico. 


\section{ABSTRACT}

Silva RL. Allelic dimorphism in Plasmodium falciparum merozoite surface protein-6 (MSP-6) [Master thesis]. São Paulo: Instituto de Ciências Biomédicas da Universidade de São Paulo; 2008.

The development of a vaccine against malaria caused by Plasmodium falciparum has been hampered by the high level of antigen polymorphism exhibited by this parasite. Allelic dimorphism is a pattern in which every observed allele of a gene is clearly grouped into one of two families. The dimorphic protein MSP-6 forms a complex with MSP-1 (also dimorphic) on merozoite surface, and this complex is believed to be involved in erythrocyte invasion. The $m s p-6$ genes were sequenced in isolates obtained from 21 patients from Brazil, plus 2 isolates from Tanzania, Africa, to study nucleotide diversity and geographic distribution of alleles. Both families are globally distributed. Moreover, no association was observed between the MSP-1 and MSP-6 allelic types. Orthologous gene of $m s p-6$ in $P$. reichenowi, chimpanzee parasite and sister group of $P$. falciparum, was sequenced for evolutionary studies. Dimorphic alleles of MSP-6 seem to have originated from an ancestral polymorphic population and are maintained by balancing selection. The high degree of conservation observed within each allelic family makes MSP-6 an promising target for vaccine development.

Key words: Malaria; Plasmodium falciparum; Merozoite surface protein-6 (MSP-6); Allelic dimorphism. 


\section{LISTA DE FIGURAS}

Figura 1. Regiões do globo endêmicas para Plasmodium falciparum.

Figura 2. Áreas de risco de malária no território brasileiro

Figura 3. Evolução dos casos de malária causada por P. falciparum na Amazônia Legal.

Figura 4. Representação esquemática das fases sangüíneas do ciclo de P. falciparum

Figura 5. Representação esquemática do principal complexo protéico presente na superfície de merozoítos de $P$. falciparum

Figura 6. Genealogia de alelos de acordo com os modelos de evolução neutra, seleção balanceada e dimorfismo alélico.

Figura 7. Representação esquemática de genes de proteínas de superfície de $P$. falciparum para os quais é sugerida a ocorrência de dimorfismo alélico.. 32

Figura 8. Região de anelamento dos oligonucleotídeos desenhados para amplificação das duas formas alélicas de msp-6.

Figura 9. Visualização dos produtos da amplificação de $m s p-6$ por PCR

Figura 10. Diversidade nucleotídica entre seqüências de $m s p-6$.

Figura 11. Alinhamento entre as seqüências de msp-6 dos isolados $K 1$, 3D7 e Dd2

Figura 12. Genealogia das amostras de msp-6. 
Figura 13. Amplificação do gene ortólogo de $m s p-6$ em $P$. reichenowi.

Figura 14. Alinhamento da região dimórfica de msp-6 tipo K1 e 3D7 de $P$. falciparum e do gene ortólogo de $P$. reichenowi.

Figura 15. Uma hipótese para a história da região dimórfica de $m s p-6$ de $P$. falciparum. 


\section{LISTA DE QUADROS}

Quadro 1. Local e data de coleta dos isolados de Plasmodium falciparum

Quadro 2. Seqüência dos oligonucleotídeos utilizados nas reações de nested PCR, PCR e sequenciamento do gene msp-6 de $P$. falciparum e do gene ortólogo em $P$. reichenowi.

Quadro 3. Outras seqüências de $m s p-6$ utilizadas para cálculo de diversidade nucleotídica e associação entre alelos.

Quadro 4. Identificação dos tipos alélicos de $m s p-6$ e da região composta pelos blocos 6-16 de msp-1 de P. falciparum. 


\section{LISTA DE TABELAS}

Tabela 1. Identificação dos tipos alélicos presentes nas amostras colhidas em estados da Amazônia Legal.

Tabela 2. Distribuição das amostras estudadas conforme o tipo alélico de $m s p-1$

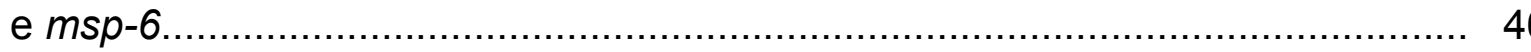

Tabela 3. Diversidade nucleotídica intra e entre famílias alélicas de $m s p-6$

Tabela 4. Valores de substituições sinônimas por sítio sinônimo (dS) e substituições não -sinônimas por sítio não-sinônimo (dN) para os alelos de $m s p-6$

Tabela 5. Número médio de substituições por sítio na comparação entre seqüências de msp-6 de $P$. reichenowi e dos alelos de $P$. falciparum 


\section{LISTA DE ABREVIATURAS E SIGLAS}

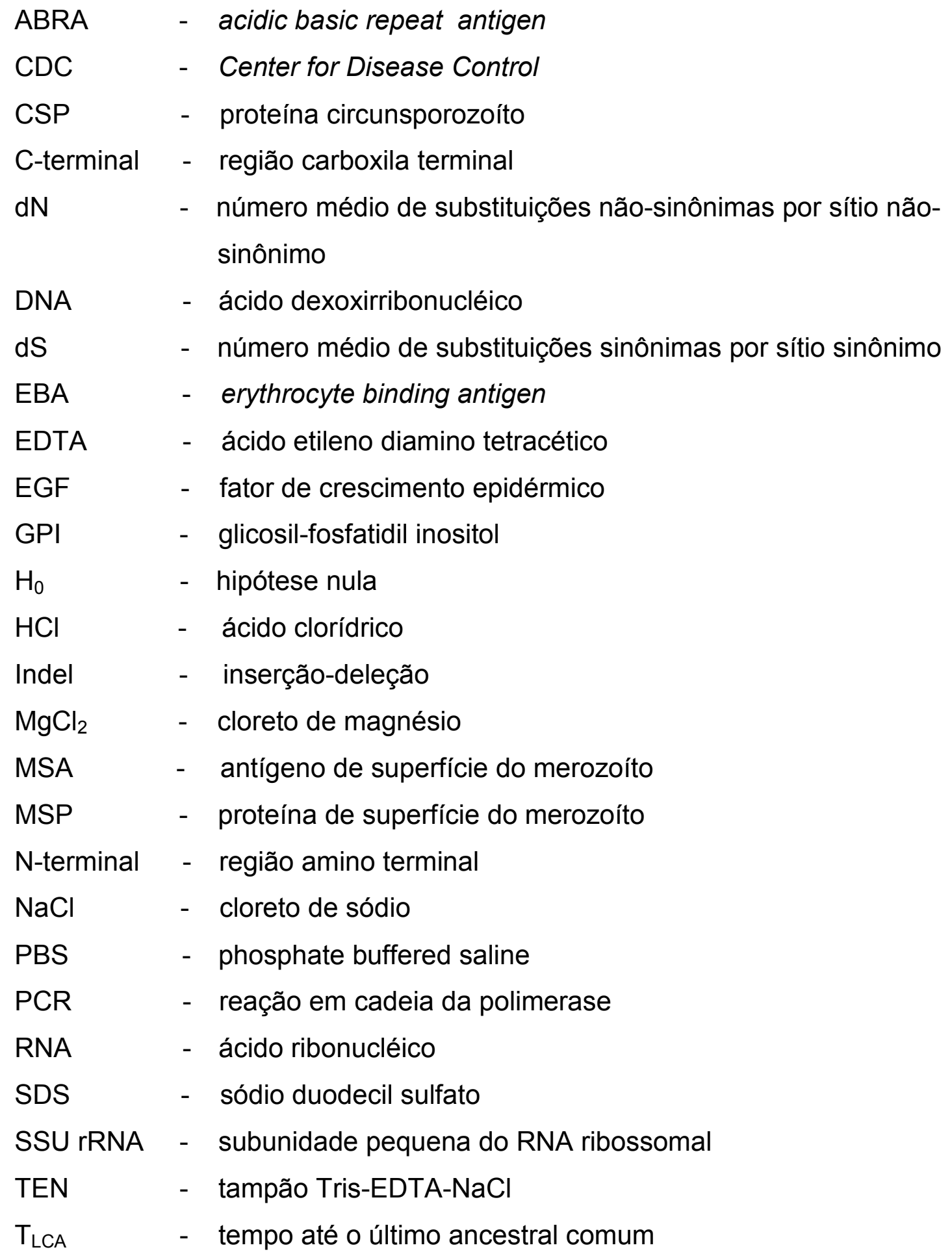




\section{SUMÁRIO}

1 INTRODUÇÃO. 19

1.10 agente causador da malária. 19

1.2 Origem de Plasmodium falciparum como parasito de humanos. 20

1.3 Situação atual da malária, no mundo e no Brasil.

1.4 Ciclo de vida dos plasmódios no homem e sintomas clínicos da doença

1.5 Imunidade adquirida no hospedeiro humano e mecanismos de evasão do parasito.

1.60 complexo de proteínas de superfície do merozoito.

1.70 dimorfismo alélico em proteínas de superfície de membrana do merozoíto

1.8 Tempos de divergência entre alelos de genes dimórficos

1.9 Importância do dimorfismo alélico para estratégias de imunização. 33

2 OBJETIVOS 35

3 MATERIAL E MÉTODOS 36

3.1 Amostras de DNA de $P$. falciparum e $P$. reichenowi. 36

3.1.1 Amostras de DNA de P. falciparum. 36

3.1.2 Amostras de DNA de P. reichenowi. 37

3.2 Extração de DNA a partir de amostras de sangue 37

3.3 Reação de PCR para amplificação do gene msp-6. 37

3.4 Sequenciamento do gene de msp-6. 38

3.5 Montagem das seqüências de $m s p-6$ de $P$. falciparum e $P$. reichenowi.. 39

3.6 Outras seqüências de $m s p-6$. 40 
3.7 Teste de Fisher para verificar a associação entre alelos de msp-1 e msp-6

3.8 Análise da diversidade entre as seqüências

3.9 Cálculo de mutações sinônimas e não-sinônimas e identificação de regiões selecionadas positivamente

4 RESULTADOS

4.1 Amplificação e sequenciamento do gene de msp-6 em amostras de sangue de pacientes de malária em estados da Amazônia Legal.

4.2 Ausência de associação entre as formas alélicas de msp-1 e msp-6......

4.3 Diversidade intra- e entre-famílias alélicas de msp-6 em amostras do Brasil.

4.4 Diversidade intra- e entre-famílias alélicas de msp-6 utilizando o conjunto ampliado de seqüências

4.4.1 Diversidade nas regiões $\mathbf{N}$ - e C-terminal

4.4.2 Diversidade na região dimórfica

4.4.3 Deleção secundária na amostra Dd2.

4.4.4 Regra do um quarto aplicada aos alelos de msp-6.

4.5 Seleção positiva em msp-6.

4.6 Amplificação e seqüenciamento do gene ortólogo de msp-6 em

P. reichenowi.

5 DISCUSSÃO

5.1 Antígenos de superfície como alvos para uma vacina contra malária.... 57

5.2 Distribuição dos alelos de msp-6.

5.3 Diversidade nucleotídica em msp-6.

5.4 Ausência de associação entre alelos de msp-1 e msp-6. 
5.5 Seleção positiva em msp-6.

5.6 MSP-6 como possível alvo de uma vacina contra malária.................... 60

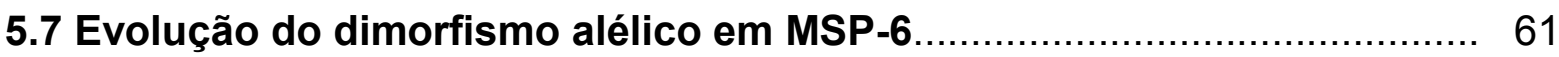

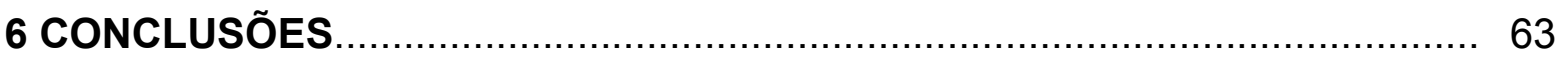

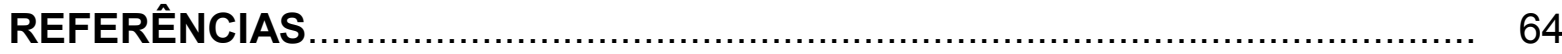

ANEXO A - ALINHAMENTO DAS SEQÜÊNCIAS DE $m s p-6 \ldots \ldots \ldots \ldots \ldots \ldots \ldots . . \ldots 3$

ANEXO B - ALINHAMENTO DAS SEQÜÊNCIAS REPRESENTATIVAS DOS

ALELOS DE msp-6 DE $P$. falciparum COM O GENE ORTÓLOGO EM $P$. reichenowi 


\section{INTRODUÇÃO}

\subsection{0 agente causador da malária}

A malária é uma doença causada por protozoários do gênero Plasmodium, pertencentes ao Filo Apicomplexa (caracterizado pela presença, em seus integrantes, de uma estrutura na região anterior, o complexo apical, relacionado com a invasão das células do hospedeiro), Classe Aconoidasida, Ordem Haemosporida, Família Plasmodidae.

O Filo Apicomplexa Levine, 1970, possui cerca de 5000 espécies conhecidas, todas parasitos. A origem desse filo é objeto de discussão e especulação. Acreditase que tenham surgido como parasitos de ostras ou poliquetas, tendo depois passado a parasitor outros invertebrados marinhos, até atingirem finalmente os artrópodes e, através destes, os vertebrados (Levine, 1988).

A ordem Haemosporida Danilewsky, 1885, é composta por parasitos sanguíneos, e abrange dez gêneros que contém cerca de 450 espécies. Alguns de seus caracteres diagnósticos são familiares para quem conhece o ciclo de vida de Plasmodium: heteroxenia, com merogonia no hospedeiro vertebrado e esporogonia no hospedeiro invertebrado; presença de pigmento (hemozoína) nas células infectadas; desenvolvimento independente de macro e microgametócitos; zigoto móvel (oocineto); transmissão por insetos sugadores. Outras características não tão evidentes são a ausência de conóide (estrutura presente nos anéis polares do complexo apical de outras classes de apicomplexos), esporozoítos com parede formada por três membranas; microgamontes produzindo cerca de oito microgametas flagelados, e ausência de sigizia (fusão permanente das membranas do micro e macrogametócito) (Levine, 1988). Os principais gêneros dentro de Haemosporida são Plasmodium, Hepatocystis e Leucocytozoon. Espécies pertencentes a esses dois últimos gêneros antigamente eram usadas como grupo externo para estudos filogenéticos do gênero Plasmodium.

Há cerca de 200 espécies de plasmódios conhecidas, que parasitam reptéis, aves e mamíferos (Garnham, 1966). Dentre essas, quatro infectam humanos: $P$. ovale, $P$. malariae, $P$. vivax e $P$. falciparum. Esta última é responsável pela maioria 
absoluta da mortalidade causada pela doença. A transmissão da malária se dá através de picadas de mosquito do gênero Anopheles spp.

\subsection{Origem de Plasmodium falciparum como parasito de humanos}

Estudos clássicos que visavam elucidar as relações filogenéticas dentro do gênero Plasmodium, e desse gênero com outros integrantes da Ordem Haemosporida, baseavam-se em caracteres morfológicos e características do ciclo de vida dos parasitos, incluindo a espécie de hospedeiro, vertebrado e invertebrado, e a periodicidade dos paroxismos (febre em intervalos regulares) (Garnham, 1966). Caracteres presentes nos microgametócitos (número formado durante o ciclo sanguíneo, quantidade de flagelos, tamanho), oocistos (tamanho, ocorrência de esporocisto, número de esporozoítos formados) e durante a esquizogonia (número de merozoitos formados) formavam a base de dados disponível para se classificar as diferentes espécies de plasmódios. A partir desses critérios, os plasmódios parasitos de mamíferos foram divididos em três sub-gêneros: $P$. (Vinckeia), contendo os parasitos de mamíferos não-símios; $P$. (Plasmodium), parasitos de macacos, e que contém 3 espécies infectantes de Homo sapiens, nominalmente $P$. vivax, $P$. ovale e $P$. malariae; e $P$. (Laverania), que contém 2 espécies, $P$. falciparum e $P$. reichenowi, parasito de Pan troglodites (chimpanzés) (Garnham, 1966).

O advento das técnicas moleculares forneceu ferramentas para que sistematas de Apicomplexa compensassem a ausência de fósseis desse grupo para estudo (Rich e Ayala, 2003). Em especial, a questão sobre como se deu a evolução de parasitos de humanos (por co-especiação com hospedeiros ou por transferência lateral) pôde ser melhor examinada.

O primeiro estudo molecular visando elucidar as relações filogenéticas dentro do gênero Plasmodium se baseou em seqüências da subunidade pequena de RNA ribossomal (SSU rRNA) de seis espécies, incluindo $P$. falciparum, expressas durante o estágio assexual do parasito (Waters et al., 1991). A partir da análise filogenética desse conjunto de dados foi concluído que $P$. falciparum formaria um grupo monofilético com $P$. gallinaceum e $P$. lophurae, parasitos de aves, reforçando a hipótese de que $P$. falciparum teria se tornado um parasito de humanos a partir de uma troca horizontal de hospedeiro. 
Um estudo posterior, que utilizou também seqüências de SSU rRNA de um número maior de espécies (11) estabeleceu $P$. reichenowi como grupo irmão de $P$. falciparum, formando um grupo monofilético (Escalante e Ayala, 1994). No entanto, a relação desse grupo com os demais variava conforme o grupo externo selecionado. A hipótese de surgimento de $P$. falciparum como parasito de humanos através de coevolução a partir do ancestral comum de homens e chimpanzés foi reforçada a partir desse estudo. Ficou também reforçada a idéia de que as demais espécies de Plasmodium que parasitam o homem pertencem a um grupo claramente distinto do formado por $P$. falciparum - P.reichenowi.

A obtenção de filogenias do gênero Plasmodium a partir do gene de SSU rRNA foi questionada devido à ocorrência de cópias distintas e não agrupadas desse gene, cópias essas cuja regulação da expressão ocorre de forma diferenciada, conforme o momento do ciclo de vida no qual o parasito se encontra (McCutcham et al., 1995). Da mesma forma, um estudo posterior que usou seqüências da proteína circunsporozoito (circunsporozoite protein - csp) (Escalante et al., 1995) para obtenção de filogenias foi questionado, visto que essa proteína de membrana está sob forte pressão evolutiva exercida pelo sistema imune do hospedeiro.

Um estudo abrangente feito por Perkins e Schall (2002), utilizando seqüências de citocromo b de 37 espécies de plasmódios infectantes de diversos grupos, e 16 espécies de outros parasitos apicomplexos, estabeleceu que todas as espécies estudadas de Plasmodium infectantes de mamíferos se agrupavam em um único clado, que no entanto é parafilético devido à presença de espécies de Hepatocystis, fato que já havia sido notado por Escalante et al. (1998). O grupo formado por $P$. falciparum - $P$. reichenowi continuou claramente separado dos demais grupos de parasitos de mamíferos, confirmando que $P$. falciparum tem uma origem distinta da de outras espécies de plasmódios como parasitos de humanos.

\subsection{Situação atual da malária, no mundo e no Brasil}

Estimativas indicam que em 2007 cerca de 2 bilhões de pessoas estiveram expostas ao risco de infecção por malária, com a ocorrência de 300-600 milhões de casos clínicos resultando em 1-3 milhões de mortes (Snow et al., 2005; Guerra et al., 2008 - Figura 1). A maior parte das mortes ocorre na África sub-saariana, em 
crianças com até 5 anos de idade. A doença é endêmica em boa parte dos países da África, Ásia e das Américas Central e do Sul (Organização Mundial de Saúde, 2005).

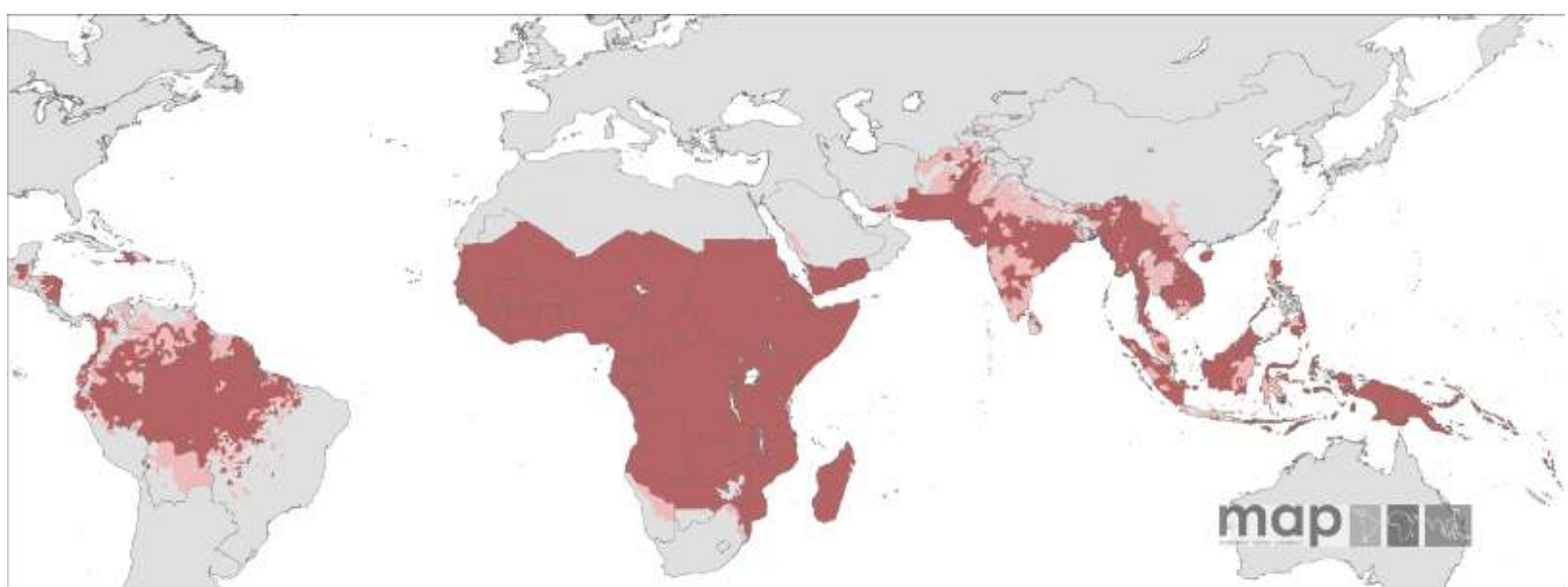

Figura 1. Regiões do globo endêmicas para Plasmodium. falciparum. As áreas do globo foram classificadas como de transmissão estável (vermelho), instável (rosa) e sem risco de transmissão (cinza) (Guerra et al., 2008).

No Brasil, ampla maioria dos casos da doença $(99,5 \%)$ ocorre nos Estados da Amazônia Legal (Acre, Amazonas, Amapá, Maranhão, Mato Grosso, Pará, Rondônia, Roraima e Tocantins) (Figura 2). Nessa região, foram notificados 466.199 casos em 2007, com maior número nos estados do Amazonas, Pará e Rondônia (mais de 100.000 casos em cada estado; Ministério da Saúde, 2008). O principal vetor da doença no Brasil é $A$. darlingi, que possui vasta distribuição no território nacional, é altamente antropofílico sendo capaz de transmitir as três espécies de plasmódios humanos que ocorrem no país: $P$. falciparum, $P$. vivax e $P$. malariae (Ministério da Saúde, 2005).

Historicamente, a malária sempre foi um grave problema de saúde pública no Brasil, estando presente em praticamente todo o território brasileiro até fins do século XIX (Camargo, 2003). Na primeira metade do século XX, grandes surtos da doença assolaram as regiões Norte e Nordeste do país. A partir da década de 1940, a estratégia mundial de combate à doença, focado principalmente no controle dos vetores, foi iniciada no Brasil. Associado a outras medidas essa estratégia possibilitou a redução do número de casos, os quais permaneceram estáveis até meados da década de 70 , quando teve início a ocupação desordenada da região amazônica (Ministério da Saúde, 2005). A partir de então, foram notados aumentos sucessivos no número de casos da doença: em 1983, foram registrados 300.000 
casos; entre 1984 e 1986, a média anual foi de cerca de 400.000 casos; entre 1987 e 1995, foram registrados cerca de 500.000 casos de malária anualmente. Após uma redução significativa nos anos de 1996 e 1997, ocorreu um aumento preocupante no número de casos, que chegou ao seu ápice no ano de 1999, com 637.472 casos registrados.

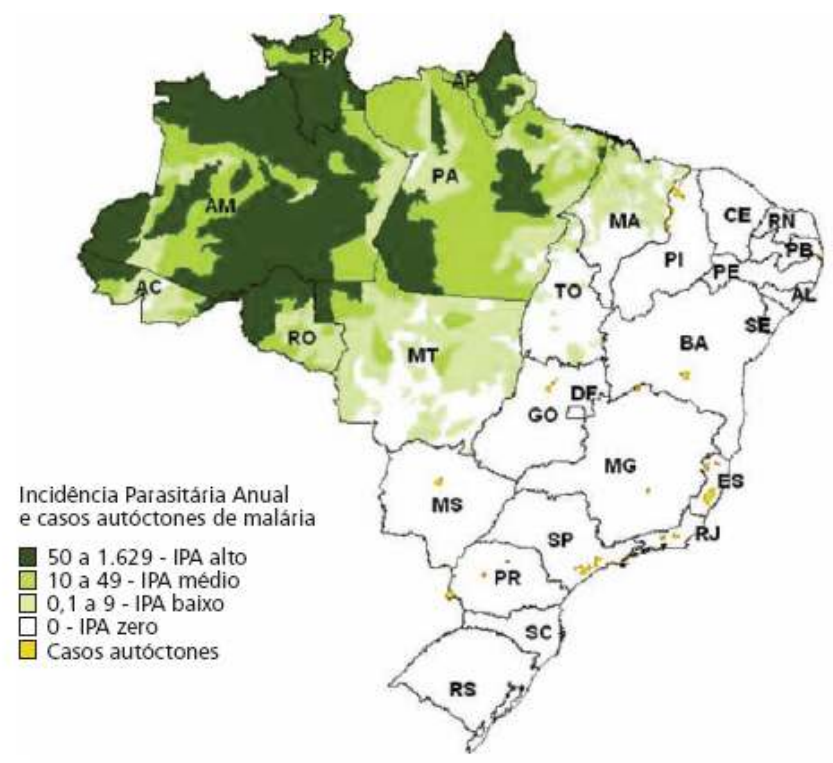

Figura 2. Áreas de risco de malária no território brasileiro (Ministério da Saúde, 2006).

A implementação, a partir de 2000 , de uma série de medidas para reduzir a incidência de malária - tais como a redução no tempo de diagnóstico e tratamento da doença, o monitoramento da resistência do parasito às drogas e do vetor aos inseticidas, e a capacitação dos profissionais de saúde - resultou numa diminuição no número de casos no período de 2000 até 2002. Contudo, a partir de 2003 um aumento significativo no número de casos voltou a ser observado especialmente nos estados de Rondônia e do Acre. Dentre as causas possíveis para esse fato, citam-se a disseminação de parasitos resistentes às drogas antimaláricas, fragilidade das campanhas de combate ao vetor e, supostamente, a ocorrência de pacientes assintomáticos, que podem servir como reservatórios da doença (Coura et al., 2006). Até a década de 1980, havia equivalência entre os casos de malária causados por $P$. falciparum e $P$. vivax. A partir de então, houve aumento progressivo na proporção de 
casos devidos a infecções por $P$. vivax, que causa uma forma mais branda da doença, embora tenha sido notado um aumento preocupante na proporção de casos de $P$. falciparum entre 1999 a 2005 , de $18,6 \%$ para quase $26 \%$ do total (Figura 3 ). Em 2007, essa proporção se reduziu para cerca de $20 \%$ do total de casos registrados.

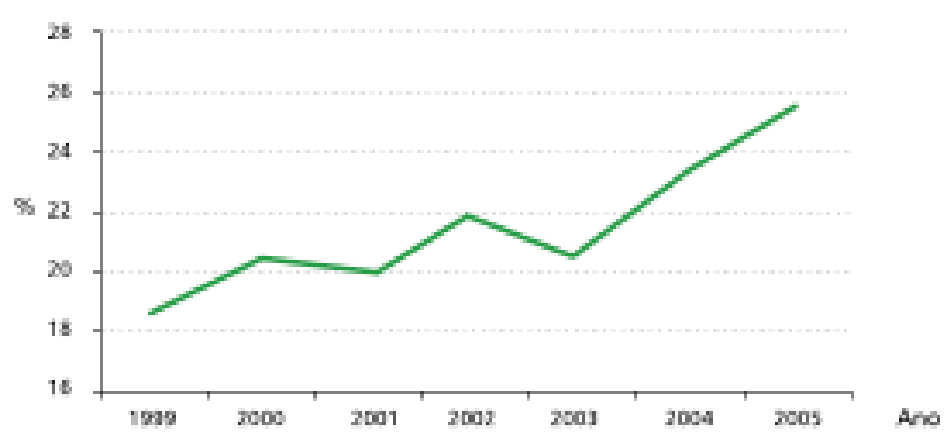

Figura 3. Evolução dos casos de malária causada por $P$. falciparum na Amazônia Legal (Ministério da Saúde, 2006).

\subsection{Ciclo de vida dos plasmódios no homem e sintomas clínicos da doença}

A forma infectante do parasito para os hospedeiros vertebrados são os esporozoítos, que se alojam nas glândulas salivares de anofelinos, e são depositados na pele, quando estes realizam repasto sanguíneo (Figura 4). Os parasitos atingem a corrente sangüínea em alguns minutos, e rapidamente são transportados para o fígado (Frevert, 2004). No hepatócito ocorre a primeira fase de reprodução assexuada (esquizogonia). Ao final de cinco a sete dias, os merozoítos formados (entre 30.000 e 50.000) são liberados na corrente sanguínea, possivelmente após o rompimento do hepatócito infectado (Sinden e Gilles, 2002), embora em $P$. berghei (parasito de roedores) tenha sido descrito um processo no qual os merozoitos são liberados envolvidos em uma estrutura chamada merossomo (Sturm et al., 2006). Esta fase da infecção é assintomática. Uma vez liberados no sangue, os merozoítos invadem eritrócitos. Esse processo ocorre através dos seguintes passos: (a) ligação do merozoíto ao eritrócito, (b) reorientação apical (que coloca as organelas secretoras do merozoíto, as roptrias e os micronemas, em 
contato com a membrana plasmática do eritrócito), (c) formação de um vacúolo parasitóforo, e (d) entrada do parasito no vacúolo (Gaur et al., 2004). No interior dos eritrócitos, o parasito se diferencia na forma intra-eritrocitária conhecida como trofozoíto, que se alimenta das substâncias contidas no citoplasma, principalmente de hemoglobina. Segue-se uma nova esquizogonia, denominada eritrocitária. Ao final deste processo o eritrócito rompe-se, liberando 8-32 novos merozoítos na corrente sangüínea, que invadem novas hemácias (Sinden e Gilles, 2002). Ao final de alguns ciclos sangüíneos, formam-se gametócitos masculinos e femininos que, ao serem ingeridos por mosquitos, dão início ao ciclo sexuado que ocorre no vetor (Barillas-Mury e Kumar, 2005).

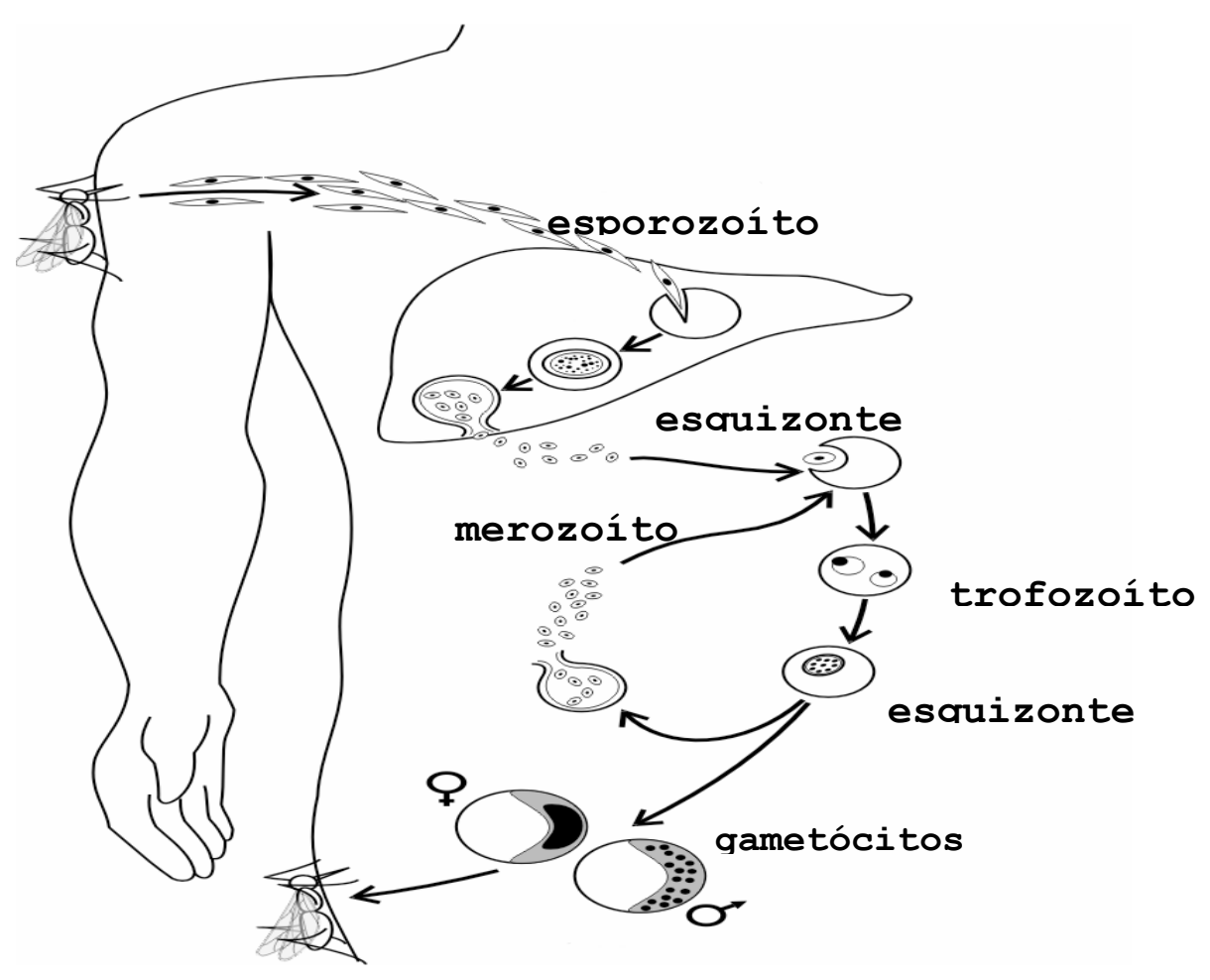

Figura 4. Representação esquemática das fases sangüíneas do ciclo de $P$. falciparum (adaptado de Ferreira et al., 2004).

A gravidade da malária está associada à espécie de plasmódio infectante, ao estado geral de saúde da pessoa infectada e à ocorrência ou não de contato anterior com a doença. Em casos de infecção por $P$. falciparum, após o período assintomático de invasão do fígado, uma série de sintomas clínicos gerais se manifestam, dentre os quais se podem citar: dores de cabeça (às vezes intensa), 
anorexia e náusea, entre outros (Warrel, 2002). Em caso de não tratamento, surgem os paroxismos, ou febres regulares, que valeram à doença o nome popular de febre terçã, ou sub-terçã, maligna.

Além da anemia severa causada pela destruição dos eritrócitos, outras complicações da malária causada por $P$. falciparum advém da propriedade que as hemácias infectadas têm de aderirem às paredes de pequenos vasos sanguíneos (seqüestro), e também de formarem rosetas (estruturas que surgem quando um eritrócito infectado se liga a dois ou mais eritrócitos não infectados) (Wahlgreen et al., 1998). A obstrução de pequenos vasos devido ao acúmulo de eritrócitos no cérebro pode levar ao quadro conhecido como malaria cerebral, cuja evolução acaba resultando em coma e morte (Mackintosh et al., 2004). Outras complicações possíveis são a ocorrências de malária placentária, comum em mulheres primigrávidas de regiões endêmicas, e o comprometimento de órgãos diversos (Warrel, 2002).

\subsection{Imunidade adquirida no hospedeiro humano e mecanismos de evasão do parasito}

Crianças recém-nascidas, provenientes de áreas endêmicas para malária, possuem uma imunidade passiva contra a doença, adquirida pela transferência de anticorpos maternos. Após cerca de seis meses, essa imunidade cessa, e a criança entra na fase em que está mais susceptível à doença. A maior taxa de mortalidade causada por malária se concentra em crianças com até cinco anos de idade, decorrente dos efeitos da anemia grave, malária cerebral ou acidose metabólica (Schofield e Grau, 2005). Após essa fase, a imunidade à malária se desenvolve em 3 fases seqüênciais: imunidade ao desenvolvimento letal da doença, à infecção sintomática e, finalmente, imunização parcial à parasitose (capacidade de manter um baixo nível de parasitemia no sangue, sem desenvolver os sintomas clínicos da doença) (Troye-Blomberg et al., 1999; Schofield e Grau, 2005). O mecanismo pelo qual residentes de regiões endêmicas adquirem imunidade à malária não está esclarecido. No entanto, sabe-se que essa imunidade não é estável, estando vinculada á continuidade do indivíduo na região. Após um período ausente, uma pessoa anteriormente imune se torna novamente susceptível à malária (Marsh, 2002). 
Diversas características da biologia de Plasmodium falciparum tornam difícil tanto seu reconhecimento por células do sistema imune quanto o desenvolvimento de uma vacina efetiva contra o parasito. Dentre essas características, podemos citar: - seu complexo ciclo de vida, com expressão estágio-específica de antígenos (Figura 4); as diferentes respostas imunológicas desenvolvidas pelo hospedeiro; a variação temporal na expressão de antígenos (variação clonal), e o polimorfismo antigênico que ocorre nas proteínas de membrana dos plasmódios (Tsuji et al., 2001; Sinden e Gilles, 2002; Dzikowski et al., 2006). Essa última característica faz com que o parasito não seja reconhecido pelas células de memória geradas por uma exposição anterior ao mesmo patógeno.

O polimorfismo é gerado tanto por substituições em um único nucleotídeo (evento raro, porém constante, que ocorre ao longo de todo o genoma), quanto por eventos de recombinação gênica. Alguns genes de proteínas de membrana (por exemplo, csp, msp-1 e msp-2) possuem regiões com motivos repetidos, onde a ocorrência de inserções e deleções (indels) é mais acentuada (Ferreira et al., 2004). Essas regiões constituem importantes mecanismos de evasão imune, pois tanto geram novas conformações estruturais nos antígenos expostos na superfície do parasito, como também estimulam uma resposta de células $B$ não mediada por células T, não gerando, portanto, células de memória.

\subsection{0 complexo de proteínas de superfície do merozoíto}

A busca de antígenos que fossem potenciais candidatos para o desenvolvimento de uma vacina contra a malária levou à descoberta da proteína mais abundante na superfície do merozoíto, MSP-1 (Merozoite Surface Protein-1). Essa proteína é sintetizada nos estágios finais do desenvolvimento intracelular do parasito como uma molécula precursora de alto peso molecular (180-225 kDa), que sofre uma posterior clivagem proteolítica, resultando em um fragmentos de $83 \mathrm{kDa}$ (p43 ou MSP-143), 28-30 kDa (p30 ou MSP-1 ${ }_{30}$ ), 38 kDa (p38 ou MSP-1 ${ }_{38}$ ) e 42 kDa (p42 ou MSP-142)(Holder et al., 1992). Esse fragmento de 42 kDa também será clivado, resultando em fragmentos com os tamanhos de 33 kDa (p33) e 19 kDa (p19 ou MSP-1 $\left.{ }_{19}\right)$; somente este último (MSP-1 $\left.{ }_{19}\right)$ mantém-se ancorado à membrana do parasito, por meio de uma âncora de glicosil-fosfatidil-inositol (GPI) (Gaur et al., 2004). A presença, em MSP-119, de dois domínios semelhantes ao fator de 
crescimento epidérmico (epidermal growth factor - EGF), que em outras moléculas exerce funções de adesão (O’Donnell et al., 2000), aliada à redução no número de eritrócitos infectados em ensaios com anticorpos que afetam a clivagem de MSP-1 42 (Blackman et al., 1994), são indicadores da importância de MSP-1 no processo de invasão das hemácias.

Devido à sua abundância na superfície do merozoíto e capacidade de causar uma forte resposta imune, a proteína MSP-1 logo se tornou alvo de vários estudos, sendo até o momento a proteína de superfície de merozoitos melhor caracterizada. Esses estudos demonstraram a presença de duas outras proteínas associadas com os fragmentos processados de MSP-1 na superfície do merozoíto (McBride e Heidrich, 1987), que foram posteriormente identificadas como MSP-6 e MSP-7.

MSP-6 é uma proteína codificada por um gene de um único éxon (Trucco et al., 2001). O polipeptídeo correspondente tem 371 aminoácidos, com peso molecular de 42 kDa, no clone 3D7 de $P$. falciparum. Essa molécula é posteriormente clivada, e o produto resultante, com 211 aminoácidos e peso molecular de 36 kDa (denominada MSP-6 ${ }_{36}$ ), é uma proteína encontrada na membrana de merozoítos, na forma de um tetrâmero, que se associa não-covalentemente com MSP-1 ${ }_{38}$ através de sua região C-terminal conservada (Figura 5) (Kauth et al., 2006). Já MSP-7 é sintetizada como um precursor de $48 \mathrm{kDa}$, que sofre uma série de clivagens proteolíticas até ser exposto na membrana como um fragmento de $22 \mathrm{kDa}\left(\mathrm{MSP}_{-} 7_{22}\right)$ (Pachebat et al., 2007), associado com os fragmentos MSP-1 ${ }_{38}, \mathrm{MSP}-1_{30}$ e MSP-1 83 (Kauth et al., 2006).

MSP-9, antigamente denominada p101 ou ABRA (acidic basic repeat antigen), é outra proteína que se associa com esse complexo, através do fragmento MSP-1 42 ou MSP-1 19 (Kariuki et al., 2005). A região de interação entre essas duas proteínas seria responsável pelo reconhecimento de um ligante (Banda 3, uma proteína trocadora de íons) presente na membrana de eritrócitos (Goel et al., 2003) (Figura 5).

Acredita-se que o complexo constituído pelos fragmentos processados das proteínas MSP-1, MSP-6, MSP-7 e MSP-9 esteja envolvido em uma via alternativa de invasão de eritrócitos, independente da via do ácido siálico, que ocorre por meio dos antígenos ligantes do eritrócito (erythrocyte binding antigen - EBA) EBA-175 e parálogos (Gaur et al., 2004). Embora seja reconhecida a importância de MSP-1 e MSP-9 nesse processo, o papel das proteínas MSP-6 e MSP-7 ainda não está esclarecido. 


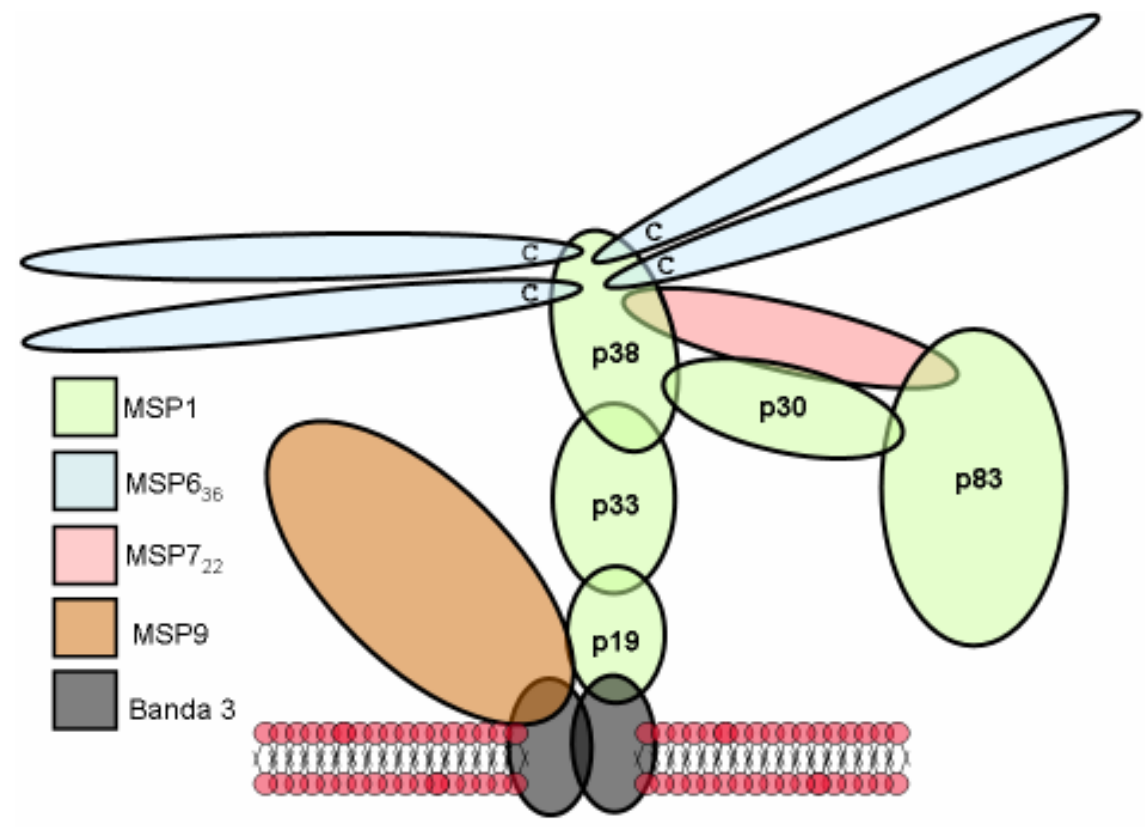

Figura 5. Representação esquemática do principal complexo proteico presente na superfície de merozoítos de $\boldsymbol{P}$. falciparum. Os fragmentos resultantes do processamento proteolítico da proteína MSP-1 permanecem não-covalentemente ligados entre si, e se associam com os fragmentos de MSP-6, MSP-7 e MSP-9. Durante o momento da invasão, esse complexo é clivado, e somente MSP-1 19 permanece na superfície do merozoíto. O complexo reconhece o transportador de íons Banda 3, presente na superfície das hemácias.

\subsection{O dimorfismo alélico em proteínas de superfície de membrana de merozoítos}

Uma característica importante de alguns antígenos de superfície de merozoítos é a presença de dimorfismo alélico. Nesse tipo particular de polimorfismo, as diversas variantes de um determinado antígeno agrupam-se claramente em duas famílias.

A partir de uma amostra de alelos, pode-se, com base em modelos de coalescência, estimar o tempo esperado até o último ancestral comum dessa amostra (TLCA), sob evolução neutra. Esse tempo é estimado a partir da análise do grau de divergência entre as seqüências. No caso do dimorfismo alélico, os níveis de divergência entre alelos de diferentes famílias, quando comparada à divergência encontrada no interior da mesma família, excedem de modo significante as expectativas de modelos clássicos de evolução neutra ou seleção balanceada (Figura 6). 
Se dividirmos a amostra de alelos em duas classes, pode-se estimar o tempo médio esperado de coalescência de cada par de alelos em cada classe, que corresponde ao conjunto de tempos de coalescência até o penúltimo evento de coalescência na amostra. Deste modo, pode-se mostrar que $T_{\text {LCA }}$, sob evolução neutra, é cerca de quatro vezes o tempo médio de coalescência entre pares de alelos cujo último ancestral comum é posterior ao último ancestral da amostra (Figura 6A). No modelo de seleção balanceada (Figura 6B), TLCA é muito maior do que em (6A), pois a pressão seletiva tende a manter o tempo de persistência de diversos alelos na população que seriam eliminados por deriva gênica na ausência de seleção, mas o tempo médio de coalescência dos demais alelos também é prolongado, mantendo-se a proporção entre ramos basais e distais (Richman, 2000).

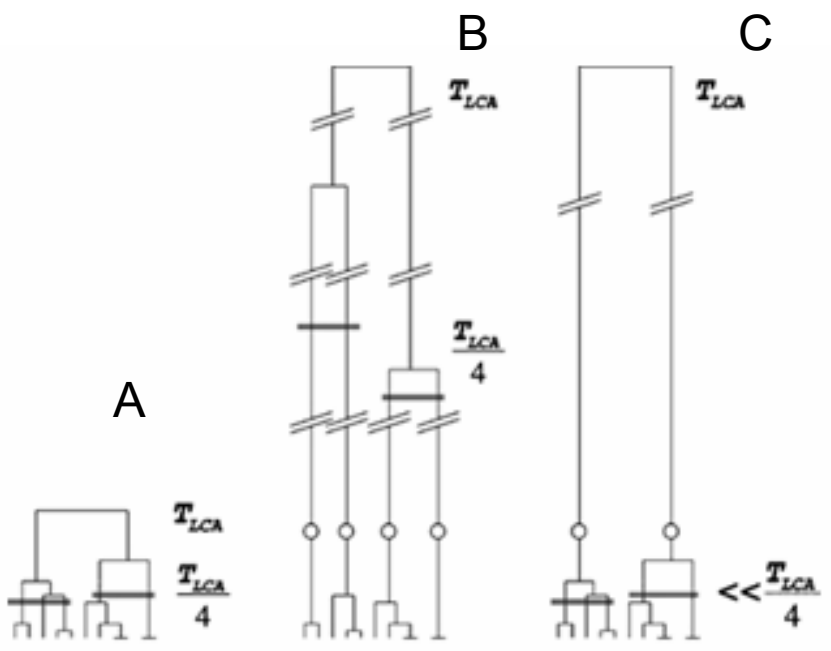

Figura 6. Genealogia de alelos de acordo com os modelos de evolução neutra, seleção balanceada e dimorfismo alélico. Nos modelos de evolução neutra (A) e seleção balanceada (B), o tempo médio de coalescência entre os alelos da cada ramo é cerca de um quarto do tempo da coalescência até o mais antigo ancestral comum de toda a amostra. No caso do dimorfismo alélico (C), o tempo médio de coalescência entre os alelos de ramos diferentes é muito menor que um quarto de $T_{L C A}$. Reproduzido de Roy et al. (2008).

O modelo de dimorfismo alélico (Figura 6C) caracteriza-se por um alongamento desproporcional dos ramos basais da genealogia; deste modo, TLCA é muito superior ao tempo médio de coalescência do mais antigo ancestral de cada um dos ramos dimórficos. Com base nessas relações, pode-se propor um teste estatístico simples para definir dimorfismo alélico como um padrão que se desvia do 
esperado sob evolução neutra: confirma-se sua ocorrência em genealogias em que a divergência entre alelos de classes opostas é quatro vezes maior do que a divergência média entre alelos da mesma classe (Roy et al., 2008). Esse teste será referido, daqui em diante, como "regra de um quarto".

Este padrão dimórfico foi inicialmente descrito em MSP-1 de $P$. falciparum (Tanabe et al., 1987). O estudo de diferentes seqüências do gene dessa proteína levou à identificação de regiões com alta diversidade flanqueadas por regiões muito conservadas. O gene msp-1 foi dividido em blocos (17 ao todo) que podem ser classificados como conservados, semi-conservados ou altamente divergentes (Figura 7). O dimorfismo foi observado nos blocos com alta divergência, e as duas famílias alélicas originadas pela combinação desses blocos são conhecidas como MAD20 e K1 (Tanabe et al., 1987).

Em 1991, foi observada a ocorrência de dimorfismo alélico na proteína MSP-2 (então chamada merozoite surface antigen 2 - MSA2) (Smythe et al., 1991; Snewin et al., 1991). Assim como MSP-1, essa proteína, com peso molecular de cerca de 45-50 kDa, liga-se à superfície do merozoíto por meio de uma âncora de GPI (Gaur et al., 2004). A análise de seqüências diversas de $m s p-2$ também permitiu sua divisão em 2 famílias alélicas, 3D7 e FC27. A proteína pode ser dividida em blocos (5 no total) conforme o grau de divergência encontrado entre as seqüências (Figura 7). Classificam-se como conservadas as regiões $\mathrm{N}$ - e C-terminal (correspondentes aos blocos 1 e 5), que limitam regiões dimórficas (blocos 2 e 4) e uma região central, flanqueada pelas dimórficas, composta por motivos repetitivos (bloco 3). A estrutura desses motivos repetitivos também é característica de cada família (Felger et al., 1997).

Finalmente, em 2004 foi verificada a existência de duas famílias alélicas para a proteína MSP-6, que foram denominadas K1 e 3D7 (Pearce et al., 2004). Assim como MSP-1 e MSP-2, as regiões N- e C-terminal dessa proteína são altamente conservadas, e flanqueiam a região central dimórfica (Figura 7). Os sítios dimórficos são conservados dentro de cada família, mas $\mathrm{K} 1$ se distingue por possuir 3 blocos de seqüências (com 15, 24 e 129 bp de extensão) ausentes em 3D7, o que permite rápida identificação dos tipos alélicos por meio de visualização em gel de agarose. Alelos de tipo 3D7 foram encontrados em parasitos distribuídos em várias regiões do mundo, enquanto os alelos $\mathrm{K} 1$ parecem geograficamente restritos a países do Sudeste Asiático (Pearce et al., 2004). 


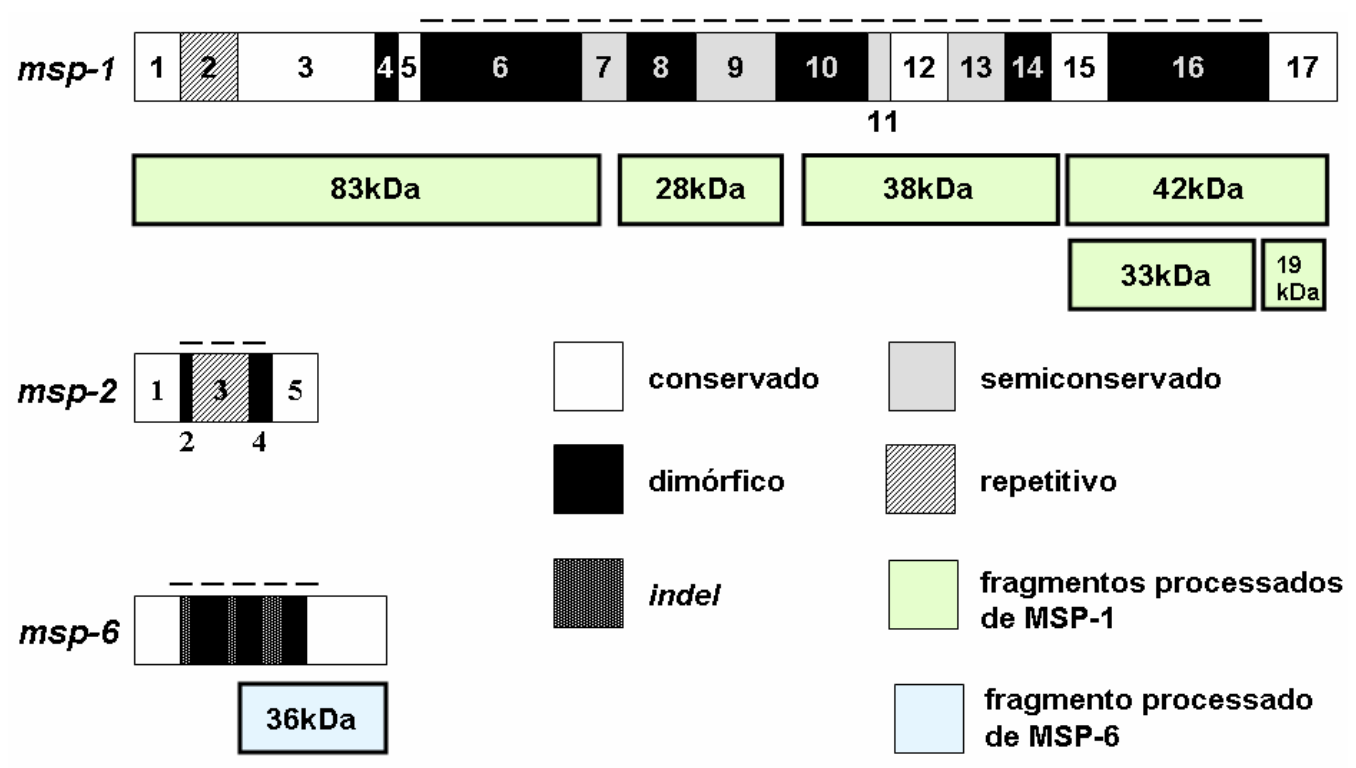

Figura 7. Representação esquemática de genes de proteínas de superfície de $P$. falciparum para os quais é sugerida a ocorrência de dimorfismo alélico. Os genes são divididos em blocos, de acordo com a variabilidade encontrada nessas regiões. As regiões correspondentes às extremidades amina e carboxila de cada proteína são conservadas (adaptado de Roy et al., 2008).

\subsection{Tempos de divergência entre alelos de genes dimórficos}

A ocorrência de dimorfismo alélico resulta em suposições importantes para o estudo das genealogias em que a sua ocorrência é sugerida. Uma delas é a de que não ocorra recombinação, na região dimórfica, entre os genes de famílias alélicas diferentes, visto que isso levaria a uma redução no número de diferenças observadas, por meio de um efeito homogenizador. De fato, um estudo feito com 34 seqüências de $m s p-1$ de $P$. falciparum não encontrou evidências da ocorrência, entre as famílias alélicas MAD20 e K1, de recombinação na região compreendida entre os blocos 4 e 16 (Tanabe et al., 2007a). Dessa forma, o dimorfismo deve ter surgido como um evento basal na genealogia, tendo sido mantido, por razões desconhecidas, até o presente (Roy et al., 2008).

A data de divergência entre os alelos de genes dimórficos de P.falciparum foi estimada pela comparação com os genes ortólogos de outras espécies de Plasmodium. Hughes (1992) estimou que os grupos alélicos de MSP-1 teriam divergido há cerca de 35 milhões de anos, comparando duas porções similares nesse gene e nos genes ortólogos de $P$. yoelli e $P$. chabaudi, parasitos de roedores. Estimativas realizadas posteriormente, em que a comparação foi feita com o gene 
ortólogo de msp-1 em $P$. reichenowi, forneceram um valor aproximado para divergência dos alelos de MSP-1 entre cerca de 28-40 milhões de anos (Polley et al., 2005; Roy et al., 2008). Esses valores colocam o dimorfismo de MSP-1 como um dos mais antigos polimorfismos já descritos, pré-datando a especiação de $P$. falciparum $P$. reichenowi, que, estima-se, tenha ocorrido entre 5 a 7 milhões de anos (Escalante et al., 1998).

De forma contrastante, o dimorfismo alélico de MSP-2 de P.falciparum parece ter origem bem mais recente. $O$ alinhamento de 32 seqüências dos blocos 1 e 5 (conservados) desse gene e do gene ortólogo de $P$. reichenowi forneceu um valor estimado entre cerca de 450.000 e 640.000 anos para a divergência entre os alelos (Ferreira e Hartl, 2007).

Uma comparação prévia, feita com as seqüências disponíveis de $m s p-6$ de $P$. falciparum e uma seqüência montada a partir do seqüênciamento do genoma de $P$. reichenowi realizado pelo Sanger Institute, estimou a data de divergência dos alelos desse gene como concomitante à especiação de $P$. falciparum $-P$. reichenowi (Roy et al., 2008).

O dimorfismo alélico se apresenta dessa forma como um fenômeno que surgiu em diferentes épocas da evolução de Plasmodium falciparum, seja nesse parasito em si ou em seus ancestrais. A manutenção dos alelos por um período de tempo tão extenso, como o sugerido para MSP-1, reforça a hipótese de seleção balanceadora prolongando o tempo de permanência dos alelos, embora os fatores que exerçam essa seleção não estejam esclarecidos (Hughes,1992).

\subsection{Importância do dimorfismo alélico para estratégias de imunização}

Os anticorpos produzidos como parte da resposta imune do hospedeiro são específicos para as formas variantes das proteínas de Plasmodium apresentadas na superfície do parasito. Estratégias de imunização baseadas em proteínas dimórficas apresentam a vantagem de lidarem com antígenos de superfície que apresentam regiões antigênicas de variabilidade reduzida, devido à ausência de variantes gerados por recombinação (Tanabe et al., 2007a). Dessa forma, sugere-se que vacinas que incorporassem regiões conservadas das duas formas alélicas de antígenos dimórficos teriam maior probabilidade de induzir uma resposta eficaz contra esses antígenos (Genton et al., 2002; Polley et al., 2007). 
A proteína MSP-6, dimórfica, representa um potencial integrante de uma vacina contra malária. Tanto o fragmento processado MSP- $6_{36}$ quanto regiões presentes somente na molécula precursora MSP-6 são reconhecidos pelo sistema imune (Wang et al., 2003). Anticorpos que reconhecem a região C-terminal de MSP6 , produzidos naturalmente por indivíduos infectados por $P$. falciparum, são capazes de reduzir o crescimento de parasitos in vitro, por meio de resposta mediada por monócitos (Singh et al., 2005). Ensaios de inibição de invasão, realizados com IgG de coelhos imunizados com MSP-6 do tipo 3D7, resultaram em redução expressiva do número de eritrócitos infectados por parasitos com o mesmo tipo alélico. Quando o ensaio foi realizado com parasitos com MSP-6 do tipo K1, nenhuma redução foi notada (Pearce et al., 2004). Esses dados demonstram que o potencial efeito protetor desses anticorpos depende do reconhecimento de regiões alelo-específicas da proteína.

A diversidade dentro das famílias alélicas de $m s p-6$ ainda não foi explorada, tendo seu dimorfismo sido descrito a partir de somente 8 seqüências (Pearce et al., 2004). Essa informação, associada ao conhecimento das formas alélicas presentes em uma região endêmica para malária, são essenciais para o estudo da imunidade adquirida dos habitantes dessa região, e para o desenho de estudos que visem estudar a epidemiologia e estabelecer estratégias de imunização contra a doença. 


\section{OBJETIVOS}

Caracterizar o dimorfismo alélico de MSP-6, uma proteína de superfície de merozoíto de Plasmodium falciparum dimórfica, presente em isolados coletados em Estados da Amazônia Legal Brasileira.

Estabelecer hipóteses para o surgimento do dimorfismo alélico nessa proteína, a partir do seqüênciamento do gene ortólogo de msp-6 em Plasmodium reichenowi. 


\section{MATERIAL E MÉTODOS}

\subsection{Amostras de DNA de $P$. falciparum e $P$. reichenowi}

\subsubsection{Amostras de DNA de $P$. falciparum}

As amostras de $P$. falciparum disponíveis para este projeto foram obtidas através da coleta de sangue de pessoas infectadas (Quadro 1). Os doadores forneceram consentimento informado e seu anonimato foi garantido. Todas as amostras selecionadas tiveram seu gene $m s p-1$ previamente tipado com base em uma estratégia que envolve amplificação, através de reação em cadeia da polimerase (polymerase chain reaction - PCR) com oligonucleotídeos aleloespecíficos, de três regiões dimórficas ou polimórficas do gene. Selecionaram-se para este projeto amostras brasileiras em que um único alelo de MSP-1 foi encontrado, para permitir o estudo de eventual associação entre famílias alélicas de MSP-1 e MSP-6 nos mesmos isolados (Quadro 1); os isolados da Tanzânia, entretanto, foram escolhidos independentemente desse critério, em função da alta proporção de infecções geneticamente mistas entre eles.

Quadro 1. Local e data de coleta dos isolados de Plasmodium falciparum.

\begin{tabular}{|l|l|l|l|l|l|}
\hline País & Local & Região & Número & Data de & Referência \\
& & & de amostras & coleta & \\
\hline Brasil & Pará & Amazônia Oriental & 6 & $1985-1994$ & Silva et al., 2000 \\
\hline Brasil & Acre & Amazônia Ocidental & 4 & 1999 & Silva et al., 2000 \\
\hline Brasil & Rondônia & Amazônia Ocidental & 16 & 1997 & da Silveira et al., 1999 \\
\hline Tanzânia & Tanga & Norte da Tanzânia & 2 & 1996 & Ferreira et al., 1998a \\
\hline
\end{tabular}




\subsubsection{Amostra de DNA de $P$. reichenowi}

A amostra de DNA de $P$. reichenowi utilizada nesse projeto foi gentilmente cedida pelo Dr. John Barnwell, do Center for Disease Control and Prevention (CDC), Atlanta, Estados Unidos.

\subsection{Extração do DNA a partir de amostras de sangue}

Nas amostras de sangue em que ainda não havia sido realizada a extração de DNA, foi seguido o protocolo proposto por Ferreira et al. (1998b). Brevemente, $200 \mu \mathrm{L}$ de sangue foram lisados com $0,15 \%$ de saponina diluída em tampão de fosfato (phosphate buffered saline - PBS - pH 7,4), e ressuspendidos em $200 \mu \mathrm{L}$ de tampão TEN (10 mM Tris- $\mathrm{HCl}, \mathrm{pH} 8,0,5 \mathrm{mM}$ ácido etileno diamino tetra-acético Ethylene Diamine Tetracetic acid EDTA - e $100 \mathrm{mM} \mathrm{NaCl}$ ) com 0,5\% de sódioduodecil-sulfato (SDS) e $200 \mu \mathrm{g} / \mathrm{mL}$ de proteinase K. Após uma incubação noturna a $37^{\circ} \mathrm{C}$, o DNA foi recuperado através de uma extração comum de fenol-clorofórmio, precipitado com etanol $100 \%$ na presença de $125 \mathrm{mM}$ de acetato de sódio a $-80^{\circ} \mathrm{C}$, lavado em etanol $70 \%$ e ressuspendido em $30 \mu \mathrm{L}$ de água destilada autoclavada.

\subsection{Reação de PCR para amplificação do gene msp-6}

O gene msp-6 completo foi amplificado utilizando-se os oligonucleotídeos descritos por Pearce et al. (2004), denominados FWD1 e REV1 (Quadro 2).

As reações de PCR foram realizadas com as seguintes concentrações finais de reagentes em um volume de $20 \mu \mathrm{L}: 1,5 \mathrm{mM}$ de cloreto de magnésio $\left(\mathrm{MgCl}_{2}\right)$, 0,25 $\mu \mathrm{M}$ de oligonucleotídeos (FWD1 e REV1), $250 \mu \mathrm{M}$ de nucleotídeos trifosfatados (adenina, citosina, guanina e timina) e 2 unidades da enzima polimerizadora de DNA (taq). As condições de amplificação foram:

$-94^{\circ} \mathrm{C}$ por 4 minutos (denaturação inicial do DNA).

-35 ciclos de: $94^{\circ} \mathrm{C}$ por 1 minuto (denaturação do DNA)

$40^{\circ} \mathrm{C}$ por 1 minuto (anelamento dos oligonucleotídeos)

$72{ }^{\circ} \mathrm{C}$ por 2 minutos (extensão do DNA).

$-72^{\circ} \mathrm{C}$ por 10 minutos (extensão final do DNA). 
Nas amostras em que não foi possível amplificar o gene $m s p-6$ utilizando-se o protocolo acima, foi adotado um procedimento de nested PCR, utilizando-se os oligonucleotídeos FWDEXT1 e REVEXT1 (Quadro 2). As concentrações de reagentes $e$ as condições de amplificação foram mantidas, com exceção da temperatura de anelamento: na primeira reação (nested), foi utilizada uma temperatura de $44^{\circ} \mathrm{C}$, e na reação de PCR seguinte essa temperatura foi aumentada para $55^{\circ} \mathrm{C}$.

Parte do produto da reação foi visualizado através de eletroforese em gel de agarose $1,5 \%$, juntamente com um peso molecular de DNA de $100 \mathrm{bp}$ (GeneRuler ${ }^{\mathrm{TM}}$ 100bp DNA Ladder Plus - Fermentas), para verificar a presença do fragmento desejado. Para alelos da família K1, o tamanho esperado do fragmento amplificado era de 1,3 Kbp, e para a família 3D7, 1,1 Kbp (Pearce et al., 2004). Em caso de resultado positivo, esse material era utilizado para reações de seqüênciamento.

\subsection{Seqüenciamento do gene $m s p-6$}

As reações de seqüenciamento foram feitas utilizando-se o kit comercial Big Dye Terminator v3.1 (Applied BioSystems), seguindo-se o protocolo recomendado pelo fabricante. Além dos oligonucleotideos utilizados para amplificação do gene msp-6 (FWD1 e REV1), forma utilizados os oligonucleotídeos denominados FWD2, FWD3, FWD4, REV2 e REV3. As seqüências podem ser vistas na Tabela 2, e sua localização dentro de cada variante do gene $m s p-6$ é mostrada na Figura 8. No caso do seqüênciamento do gene ortólogo de $m s p-6$ de $P$. reichenowi, o oligonucleotídeo FWD2alt foi utilizado no lugar de FWD2. As condições de amplificação foram:

$-96^{\circ} \mathrm{C}$ por 2 minutos (denaturação inicial do DNA).

-35 ciclos de: $96^{\circ} \mathrm{C}$ por 45 segundos (denaturação do DNA)

$48^{\circ} \mathrm{C}$ por 30 segundos (anelamento dos oligonucleotídeos)

$60^{\circ} \mathrm{C}$ por 4 minutos (extensão do DNA).

$O$ produto da reação foi seqüenciado em um Seqüenciador Automático $A B I$ PRISM 3100 (Applied BioSystems). 
Quadro 2. Seqüência dos oligonucleotídeos utilizados nas reações de nested PCR, PCR e seqüênciamento do gene msp-6 de $P$. falciparum e o gene ortólogo em $P$. reichenowi.

\begin{tabular}{|l|l|l|}
\hline \multicolumn{1}{|c|}{ Oligonucleotídeo } & \multicolumn{1}{|c|}{ Reação } & \multicolumn{1}{c|}{ Seqüência $\left(\mathbf{5}^{\prime} \mathbf{=}^{\mathbf{2}} \mathbf{3}^{\prime}\right)$} \\
\hline FWDEXT1 & Nested PCR & GTTTCTTTTTAGATTATTCAAAATG \\
\hline REVEXT1 & Nested PCR & CCTATAGATAGGTTAATTATTAC \\
\hline FWD1 & PCR e Seqüênciamento & ATGAATAAGATTTATAATATAC \\
\hline REV1 & PCR e Seqüênciamento & ATTATTACTAAATAGATGGATCAT \\
\hline FWD2 & Seqüênciamento & GGTTTAACTGGTGCAACAG \\
\hline FWD2alt & Seqüênciamento $(P$. reichenowi) & CTCTGAATAATAATATACTTGG \\
\hline FWD3 & Seqüênciamento & GATTCAGAAATTCCTTTTTC \\
\hline FWD4 & Seqüênciamento & GATGACATAGATGAAGAAAG \\
\hline REV2 & Seqüênciamento & CTTTTTATCTTCTGCAGCTC \\
\hline REV3 & Seqüênciamento & CAGATTCGTGAATACTATTTTC \\
\hline
\end{tabular}
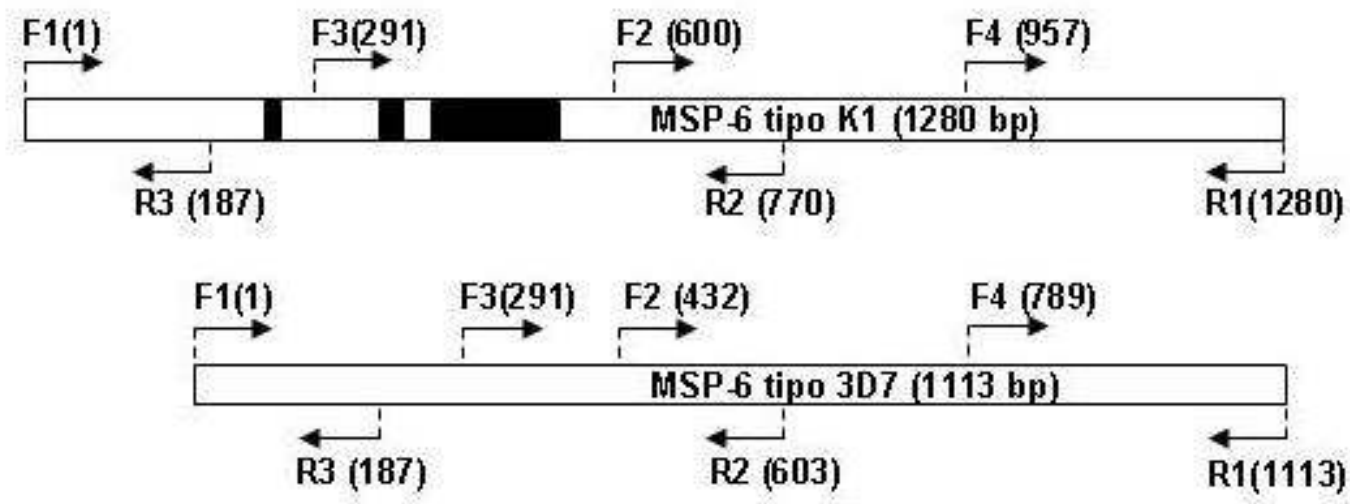

Figura 8. Região de anelamento dos oligonucleotídeos desenhados para amplificação das duas formas alélicas de $m s p-6$. Números entre parênteses indicam o número da base em que se liga a extremidade $5^{`}$ do respectivo primer. As áreas pretas no alelo do tipo K1 correspondem aos indels ausentes no alelo 3D7.

\subsection{Montagem das seqüências de $m s p-6$ de $P$. falciparum e $P$. reichenowi}

A seqüência completa de $m s p-6$ de cada isolado de $P$. falciparum foi montada a partir dos seqüênciamentos parciais em uma única seqüência (contig), através do programa SeqMan (DNAStar 5.00, Madison, WT). Quando ocorriam conflitos, correções manuais foram feitas, baseadas nos cromatogramas originais, de forma a eliminar falsos polimorfismos.

O Instituto Sanger realizou um seqüênciamento parcial de P.reichenowi, cujos resultados estão disponíveis on-line (http://www.sanger.ac.uk/Projects/ P_reichenowi). Após o seqüênciamento do gene ortólogo de msp-6 em 
$P$. reichenowi, foi feita uma busca por seqüências semelhantes, através do programa BLAST. Dentre as seqüências obtidas, foram selecionadas aquelas com os melhores índices (scores) de alinhamentos, e menores valores de e (probabilidade de se encontrar, ao acaso, uma seqüência semelhante à da nossa busca). A partir dessas seqüências, foi montado um contig, da maneira descrita no item anterior. Foi feita uma comparação entre o nosso seqüênciamento e o contig obtido, para se obter a seqüência final utilizada em nossa análise.

\subsection{Outras seqüências de $m s p-6$}

Além das seqüências de msp-6 obtidas conforme descrito nos itens $3.2-3.5$, foram utilizadas outras seqüências para os estudos com msp-6. A origem dessas amostras e outras informações são apresentadas no Quadro 3.

Quadro 3 - Outras seqüências de msp-6 utilizadas para cálculo de diversidade nucleotídica e associação entre alelos.

\begin{tabular}{|c|c|c|c|}
\hline Amostra & Origem & Código de acesso GenBank & Referência \\
\hline T9/96 & Tailândia & AY007721 & Trucco et al., 2001 \\
\hline 3D7 & Oeste africano & XM 001347594 & Gardner et al., 2002 \\
\hline 7G8 & Brasil & AY518887 & Pearce et al., 2004 \\
\hline D10 & Papua Nova Guiné & AY518888 & Pearce et al., 2004 \\
\hline HB3 & Honduras & AY518889 & Pearce et al., 2004 \\
\hline K1 & Tailandia & AY518890 & Pearce et al., 2004 \\
\hline Malay Camp & Malasia & AY518891 & Pearce et al., 2004 \\
\hline NF7 & Ghana & AY518892 & Pearce et al., 2004 \\
\hline W2mef & Laos & AY518893 & Pearce et al., 2004 \\
\hline Dd2 & Laos & AASM01000000 & Volkman et al., 2007 \\
\hline Isolado clínico & Gana & & Jeffares et al., 2007 \\
\hline IT & Brasil & & Jeffares et al., 2007 \\
\hline
\end{tabular}

*- busca feita no site: http://www.sanger.ac.uk/Projects/P_falciparum/

\subsection{Teste de Fisher para verificar a associação entre alelos de msp-1 e msp-6}

A partir da identificação das formas alélicas de MSP-1 e MSP-6 presentes nas amostras estudadas, foi verificada a ocorrência de evidência de associação entre essas formas na montagem do complexo protéico presente na membrana do merozoíto de $P$. falciparum, montando-se uma tabela $2 \times 2$, a partir da qual foi realizado um teste exato de Fisher. 


\subsection{Análise da diversidade entre as seqüências}

As seqüências obtidas foram alinhadas com o programa MEGA 4.0 (Tamura et al., 2007). A diversidade entre as seqüências foi analisada com o programa DnaSP 4.0 (Rozas et al., 2003), que utiliza o método proposto por Nei (1987). Basicamente, as $\mathrm{n}$ seqüências obtidas são comparadas duas a duas, após o alinhamento e excluindo as inserções e deleções (regiões não alinháveis), e um valor médio das diferenças encontradas $(\pi)$ é definido, de acordo com a equação:

$$
\pi=\frac{n}{\mathrm{n}-1} \sum_{i j} x_{i} \cdot x_{j} \cdot \pi_{\mathrm{ij}}
$$

Nessa equação, $x_{i}$ representa a freqüência com que uma das seqüências está presente na amostra, $x_{j}$ é a freqüência da outra seqüência, e $\pi_{\mathrm{ij}}$ é o número de diferenças encontrado nessa comparação em particular. Esse cálculo foi realizado inicialmente apenas as seqüências de um determinado tipo alélico de $m s p-6$, obtendo-se dessa forma o valor de $\pi$ de cada ramo dimórfico $\left(\pi_{\mathrm{K} 1}\right.$ ou $\left.\pi_{3 \mathrm{D} 7}\right)$. Em seguida foi calculado o valor médio de $\pi$ nesses dois grupos ( $\pi_{\text {médio }}$ ), e por fim, o

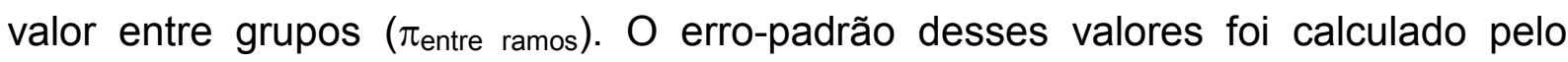
método de bootstrap, a partir de 1000 replicatas, com o programa MEGA 4.0. Gráficos de diversidade intra e entre famílias foram obtidos através do programa DnaSP 4.0, utilizando-se janelas de 100 bases com intervalos de 25 bases.

O dimorfismo alélico, segundo a regra de um quarto, foi testado comparandose os valores de $\pi_{\text {médio }}$ e $\pi_{\text {entre ramos. }} O$ valor obtido foi denominado $T_{1 / 4}$ (teste do um quarto), e definido como $T_{1 / 4}=\pi_{\text {médio }} / \pi_{\text {entre ramos }}$.

A genealogia das amostras foi obtida utilizando-se o método de neighbour joining (Saitou e Nei, 1987), através do programa MEGA 4.0.

\subsection{Cálculo de mutações sinônimas e nâo-sinônimas e identificação de regiões selecionadas positivamente}

O método utilizado será aquele proposto por Nei e Gojobori (1986). Resumidamente, para cada códon é calculado o valor de sítios sinônimos (s) e não- 
sinônimos $(n)$, ou seja, dentre todas as possíveis mutações que podem ocorrer em cada base (sítio) desse códon, quantas são sinônimas e quantas são não-sinônimas. Para uma seqüência de DNA, o valor total de sítios sinônimos $(S)$ é obtido somandose os valores de $s$ de todos os seus códons. O número de sítios não-sinônimos $(N)$ é obtido de maneira análoga, somando-se os valores de $n$.

O valor estimado de diferenças sinônimas e não-sinônimas entre duas seqüências é obtido alinhando-as e fazendo uma comparação códon a códon, desprezando-se as seqüências não alinháveis. Soma-se o valor de diferenças sinônimas $\left(s_{d}\right)$ encontradas entre os códons, obtendo-se o total de diferenças sinônimas entre as seqüências $\left(S_{d}\right)$. Procedimento análogo é feito para se obter o valor do total de diferenças não-sinônimas $\left(N_{d}\right)$. Finalmente, a proporção de mutações sinônimas por sítio sinônimo $\left(p_{S}\right)$ e de mutações não-sinônimas por sítio não-sinônimo $\left(p_{N}\right)$ pode ser obtido calculando-se $p_{S}=S_{d} / S$ e $p_{N}=N_{d} / N$

O valor de $p_{S}$ pode ser interpretado da seguinte forma: de $S$ possíveis substituições sinônimas que poderiam ocorrer, $S_{d}$ ocorreram de fato. Semelhante interpretação pode ser dada para o valor de $p_{N}$. Para se levar em conta a possibilidade de que tenham ocorrido múltiplas substituições em um mesmo sítio, será aplicada a correção proposta por Jukes e Cantor (1969) (revisão em Graur e Li, 2000).

Para verificar se há excessos significantes de substituições não-sinônimas em segmentos de $m s p-6$, foram empregados testes $Z$ (Nei e Kumar, 2000) monocaudais, com 1.000 pseudo-replicatas, em janelas de 100 códons. O excesso de substituições não-sinônimas em um domínio em particular pode ser interpretado como evidência de seleção positiva (Hughes e Nei, 1988). Todos esses cálculos foram realizados com auxílio do programa MEGA 4.0. 


\section{RESULTADOS}

\subsection{Amplificação e seqüênciamento do gene $m s p-6$ em amostras de sangue de pacientes de malária em estados da Amazônia Legal}

Foi amplificado o gene msp- 6 de $P$. falciparum presente em 26 amostras provenientes de estados da Amazônia Legal, e 2 amostras provenientes da Tanzânia, África. A visualização em gel de agarose contendo brometo de etídeo permitiu a identificação do tipo alélico de msp-6 (K1 ou 3D7) presente na amostra (Figura 9). Essa identificação visual foi posteriormente confirmada por seqüênciamento de DNA em 23 amostras (21 do Brasil e 2 da Tanzânia). Os dois tipos alélicos de msp-6 estavam presentes nas amostras brasileiras, assim como nas amostras africanas (Tabela 1). Esses resultados demonstram que a variante do tipo $\mathrm{K} 1$ tem uma distribuição geográfica mais ampla que a anteriormente sugerida, visto que se acreditava que a ocorrência dessa família estivesse restrita ao sudeste asiático (Pearce et al., 2004). No geral, foi observado predomínio de alelos da família 3D7 em relação a K1 (16 contra 10 , ou 0,62 contra 0,38 , não significante considerando um intervalo de confiança de $95 \%$ ).

Tabela 1. Identificação dos tipos alélicos presentes nas amostras colhidas em estados da Amazônia Legal.

\begin{tabular}{cccc}
\hline Estado & $\begin{array}{c}\text { Amostras } \\
\text { Identificadas }\end{array}$ & Tipo K1 & Tipo 3D7 \\
\hline Rondônia & 16 & 7 & 9 \\
Acre & 4 & 0 & 4 \\
Pará & 6 & 3 & 3 \\
\hline
\end{tabular}




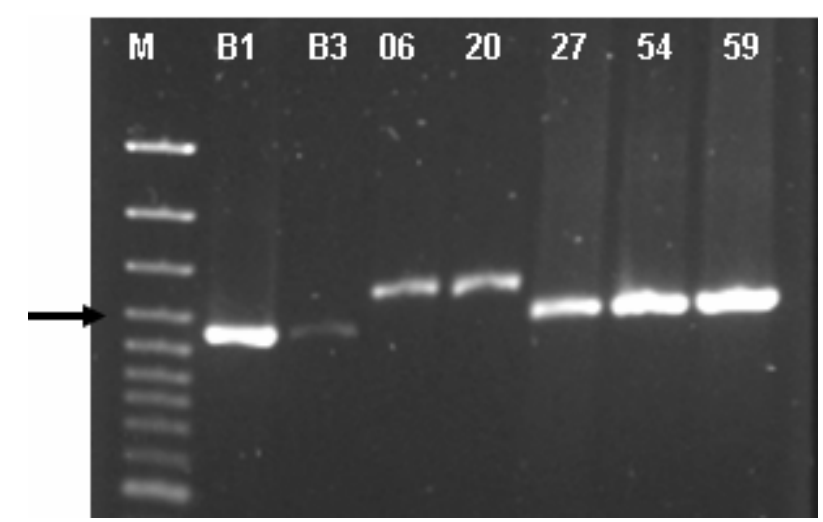

Figura 9. Visualização dos produtos da amplificação de $\boldsymbol{m s p - 6}$ por PCR. As amostras B1e B3 são provenientes do estado do Pará, e as restantes do estado de Rondônia. M indica o marcador molecular de $100 \mathrm{bp}$, com a seta indicando o fragmento referente ao tamanho de 1200 bp. As amostras 06 e 20 são do tipo alélico K1.

\subsection{Ausência de associação entre formas alélicas de msp-1 e msp-6}

O Quadro 2 mostra o tipo alélico das amostras identificadas no Brasil. O material utilizado em nosso trabalho (23 amostras) já havia sido previamente identificado com relação ao gene da proteína MSP-1 (Ferreira et al., 1998a; Silva et al., 2000; da Silveira et al., 1999). Essa informação foi recuperada das outras amostras utilizadas (12 amostras, item 3.6). Dessa forma, o $\mathrm{n}$ total obtido para estudo de associação entre as formas alélicas de $m s p-1$ e $m s p-6$ foi de 35 . É mostrada somente a tipagem da região compreendida entre os blocos 6-16 de msp-1 porque é nessa região em que se acredita ocorrer a interação entre as duas proteínas (Kauth et al., 2006).

Os dados obtidos no Quadro 4 foram utilizados para compor a Tabela 2. Nessa tabela, as formas alélicas de $m s p-1$ e $m s p-6$ são dados qualitativos, e o número dentro de cada célula corresponde a quantidade de amostras que possuía os respectivos tipos alélicos dos genes. Um teste exato de Fisher foi realizado para verificar a hipótese nula $(\mathrm{Ho})$ de que não existe associação entre as formas alélicas de $m s p-1$ e msp-6. Dado o valor de $p$ encontrado em nossa análise $(p=0,875)$, podese sugerir que não existe associação entre os diferentes tipos dimórficos de $m s p-1$ e msp-6 na formação do complexo de proteínas de superfíce do merozoíto. 
Quadro 4. Identificação dos tipos alélicos de msp-6 e da região composta pelos blocos 6-16 de $\boldsymbol{m s p}-1$ de $\boldsymbol{P}$. falciparum. Para $m s p-6$ há dois tipos alélicos possíveis: K1 e 3D7. Para $m s p-1$, os tipos possíveis são MAD20 e K1. Foram acrescentados os resultados de amostras cujos seqüênciamentos estão disponíveis. As amostras identificadas nesse projeto estão marcadas com um asterisco( $\left.{ }^{*}\right)$.

\begin{tabular}{|c|c|c|c|}
\hline Amostra & Origem & $m s p-6$ & msp-1 bloco 6-16 \\
\hline $04^{*}$ & Rondônia & 3D7 & MAD20 \\
\hline $06^{*}$ & Rondônia & K1 & MAD20 \\
\hline $20^{*}$ & Rondônia & K1 & MAD20 \\
\hline $27^{*}$ & Rondônia & $3 \mathrm{D} 7$ & MAD20 \\
\hline $32^{*}$ & Rondônia & $3 \mathrm{D} 7$ & MAD20 \\
\hline $34^{*}$ & Rondônia & K1 & MAD20 \\
\hline $42^{*}$ & Rondônia & $3 \mathrm{D} 7$ & MAD20 \\
\hline $45^{*}$ & Rondônia & $3 \mathrm{D} 7$ & MAD20 \\
\hline $59^{*}$ & Rondônia & $3 \mathrm{D} 7$ & MAD20 \\
\hline $62^{*}$ & Rondônia & K1 & MAD20 \\
\hline BA24* & Acre & $3 \mathrm{D} 7$ & MAD20 \\
\hline DE28* & Acre & $3 \mathrm{D} 7$ & MAD20 \\
\hline PC11* & Acre & $3 \mathrm{D} 7$ & MAD20 \\
\hline PC17* & Acre & $3 \mathrm{D} 7$ & MAD20 \\
\hline $\mathrm{B} 1^{*}$ & Pará & $3 \mathrm{D} 7$ & MAD20 \\
\hline B2* & Pará & K1 & MAD20 \\
\hline B3* & Pará & $3 \mathrm{D} 7$ & MAD20 \\
\hline $\mathrm{B}^{*}$ & Pará & K1 & MAD20 \\
\hline $\mathrm{P} 12^{*}$ & Pará & 3D7 & MAD20 \\
\hline $350 / 94^{*}$ & Pará & K1 & MAD20 \\
\hline $\mathrm{D} 2^{*}$ & noroeste da Tanzânia & K1 & K1 \\
\hline $\mathrm{NHC}^{*}{ }^{*}$ & Tanga - Tanzânia & $3 \mathrm{D} 7$ & MAD20 \\
\hline T9/96 & Tailândia & $3 \mathrm{D} 7$ & MAD20 \\
\hline $7 G 8$ & 7G8 (Brasil) & $3 \mathrm{D} 7$ & MAD20 \\
\hline Dd2 & Dd2 (Indochina) & K1 & MAD20 \\
\hline $\mathrm{Hb} 3$ & Hb3 (Honduras) & $3 \mathrm{D} 7$ & K1 \\
\hline Ghanian isolate & Gana & K1 & MAD20 \\
\hline 3D7 & Oeste africano & $3 \mathrm{D} 7$ & MAD20 \\
\hline IT & Amazonas, Brasil & $3 \mathrm{D} 7$ & K1 \\
\hline NF7 & Gana & 3D7 & MAD20 \\
\hline MC & Malasia & K1 & MAD20 \\
\hline K1 & Tailândia & K1 & K1 \\
\hline D10 & Papua Nova Guiné & 3D7 & MAD20 \\
\hline
\end{tabular}


Tabela 2. Distribuição das amostras estudadas conforme o tipo alélico de $m s p-1$ e $m s p-6$. O teste exato de Fisher foi aplicado considerando os dados abaixo.

\begin{tabular}{lcc}
\hline & $m s p-1$ tipo K1 & $m s p-1$ tipo MAD20 \\
\cline { 2 - 3 }$m s p-6$ tipo K1 & 2 & 10 \\
$m s p-6$ tipo 3D7 & 2 & 19 \\
\hline
\end{tabular}

\subsection{Diversidade intra- e entre-famílias alélicas de $m s p-6$ em amostras do Brasil}

A análise da diversidade nucleotídica em $m s p-6$ foi realizada a partir das 21 seqüências completas do Brasil obtidas para análise, sendo que 8 eram da família K1 e 13 pertenciam à família 3D7.

Essas amostras apresentaram baixo grau de diversidade nucleotídica. Foi encontrado apenas um haplótipo de alelo do tipo 3D7 $(\pi=0,0)$, e dois haplótipos em alelos da família $\mathrm{K} 1 \quad(\pi=0,00045)$. Na comparação entre famílias, o valor de diversidade encontrado foi $\pi=0,01497$.

Os dois haplótipos de K1 se distinguem pela ocorrência de uma mutação na região $\mathrm{N}$ conservada do gene, presente em 4 amostras de Rondônia (06, 20, 134 e 608). Essa mutação ( $C=>T$ na base 100$)$, não-sinônima, causa uma mudança no aminoácido codificado, de histidina para tirosina. Esses dois aminoácidos são polares, hidrofóbicos e aromáticos, o que caracteriza essa substituição como nãoradical. Essa região da proteína é eliminada durante a clivagem que precede sua exposição na superfície do merozoíto.

Com exceção dessa mutação, não foram encontradas outras variações em amostras do Brasil, com exceção das já descritas como sítios dimórficos. Não foram encontradas diferenças entre os sítios dimórficos das amostras do Brasil com relação as amostras de outras localidades, de forma que essa região será analisada no item 4.4.2. 


\subsection{Diversidade intra- e entre-famílias alélicas de $m s p-6$ utilizando o conjunto ampliado de seqüências}

\subsubsection{Diversidade nas regiões $\mathrm{N}$ - e C-terminal}

As regiões $\mathrm{N}$ - e C-terminal de $m s p-6$ são altamente conservadas em todas as amostras estudadas.

Na região N-terminal, foi encontrada uma única mutação em um conjunto de amostras do tipo K1 provenientes de Rondônia, conforme descrito no item 4.3.

Na região C-terminal conservada (bases 685-1281 em amostras do tipo K1, e 517- 1113 em amostras do tipo 3D7; Anexo A), foram observadas 2 mutações nãosinônimas e uma inserção. A primeira mutação $(A=>T)$ está presente em 6 amostras do tipo 3D7 (base 680) coletadas no Brasil (amostra IT), África (3D7, NHC-1 e NF7), Papua Nova Guiné (D10) e Tailandia (T9/96), e faz com que seja codificado o aminoácido isoleucina no lugar de lisina (substituição radical). A segunda mutação não-sinônima foi observada em apenas uma amostra da Tanzânia, África (D2, tipo $\mathrm{K} 1$ ), e causa também uma mudança de histidina para tirosina (substituição de $C$ por T na base 1264).

A amostra Malay Camp, proveniente da Malásia (Ásia) apresenta uma inserção de 6 bases (GAAGAA), que adicionam 2 resíduos de ácido glutâmico ao polipeptídeo, não alterando o código de leitura do gene (Pearce et al., 2004). Essa inserção é precedida pelos motivos repetitivos GAAGAT (3 vezes), de forma que um evento de pareamento incorreto durante a replicação do DNA pode ter sido a causa de sua origem (Rich e Ayala, 2000). A região em que essa repetição ocorre é rica em resíduos desse aminoácido.

No geral, as mutações presentes nas regiões conservadas de msp-6 não devem afetar a conformação da proteína codificada, visto serem causadoras de substituições não radicais de aminoácidos (amostras de Rondônia e da Tanzânia) ou repetições de aminoácidos característicos de determinadas regiões do gene (amostra Malay Camp). A exceção a essa afirmação decorre da presença de uma mutação causadora de uma substituição radical de aminoácido na região C-terminal conservada de msp-6. 


\subsubsection{Diversidade na região dimórfica}

A região dimórfica de $m s p-6$ de $P$. falciparum encontra-se delimitada entre as bases 241-684, na família alélica K1, e 241-516, na família 3D7. Nesse intervalo são encontrados 36 sítios dimórficos (incluindo-se as três regiões de indels presentes em alelos do tipo K1), que resultam em 29 mudanças no aminoácido codificado (há 3 códons com mudança dupla de base). Dentre as substituições de aminoácidos presentes na região dimórfica, 17 são radicais (Taylor, 1986). Os indels são perfeitamente conservados dentro da família $\mathrm{K} 1$, com exceção de uma deleção secundária encontrada na amostra Dd2 (ítem 4.4.3).

A análise da diversidade nucleotídica $(\pi)$ ao longo dos genes $m s p-6$, intra e entre famílias alélicas, mostra que os alelos são extremamente conservados dentro de cada família, sendo a maior parte da diversidade entre famílias concentrada na região dimórfica (Figura 10A). Os picos de diversidade encontrados dentro da cada família (Figuras 10B e 10C) são referentes ao número restrito de substituições encontradas. Os valores de $\pi$ calculados para o gene completo e somente para a região dimórfica estão sumarizados na Tabela 3. Na comparação entre famílias, os valores encontrados são duas ordens de grandezas maiores que os valores intra família. Esses valores se encontram entre os menores descritos para proteínas de membrana, sendo inferiores inclusive aos apresentados por genes altamente conservados (housekeeping genes) de P. falciparum (Tanabe et al., 2004).

Tabela 3. Diversidade nucleotidica intra e entre famílias alelicas de msp-6.

\begin{tabular}{ccc}
\hline Família alélica de $\boldsymbol{m s p - 6}$ & $\boldsymbol{\pi}$ gene completo & $\boldsymbol{\pi}$ região dimórfica \\
\hline K1 $(n=14)$ & $0,00068 \pm 0,00039$ & $0,00033 \pm 0,00033$ \\
3D7 $(n=21)$ & $0,00056 \pm 0,00041$ & $0,00069 \pm 0,00046$ \\
geral $(n=35)$ & $0,01504 \pm 0,00248$ & $0,06450 \pm 0,01146$ \\
\hline
\end{tabular}


A

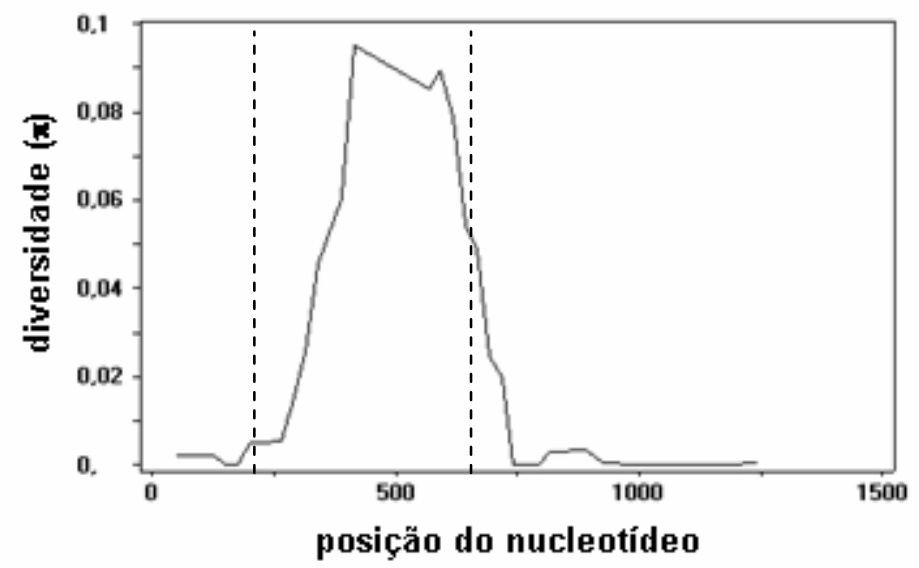

B

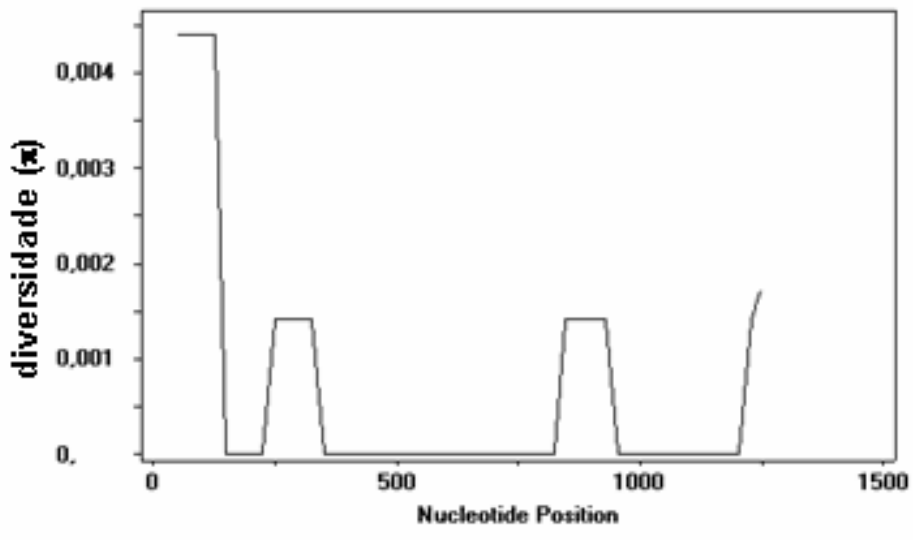

posição do nucleotídeo

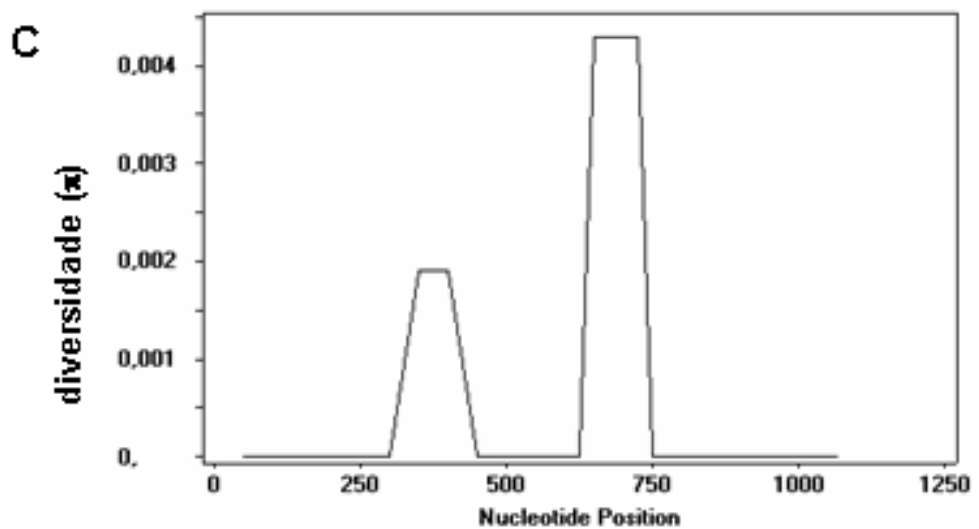

posição do nucleotídeo

Figura 10. Diversidade nucleotídica entre seqüências de msp-6. $\mathrm{Na}$ comparação entre famílias (A), a maior parte da diversidade encontra-se restrita à região dimórfica (linhas tracejadas). No interior das famílias alélicas, tanto K1 (B) quanto 3D7 (C) apresentam baixos níveis de diversidade. 


\subsubsection{Deleção secundária na amostra Dd2}

O gene msp-6 da amostra Dd2 representa uma exceção ao padrão dimórfico encontrado nas demais amostras. Embora, na comparação entre famílias, ele possua a mesmo seqüência de bases, nos sítios dimórficos, que caracteriza os alelos da família $\mathrm{K} 1$, há uma deleção de uma região de $123 \mathrm{bp}$, muito semelhante à região de 129 bp presente na família K1 e ausente em 3D7 (Figura 11). A presença da seqüência de nucleotídeos GTG nas duas extremidades do indel em alelos do tipo $\mathrm{K} 1$, e também na região preservada da deleção em $\mathrm{Dd} 2$, não permite definir exatamente as coordenadas do evento. Uma explicação possível para essa combinação mista de características (deleção semelhante a da família 3D7 e regiões dimórficas semelhantes a da família K1) seria a ocorrência de uma deleção secundária nessa região, embora o mecanismo que a tenha ocasionado não esteja a princípio bem claro.

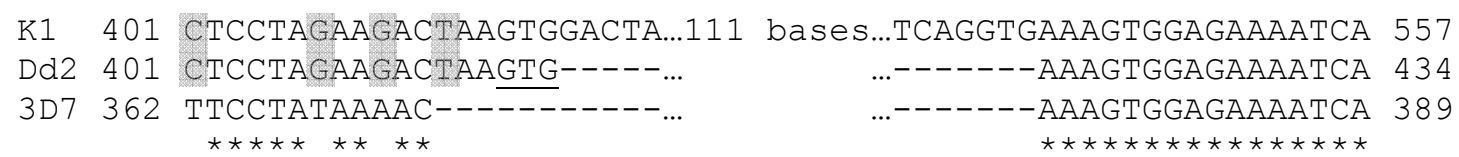

Figura 11. Alinhamento entre as seqüências de $m s p-6$ dos isolados K1, 3D7 e Dd2. É mostrada a deleção diferenciada de uma região de $123 \mathrm{bp}$, muito parecida com a deleção de 129 bp característica da família 3D7, embora a região dimórfica flanqueante seja característica da família K1 (hachuras em cinza). O trinucleotídeo GTG sublinhado não pode ser exatamente alinhado, podendo sua localização exata ser na outra extremidade da deleção.

\subsubsection{Regra do um quarto aplicada aos alelos de msp-6}

A genealogia obtida a partir da região dimórfica das seqüências de $m s p-6$, utilizando-se o método de neighbour-joining, é mostrada na Figura 12. A estrutura geral é a esperada para genes que apresentam dimorfismo alélico, com ramos basais extremamente longos quando comparados aos distais, e com dois grupos claramente distintos (Figura 6C). Para verificar a ocorrência de dimorfismo alélico, segundo a regra do um quarto, foi feita comparação do valor médio de diversidade 


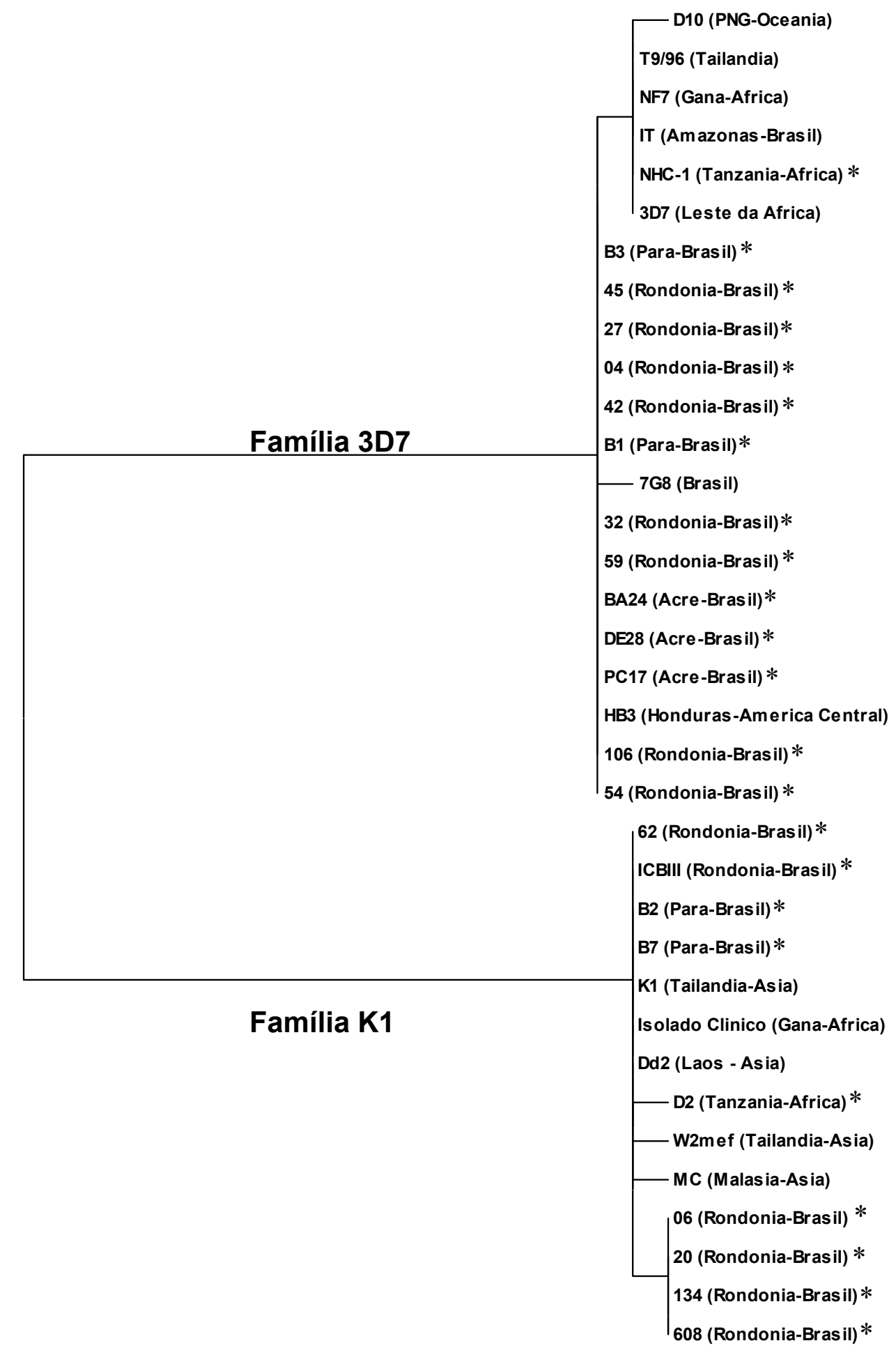

Figura 12. Genealogia das amostras de $m s p-6$. As amostras seqüenciadas nesse projeto estão marcadas por um asterisco $\left(^{*}\right)$. Todas as amostras se encontram claramente divididas em 2 grupos, ressaltando o dimorfismo alélico que ocorre nesse gene, com grande variação entre famílias e pequena variação dentro de cada família. Genealogia obtido pelo método de neighbour-joining, por comparação pareada (pairwise comparison) entre as seqüências, com o programa MEGA 4.0. 
dentro de cada um dos ramos dimórficos $\left(\pi_{\text {médio }}=0,00062\right)$ com o valor de diversidade entre as populações $\left(\pi_{\text {entre ramos }}=0,01504\right)$. O valor encontrado para essa razão foi de $T_{1 / 4}=0,041$. Quando direcionam-se os valores para diminuir a diferença entre numerador e denominador (subtraindo o desvio-padrão do valor médio da diversidade nos ramos no numerador e adicionando-se o desvio-padrão no valor de diversidade entre ramos no denominador, ou seja $T_{1 / 4}=\left[\left(\pi_{\text {médio }}+\right.\right.$ desvio

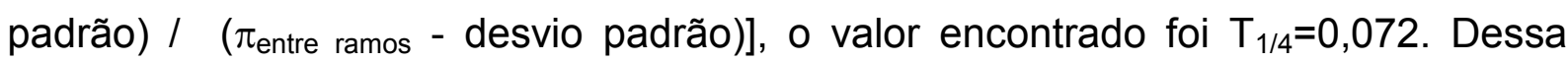
forma, a natureza dimórfica dos alelos de msp-6 é confirmada através da regra do um quarto, pois os valores encontrados são bem menores do que o esperado para alelos evoluindo sob seleção neutra ou balanceada, que seria $T_{1 / 4}=0,25$.

A estrutura dimórfica de antígenos se caracteriza pela manutenção desse padrão por longos períodos de tempo, o que implica na ausência de recombinação entre os integrantes das famílias dimórficas. Por esse motivo se espera que a diversidade entre alelos seja muito maior que a diversidade dentro de famílias de alelos dimórficos. A regra do um quarto permite distinguir genes que apresentam essa característica de outros em que variações locais possam ser interpretadas como dimorfismo. Os antígenos de superfície de merozoíto EBA-175 e MSP-3, descritos como apresentando dimorfismo, não apresentam a diversidade esperada de acordo com esse modelo (testada através da regra do um quarto), não podendo, portanto, serem considerados dimórficos (Roy et al., 2008).

\subsection{Seleção positiva em msp-6}

A região central do gene $m s p-6$ possui 33 sítios dimórficos (excluídos os indels), que codificam 31 mudanças de aminoácidos. Dentre eles, oito são sítios duas vezes degenerado, sendo que apenas um representa uma mutação nãosinônima. Cerca de metade (14, ou 42\%) dos sítios dimórficos está situada na segunda base de seus respectivos códons, posição que não apresenta degeneração (ou seja, qualquer mutação na segunda base de um códon é obrigatoriamente nãosilenciosa). Apenas um sítio dimórfico é 4 vezes degenerado (nenhuma mutação nessa posição altera o aminoácido codificado), mas outro dimorfismo no mesmo códon resulta em mudança de aminoácido. 
Os valores de dS e dN encontrados no gene completo, nas regiões conservadas e na porção dimórfica de msp-6 são apresentados na Tabela 4. Nas regiões $\mathrm{N}$ - e C-terminal conservadas, $\mathrm{dN}>\mathrm{dS}$ é significante ao nível de $5 \%$, mas não ao nível de $1 \%$. Já na região dimórfica, e considerando-se o gene completo, os valores são significantes, evidenciando a ocorrência de seleção positiva entre os alelos de $m s p-6$, sendo essa seleção concentrada na região dimórfica do gene.

Tabela 4. Valores de substituições sinônimas por sítio sinônimo (dS) e substituições nãosinônimas por sítio não-sinônimo (dN) para os alelos de msp-6. Um valor de dN significativamente maior que dS é considerada evidência de seleção positiva. A significância dos valores encontrados ( $p$-valor) foi calculada por meio de um teste de bootstrap com 1000 replicatas. Valores de p menores que 0,01 são considerados significantes.

\begin{tabular}{lccc}
\hline região de $\boldsymbol{m s p}-\mathbf{6}$ & dS & dN & p-valor \\
\hline gene completo & $0,00497 \pm 0,00328$ & $0,01822 \pm 0,00335$ & 0,00153 \\
N- e C-terminal & $0,00000 \pm 0,00000$ & $0,00089 \pm 0,00053$ & 0,03451 \\
dimórfica & $0,01639 \pm 0,01094$ & $0,08144 \pm 0,01412$ & 0,00005 \\
\hline
\end{tabular}

\subsection{Amplificação e seqüênciamento do gene ortólogo de msp-6 em $P$. reichenowi}

O protocolo utilizado foi basicamente o mesmo para amplificação de $m s p-6$ em $P$. falciparum. Com essas condições, foi possível amplificar o gene desejado (Figura 13). A visualização em gel de agarose 1,5\% mostra a presença de um fragmento com tamanho aproximado um pouco maior que 1200 bases, semelhante ao tamanho do alelo do tipo $\mathrm{K} 1$ do gene $m s p-6$ de $P$. falciparum. O gene foi seqüenciado conforme descrito no item 3.4 de Material e Métodos, e a seqüência obtida foi utilizada para estudos comparativos com as seqüências de tipo K1 e 3D7 de $m s p-6$ de $P$. falciparum. 


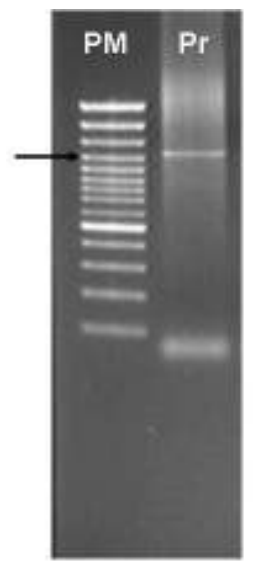

Figura 13. Amplificação do gene ortólogo de $m s p-6$ em $P$. reichenowi. $P M=P e s o$ molecular de 100bp Plus(Fermentas). $\mathrm{Pr}=P$. reichenowi. A seta indica o fragmento com tamanho equivalente a $1200 \mathrm{bp}$.

No geral, o gene de $P$. reichenowi se assemelha ao alelo $\mathrm{K} 1$, não só devido a presença dos 3 indels, mas também na maioria dos sítios dimórficos. O número médio de substituições por sítio foi calculado entre as amostras de alelos do tipo K1 e 3D7 com a seqüência de $P$. reichenowi, e entre si, para 3 regiões do gene: as extremidades $\mathrm{N}$ - e C-terminal conservadas e a região dimórfica (Tabela 5). Admitindo-se uma taxa de mutação constante ao longo do gene entre as espécies, os valores obtidos sugerem que diferentes regiões de msp-6 apresentam histórias evolutivas particulares.

Nas regiões conservadas, $m s p-6$ de $P$. reichenowi tem distância semelhante dos dois alelos de $P$. falciparum, que por sua vez possuem uma distância muito menor entre si, sugerindo que os alelos de msp-6 de P.falciparum teriam surgido após a divergência de $P$. falciparum e $P$. reichenowi. No entanto, a quantidade de diferenças acumuladas na região $\mathrm{C}$-terminal faz crer que ela tenha divergido há mais tempo do gene de $P$. reichenowi do que a região $\mathrm{N}$-terminal.

Tabela 5. Número médio de substituições por sítio na comparação entre seqüências de $m s p-6$ de $P$. reichenowi e dos alelos de $P$. falciparum.

\begin{tabular}{lccc}
\hline & \multicolumn{3}{c}{ valor médio de substituiçôes por sítio } \\
\cline { 2 - 4 } & $\operatorname{Pr} \times 3 \mathrm{D} 7$ & $\operatorname{Pr} \times \mathrm{K} 1$ & $\mathrm{~K} 1 \times 3 \mathrm{D} 7$ \\
N-term & 0,01685 & 0,01808 & 0,00119 \\
Dimórfico & 0,14371 & 0,07898 & 0,13097 \\
C-ter & 0,07188 & 0,07267 & 0,00072 \\
\hline
\end{tabular}


Na região dimórfica, a distância entre $P$. reichenowi e o alelo $\mathrm{K} 1$ é cerca da metade da distância entre $P$. reichenowi e o alelo 3D7, mas esses valores não se mantém constantes ao longo dessa região. A semelhança entre o gene de msp- 6 de $P$. reichenowi e o alelo $\mathrm{K} 1$ de $P$. falciparum é mais acentuada na porção 5 ' da região dimórfica, no qual esses 2 genes apresentam bases iguais nos primeiros 13 sítios dimórficos (incluindo a presença dos indels, Figura 14). Já na porção 3' dessa região (resíduos 126-172), P. reichenowi mostra semelhanças tanto com os alelos do tipo K1 (12 sítios) quanto os do tipo 3D7 (10 sítios) nos sítios dimórficos.

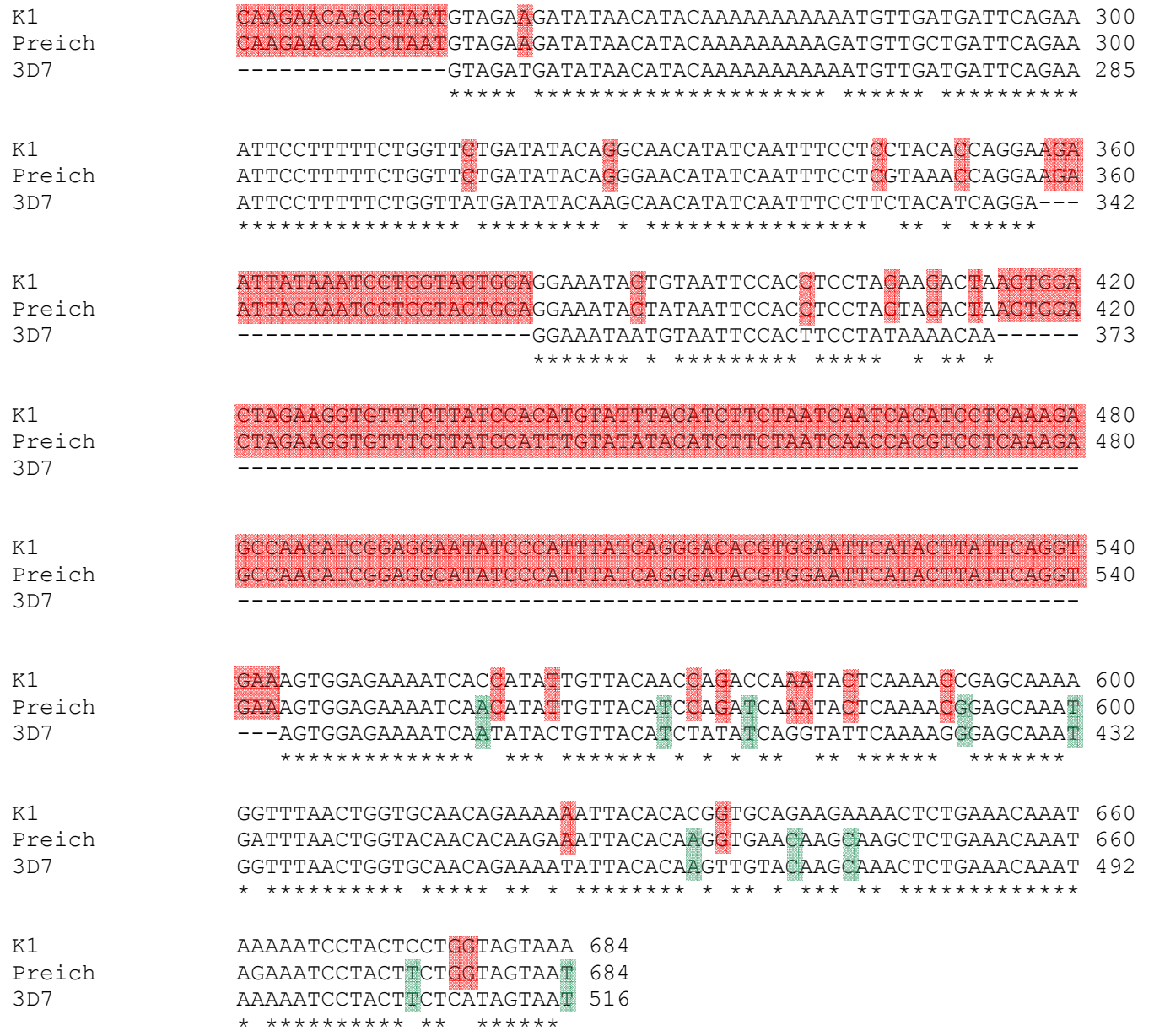

Figura 14. Alinhamento da região dimórfica de $m s p-6$ tipo K1 e 3D7 de $P$. falciparum e do gene ortólogo de $P$. reichenowi. Regiões hachuradas em vermelho e verde mostram sítios dimórficos em que a seqüência de $P$. reichenowi é idêntica, respectivamente, à de $m s p-6$ do tipo K1e 3D7 de $P$. falciparum. As 3 inserções presentes nos alelos do tipo K1 e em msp-6 de P.reichenowi foram, cada um, consideradas como um único evento e, dessa forma, foram desconsideradas diferenças encontradas dentro dessas regiões. 
Essa combinação de resultados sugere a ocorrência de 4 regiões com histórias evolutivas distintas em MSP-6. Nas regiões $\mathrm{N}$ - e C-terminal conservadas, os genes ortólogos de msp-6 teriam divergido antes do surgimento das famílias alélicas em $P$. falciparum, porém na região $C$-terminal essa divergência seria mais ancestral. A porção $5^{\prime}$ da região dimórfica de $m s p-6$ é praticamente idêntica entre os alelos do tipo $\mathrm{K} 1$ de $P$. falciparum e no gene ortólogo de $P$. reichenowi, indicando que os dois divergiram ancestralmente dos alelos do tipo 3D7 de P.falciparum. Finalmente, na porção 3 ' da região dimórfica, os 3 alelos teriam divergido em tempos muito próximos. 


\section{DISCUSSÃO}

\subsection{Antígenos de superfície como alvos para uma vacina contra malária}

Proteínas de membrana de $P$. falciparum são candidatas a alvo de uma vacina contra a malária causada por esse parasito. No entanto, fatores como os polimorfismos apresentados por essas proteínas, dificultam sua utilização no desenvolvimento de uma estratégia de imunização.

Grande parte das vacinas atualmente em teste contra malária utiliza subunidades de antígenos variados de membrana, na tentativa de estimular uma resposta imune eficaz que mimetize os efeitos da imunidade adquirida contra a doença (Matuschewski e Mueller, 2007). Muitas delas utilizam fragmentos das mais abundantes proteínas encontradas na superfície de $P$. falciparum, nominalmente CSP, presente na membrana dos esporozoítos, e MSP-1, encontrada na membrana do merozoíto (Zavala et al., 1985; Patarroyo et al., 1988). Porém, alguns testes com essas vacinas se mostraram ineficazes, devido em parte à grande variabilidade apresentada por estes antígenos em populações naturais (D’Alessandro et al., 1995).

A proteína de superfície de merozoítos MSP-6 encontra-se presente no estágio sanguíneo do parasito. Assim como outras proteínas de superfície (MSP-1 e MSP-2), ela apresenta uma forma particular de polimorfismo, denominada dimorfismo alélico, no qual todas as suas variantes são agrupadas em duas famílias, sendo encontrada pouca variação dentro das famílias e grande variação entre famílias (Pearce et al., 2004). No entanto, enquanto que nas primeiras a diversidade dentro das formas alélicas já havia sido explorada (Ferreira et al., 2003; Ferreira e Hartl, 2007), poucos dados se encontram disponíveis para o estudo de msp-6.

\subsection{Distribuição dos alelos de msp-6}

Nesse trabalho, a diversidade e a distribuição dos diferentes alelos de $m s p-6$ de $P$. falciparum foi avaliada a partir da amplificação e seqüênciamento desse gene em 21 isolados de parasitos provenientes da região da Amazônia Legal brasileira, e mais dois isolados da Tanzânia, África. As duas formas alélicas foram encontradas 
em amostras do Brasil, o que contrasta com a sugestão inicial de que variantes da família K1 estariam restritas ao sudeste asiático (Pearce et al., 2004). A variante K1 foi encontrada também em um isolado obtido de um paciente da Tanzânia, África. No geral, alelos do tipo 3D7 são predominantes, seja considerando somente as amostras do Brasil identificadas nesse projeto (16 contra 10, ou 0,62 contra 0,38, diferença não significativa), seja considerando também amostras obtidas em outros trabalhos (Pearce et al., 2004; Trucco et al., 2001), que expandem o total para 43 amostras identificas (freqüência de 0,67 para 3D7 contra 0,33 do tipo $K 1$, não significativa). Também foi reportada a identificação de alelos do tipo K1 em uma população de Gâmbia, África (Weedall, 2008). De forma constrastante aos resultados acima apresentados, nessa população, de 54 amostras identificadas de msp-6, 47 eram do tipo 3D7 e 7 do tipo K1.

Lee et al. (2006) sugerem que em infecções maláricas causadas por parasitos expressando os dois tipos alélicos de $m s p-1$ ocorre falha na ativação de linfócitos $T$, prejudicando o combate à infecção e favorecendo a manutenção dos dois tipos alélicos na população local de parasitos. No entanto, o predomínio de alelos do tipo 3D7 de msp-6 em uma população natural de Gâmbia não corrobora tal hipótese (Weedall, 2008). Dessa forma, estudos em outras regiões se fazem necessários para que se possa inferir um padrão para a distribuição dos diferentes alelos de $m s p-6$ em populações naturais de $P$. falciparum.

\subsection{Diversidade nucleotídica em msp-6}

Os valores de diversidade nucleotídica encontrados entre famílias alélicas são extremamente inferiores aos encontrados dentro de outros grupos de alelos dimórficos (Tabela 3). Além disso, a maior parte das diferenças entre famílias se encontra restrita a uma região central do gene, sendo essas diferenças essencialmente dimórficas. A diversidade nucleotídica dentro de cada família é duas ordens de grandeza menor que a encontrada entre famílias. Esse conjunto de dados levanta a hipótese de que, após o surgimento das famílias alélicas em $m s p-6$, a pressão seletiva teve como efeito a estabilização dos alelos dentro de cada família.

Dentre as 21 seqüências de $m s p-6$ obtidas de amostras do Brasil, apenas 3 haplótipos foram encontrados (um da família alélica 3D7 e 2 da família K1). Um dos haplótipos de $\mathrm{K} 1$ foi encontrado somente em amostras provenientes de Porto Velho, 
Rondônia. Essa baixa variabilidade pode ser reflexo do nível de transmissão reduzido e, por conseqüência, do pequeno número de infecções mistas encontradas em pacientes no Brasil (Machado et al., 2004). Em regiões de alta transmissão de malária, ocorre ampla oportunidade para ocorrência de recombinação no ciclo do parasito que ocorre no hospedeiro invertebrado, havendo inclusive evidência da ocorrência de eventos de recombinação entre amostras coletadas em Gâmbia (Weedal, 2008).

\subsection{Ausência de associação entre alelos de msp-1 e msp-6}

Para testar a hipótese de que a baixa diversidade encontrada dentro das famílias alélicas de $m s p-6$ estaria relacionada a uma associação entre as formas dimórficas de $m s p-1$ e $m s p-6$ na formação do complexo protéico presente na superfície de merozoítos, foi feito um teste de associação de Fisher. O valor encontrado $(p=0,875)$ não indica evidência de associação. Uma possível explicação para essa falta de associação entre duas proteínas dimórficas que se associam na formação de um complexo seria a de que a ligação entre elas ocorre em regiões conservadas. De fato, a proteína clivada $M S P-6_{36}$ interage com o produto processado $\mathrm{MSP}-1_{38}$ através de sua região C-terminal (Figura 5), que é altamente conservada (Kauth et al., 2006). Embora de MSP-1 ${ }_{38}$ seja codificado por uma região dimórfica do gene $m s p-1$, essa mesma região contém um segmento (bloco 12) que é conservado entre as duas formas alélicas desse gene (Figura 7), o que leva a sugestão que esse bloco é um potencial alvo para o estudo de como ocorre a associação entre as proteínas MSP-6 36 e MSP-1 38 .

\subsection{Seleção positiva em msp-6}

Antígenos de superfície de parasitos sofrem forte pressão seletiva exercida pelo sistema imune do hospedeiro. A manutenção de mutações não-sinônimas é favorecida, pois o polimorfismo nessas regiões representa um importante mecanismo de escape imune (Hughes e Hughes, 1995). Para verificar a hipótese de seleção positiva em $m s p-6$, foi verificado se o número de substituições não-sinônimas por sítio não-sinônimo $(\mathrm{dN})$ era significativamente maior que o número de substituições sinônimas por sítio sinônimos (dS) encontrados ao longo do gene msp-6 (Tabela 4). 
A diferença mais significativa de $\mathrm{dN}$ em relação a dS foi encontrada na região dimórfica ( $p=0,00005)$, indicando que essa região é selecionada positivamente, com um acúmulo de mutações não-sinônimas maior que o esperado em um modelo de evolução neutra. As regiões conservadas desse gene também apresentaram um valor significante de dN comparado a dS ( $p=0,034)$, mas isso provavelmente se deve à pequena quantidade de mutações presentes nessa região, que podem direcionar os valores para um falso resultado.

\subsection{MSP-6 como possível alvo de uma vacina contra malária}

A capacidade de gerar uma resposta imune protetora é uma das principais exigências para qualquer antígeno que venha a ser testado como constituinte de uma vacina. Também é necessário que esse antígeno não apresente grande variabilidade em populações naturais do patógeno, visto que a resposta imune gerada é específica. Existem evidências de que MSP-6 é capaz de induzir uma resposta imune alelo-específica (Pearce et al., 2004). O fato de existirem apenas duas famílias alélicas de MSP-6, e de que a diversidade encontrada dentro das famílias alélicas é extremamente reduzida, sugere o estudo do uso de segmentos da região dimórfica dos dois alelos de $m s p-6$ como eventuais integrantes de uma vacina baseada em subunidades de antígenos de $P$. falciparum.

A região dimórfica de MSP-6 do tipo 3D7 (com exceção de 4 sítios dimórficos) é eliminada da proteína após a clivagem que dá origem a MSP-6 ${ }_{36}$, fragmento que é efetivamente presente na membrana do merozoíto. O ponto de clivagem em MSP-6 do tipo K1 ainda não é conhecido (Pearce et al., 2004). Na comparação entre as duas famílias alélicas, os 4 sítios dimórficos remanescentes em MSP-6 ${ }_{36}$ dão origem a 3 substituições radicais de aminoácidos, que podem causar um reconhecimento diferencial das duas formas alélicas pelas células do sistema imune. Essas substituições se encontram afastadas da provável região em que MSP-6 ${ }_{36}$ interage com MSP-1 38 (Kauth et al., 2006), e constituem um objeto de estudo interessante na procura de peptídeos que desenvolvam uma resposta imune protetora 


\subsection{Evolução do dimorfismo alélico em MSP-6}

O seqüenciamento do gene ortólogo de msp-6 em $P$. reichenowi foi realizado para permitir o estudo da evolução do dimorfismo alélico nesse gene. Nas regiões amino e carboxila terminais, o gene de $P$. reichenowi demonstra ser igualmente distante dos alelos de msp-6 em $P$. falciparum, embora a divergência da região Cterminal pareça ser mais antiga, dado o maior acúmulo de diferenças (Tabela 4).

O alinhamento da região dimórfica das amostras de $P$. falciparum mostra uma maior semelhança entre os alelos de tipo $\mathrm{K} 1 \mathrm{com}$ o gene de $P$. reichenowi na porção $\mathrm{N}$-terminal, incluindo a presença dos três indels (Figura 12). No domínio C-terminal da região dimórfica, $m s p-6$ de $P$. reichenowi apresenta similaridades com os dois tipos alélicos de msp-6 de $P$. falciparum. Isso sugere que diferentes regiões desse gene apresentam histórias evolutivas diferentes. Uma possível hipótese conciliadora desses dados seria que as duas formas alélicas hoje presentes teriam se originado de uma população ancestral polimórfica (Figura 15).

Os diferentes tempos de divergência podem refletir a criação do tipo alélico 3D7 a partir de dois alelos não mais existentes, que divergiram do tipo alélico K1 em tempos diferentes: um coincidentemente com o tempo de especiação e o outro significativamente antes (Figura 7). Nesse caso, o dimorfismo atual representaria uma diminuição na diversidade alélica de uma população ancestral. Essa é uma inferência interessante, considerando-se que as origens do dimorfismo alélico ainda são desconhecidas.

As razões pelas quais esses outros alelos teriam sido perdidos não são claras. Rich et al. (1998) sugeriram que as populações atuais de $P$. falciparum seriam provenientes de um único ancestral, sobrevivente de um severo gargalo populacional ocorrido em um período recente de tempo. Essa hipótese, que foi posteriormente questionada (Hughes e Verra, 1998), explicaria a ocorrência de um número limitado de alelos para determinados genes, mas não o porquê de somente duas famílias de alelos persistirem na população (Roy et al., 2008). 


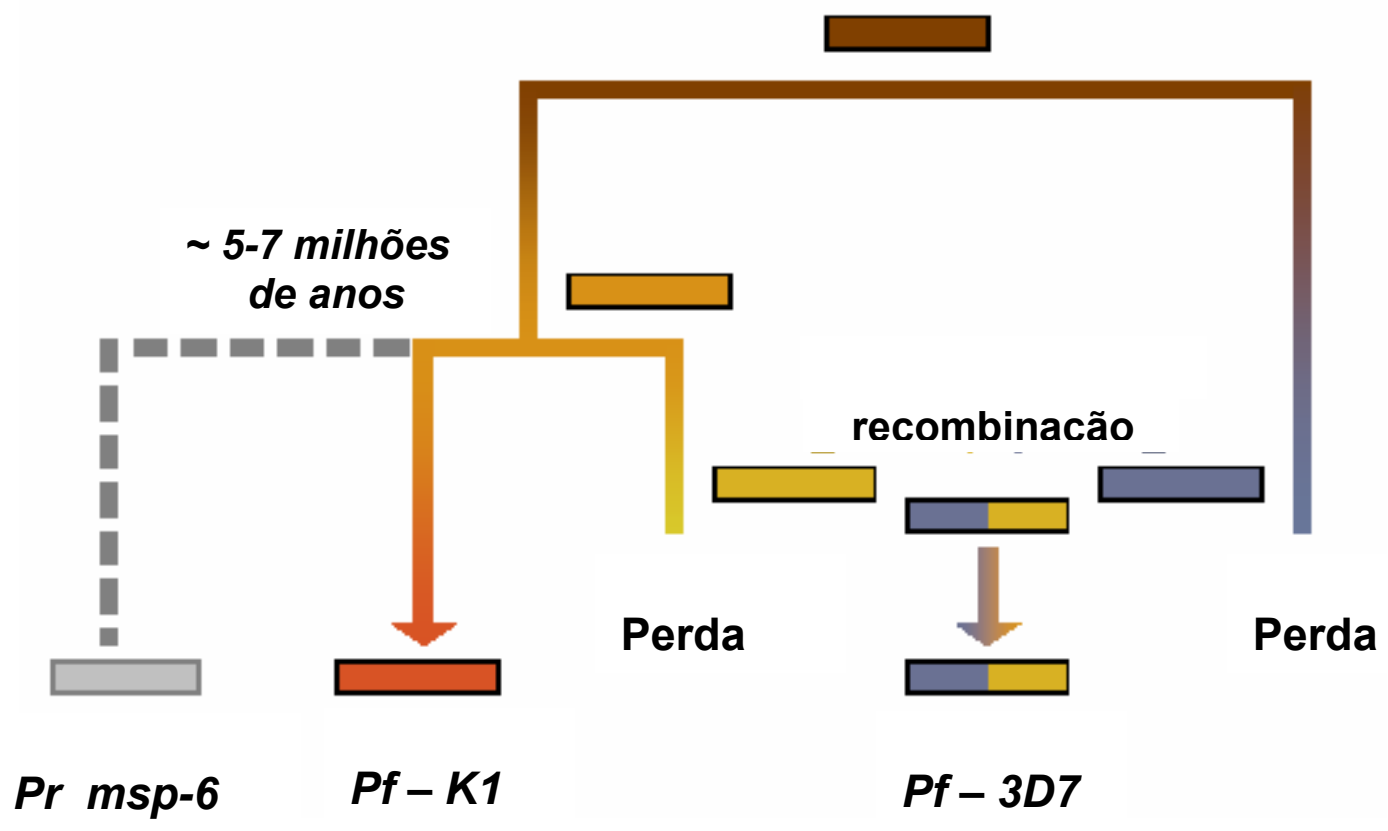

Figura 15. Uma hipótese para a história da região dimórfica de $m s p-6$ de $P$. falciparum. $O$ atual tipo alélico 3D7 pode ter sido criado por um raro evento de recombinação entre dois alelos ancestrais (atualmente extintos) (Roy et al., a ser submetido).

A limitação de dados disponíveis, inclusive a falta de outras seqüências do gene ortólogo de msp-6 de P. reichenowi, e a possibilidade de que as taxas de substituição de nucleotídeos ao longo do gene não sejam as mesmas, impedem que conclusões mais sólidas sejam obtidas a partir dos dados até o momento disponível. A disponibilização de outras seqüências de $P$. reichenowi, assim como a possibilidade da identificação de casos similares em outras espécies de Plasmodium pertencentes a clados proximamente relacionados com $P$. falciparum - P. reichenowi, podem auxiliar no esclarecimento da questão da evolução do dimorfismo alélico.

A ocorrência de dimorfismo alélico em proteínas de membrana de parasitos parece, até o momento, estar restrita a $P$. falciparum. Sua ocorrência já foi sugerida em proteínas de membrana de P. vivax (Han et al., 2004; Prajapati et al., 2006) e existe a possibilidade de que ocorra em MSP-1 de P.cynomolgi (Tanabe et al., 2007b), porém mais isolados de parasitos dessas espécies devem ser seqüenciados para que essa suspeita possa ser confirmada. Adicionalmente, seria recomendado uma análise mais ampla desses genes em outras espécies, visto que a maior parte dos estudos relacionados a polimorfismos em proteínas de membranas ocorre em parasitos de humanos, principalmente $P$. falciparum e $P$. vivax. 


\section{CONCLUSÕES}

1- O dimorfismo alélico em msp-6 foi confirmado a partir do seqüenciamento de isolados obtidos no Brasil e na Tanzânia.

2- As duas formas alélicas desse gene estão mundialmente distribuídas.

3- O gene msp-6 apresenta níveis muito baixos de diversidade nucleotídica intrafamílias, o que o qualifica como potencial alvo em estudos de uma vacina contra malária.

4- O dimorfismo em msp-6 pode ter se originado de uma população polimórfica ancestral, sendo que os demais alelos não se encontram mais presentes na população atual de parasitos. 


\section{REFERÊNCIAS}

Barillas-Mury C, Kumar S. Plasmodium-mosquito interactions: a tale of dangerous liaisons. Cell Microbiol. 2005;7(11):1539-45.

Blackman MJ, Scott-Finnigan TJ, Shai S, Holder AA. Antibodies inhibit the proteasemediated processing of a malaria merozoite surface protein. J Exp Med. 1994; 180(1):389-93.

Camargo EP. Malaria, maleita, paludismo. Cienc. Cult. 2003;55(1):26-32.

Coura JR, Suárez-Mutis M, Ladeia-Andrade S. A new challenge for malaria control in Brazil: asymptomatic Plasmodium infection--a review. Mem Inst Oswaldo Cruz. 2006 May;101(3):229-37.

Da Silveira LA, Dorta MI, Kimura EA, Katzin AM, Kawamoto F, Tanabe K, Ferreira MU. Allelic diversity and antibody recognition of Plasmodium falciparum merozoite surface protein 1 during hypoendemic malaria transmission in the Brazilian amazon region. Infect Immun. 1999;67(11):5906-5916.

D'Alessandro U, Leach A, Drakeley CJ, Bennett S, Olaleye BO, Fegan GW, Jawara M, Langerock P, George MO, Mellvile OG, Targett GA, Greenwood BM. Efficacy trial of malaria vaccine SPf66 in Gambian infants. Lancet. 1995;346(8973):462-7.

Dzikowski R, Templeton TJ, Deitsch K. Variant antigen gene expression in malaria. Cell Microbiol. 2006;8(9):1371-81.

Escalante AA, Ayala FJ. Phylogeny of the malarial genus Plasmodium derived from rRNA gene sequences. Proc Natl Acad Sci USA. 1994;91(24):11373-11377.

Escalante AA, Barrio E, Ayala FJ. Evolutionary origin of human and primate malarias: evidence from the circumsporozoite protein gene. Mol Biol Evol. 1995;12(4):616-26.

\footnotetext{
*De acordo com:

International Committee of Medical Journal Editors. Uniform requirements for manuscripts submitted to Biomedical Journal: sample references. c2003 - [updated 2005 June 15; cited 2006 May 16]. Available from:

http://www.nlm.nih.gov/bsd/uniform_requirements.html.
} 
Escalante AA, Freeland DE, Collins WE, Lal AA. The evolution of primate malaria parasites based on the gene encoding cytochrome $b$ from the linear mitochondrial genome. Proc Natl Acad Sci U S A. 1998;95(14):8124-8129.

Felger I, Marshal VM, Reeder JC, Hunt JA, Mgone CS, Beck HP. Sequence diversity and molecular evolution of the merozoite surface antigen 2 of Plasmodium falciparum. J Mol Evol. 1997;45(2):154-60.

Ferreira Mu, Liu Q, Kimura M, Ndawi BT, Tanabe K, Kawamoto F. Allelic diversity in the merozoite surface protein-1 and epidemiology of multiple-clone Plasmodium falciparum infections in northern Tanzania. J Parasitol. 1998a;84(6):1286-1289.

Ferreira MU, Liu Q, Kaneko O, Kimura M, Tanabe K, Kimura EA, Katzin AM, Isomura $S$, Kawamoto F. Allelic diversity at the merozoite surface protein-1 locus of Plasmodium falciparum in clinical isolates from the southwestern Brazilian Amazon. Am J Trop Med Hyg. 1998b;59:474-80.

Ferreira MU, Ribeiro WL, Tonon AP, Kawamoto F, Rich SM. Sequence diversity and evolution of the malaria vaccine candidate merozoite surface protein-1 (MSP-1) of Plasmodium falciparum. Gene. 2003;304:65-75

Ferreira MU, da Silva Nunes M, Wunderlich G. Antigenic diversity and immune evasion by malaria parasites. Clin Diagn Lab Immunol. 2004;11(6):987-995.

Ferreira MU, Hartl DL. Plasmodium falciparum: Worldwide sequence diversity and evolution of the malaria vaccine candidate merozoite surface protein-2 (MSP-2). Exp Parasitol. 2007;115(1):32-40

Frevert U. Sneaking in through the back entrance: the biology of malaria liver stages. Trends Parasitol. 2004;20:417-24.

Gardner MJ, Hall N, Fung E, White O, Berriman M, Hyman RW, Carlton JM, Pain A, Nelson KE, Bowman S, Paulsen IT, James K, Eisen JA, Rutherford K, Salzberg SL, Craig A, Kyes S, Chan MS, Nene V, Shallom SJ, Suh B, Peterson J, Angiuoli S, Pertea M, Allen J, Selengut J, Haft D, Mather MW, Vaidya AB, Martin DM, Fairlamb AH, Fraunholz MJ, Roos DS, Ralph SA, McFadden GI, Cummings LM, Subramanian GM, Mungall C, Venter JC, Carucci DJ, Hoffman SL, Newbold C, Davis RW, Fraser $\mathrm{CM}$, Barrell B. Genome sequence of the human malaria parasite Plasmodium falciparum Nature. 2002;419(6906):498-511. 
Garnham PCC. Malaria parasites and other haemosporidia. Oxford, Inglaterra: Blackwell Scientific Publications; 1966. p. 60-85.

Gaur D, Mayer DC, Miller LH. Parasite ligand-host receptor interactions during invasion of erythrocytes by Plasmodium merozoites. Int J Parasitol. 2004;34(1314):1413-1429.

Genton B, Betuela I, Felger I, Al-Yaman F, Anders RF, Saul A, Rare L, Baisor M, Lorry K, Brown GV, Pye D, Irving DO, Smith TA, Beck HP, Alpers MP. A recombinant blood-stage malaria vaccine reduces Plasmodium falciparum density and exerts selective pressure on parasite populations in a phase $1-2 b$ trial in Papua New Guinea. J Infect Dis. 2002;185(6):820-827

Goel VK, Li X, Chen H, Liu SC, Chishti AH, Oh SS. Band 3 is a host receptor binding merozoite surface protein 1 during the Plasmodium falciparum invasion of erythrocytes. Proc Natl Acad Sci U S A. 2003;100(9):5164-5169.

Graur D, Li W. Fundamentals of Molecular Evolution. $2^{\text {nd }}$ ed. Sunderland, Massachusets: Sinauer Associates; 2000. p. 67-98.

Guerra CA, Gikandi PW, Tatem AJ, Noor AM, Smith DL, Hay SI, Snow RW. The limits and intensity of Plasmodium falciparum transmission: implications for malaria control and elimination worldwide. PLoS Med. 2008;5(2):300-311.

Han ET, Song TE, Park JH, Shin EH, Guk SM, Kim TY, Chai JY. Allelic dimorphism in the merozoite surface protein-3alpha in Korean isolates of Plasmodium vivax. Am J Trop Med Hyg. 2004;71(6):745-749.

Holder AA, Blackman MJ, Burghaus PA, Chappel JA, Ling IT, McCallum-Deighton N, Shai S. A malaria merozoite surface protein (MSP1)-structure, processing and function. Mem Inst Oswaldo Cruz. 1992;87 Suppl 3:37-42.

Hughes AL, Nei M. Pattern of nucleotide substitution at major histocompatibility complex class I loci reveals overdominant selection. Nature. 1988;335(6186):167170.

Hughes AL. Positive selection and interallelic recombination at the merozoite surface antigen-1 (MSA-1) locus of Plasmodium falciparum. Mol Biol Evol. 1992;9(3):381393. 
Hughes MK, Hughes AL. Natural selection on Plasmodium surface proteins. Mol Biochem Parasitol. 1995;71(1):99-113.

Hughes AL, Verra F. Ancient polymorphism and the hypothesis of a recent bottleneck in the malaria parasite Plasmodium falciparum. Genetics. 1998;150(1):511-513.

Jeffares, D.C., Pain, A., Berry, A., Cox, A.V., Stalker, J., Ingle, C.E., Thomas, A., Quail, M.A., Siebenthall, K., Uhlemann, A.C., Kyes, S., Krishna, S., Newbold, C., Dermitzakis, E.T., Berriman, M. Genome variation and evolution of the malaria parasite Plasmodium falciparum. Nat Genet. 2007;39(1):120-125.

Jukes TH, Cantor CR. Evolution of protein molecules. In: Munro HN, Allison JB, editors. Mammalian protein metabolism. New York: Academic Press; 1969. p. 21132.

Kariuki MM, Li X, Yamodo I, Chishti AH, Oh SS. Two Plasmodium falciparum merozoite proteins binding to erythrocyte band 3 form a direct complex. Biochem Biophys Res Commun. 2005;338(4):1690-1695.

Kauth CW, Woehlbier U, Kern M, Mekonnen Z, Lutz R, Mucke N, Langowski J, Bujard $\mathrm{H}$. Interactions between merozoite surface proteins 1,6 and 7 of the malaria parasite Plasmodium falciparum. J Biol Chem. 2006;281(42):31517-31527

Lee EA, Flanagan KL, Minigo G, Reece WH, Bailey R, Pinder M, Hill AV, Plebanski M. Dimorphic Plasmodium falciparum merozoite surface protein-1 epitopes turn off memory T cells and interfere with T cell priming. Eur J Immunol. 2006;36(5):11681178.

Levine ND. The Protozoan Phylum Apicomplexa. Boca Raton, Flórida: CRC Press; 1988. p. 1-8.

Machado RL, Povoa MM, Calvosa VS, Ferreira MU, Rossit AR, dos Santos EJ, Conway DJ. Genetic structure of Plasmodium falciparum populations in the Brazilian Amazon region. J Infect Dis. 2004;190(9):1547-1555.

Mackintosh CL, Beeson JG, Marsh K. Clinical features and pathogenesis of severe malaria. Trends Parasitol. 2004;20(12):597-603.

Marsh K. Immunology of malaria. In: Warrell DA, Gilles HM, editors. Essential Malariology. $4^{\text {th }}$. Ed. New York: Arnold Publishers; 2002. p. 252-267. 
Matuschewski K, Mueller A. Vaccines against malaria - an update. FEBS J. 2007;274(18):4680-4687.

McBride JS, Heidrich HG. Fragments of the polymorphic Mr 185,000 glycoprotein from the surface of isolated Plasmodium falciparum merozoites form an antigenic complex. Mol Biochem Parasitol. 1987;23(1):71-84.

McCutchan TF, Li J, Mcconkey GA, Rogers MJ, Waters AP. The cytoplasmic ribosomal RNAs of Plasmodium spp. Parasitol Today. 1995;11(4):134-138

Ministério da Saúde. Guia de Vigilância Epidemiológica. Disponível em: portal.saude.gov.br/portal/arquivos/pdf/Guia_Vig_Epid_novo2.pdf. 2005 [2008 Jun 23].

Ministério da Saúde. Situação Epidemiológica da Malária do Brasil, Ano de 2006. Disponível em: http://bvsms.saude.gov.br/bvs/publicacoes/folder_malaria_2006_web.pdf. [2008 Jun 11].

Ministério da Saúde. Sistema de Informações Gerenciais - SIG - Malária http://dw.saude.gov.br/portal/page/portal/sivep_malaria/TAB99449:tab_resumo_n?An o_n=2007 [2008 Jun 26].

Nei M. Molecular Evolutionary Genetics. New York: Columbia University Press; 1987. p. 255-286.

Nei M, Gojobori T. Simple methods for estimating the numbers of synonymous and nonsynonymous nucleotide substitutions. Mol Biol Evol. 1986;3(5):418-426.

Nei M, Kumar S. Molecular evolution and phylogenetics. New York: Oxford University Press; 2000. p. 55.

O'donnell RA, Saul A, Cowman AF, Crabb BS. Functional conservation of the malaria vaccine antigen MSP-1 19 across distantly related Plasmodium species. Nat Med. 2000;6:91-95.

Organização Mundial de Saúde - World Malaria Report 2005, Section I: Global malaria situation. Disponível em: http://rbm.who.int/wmr2005/pdf/section1.pdf [2008 Jun 11]. 
Pachebat JA, Kadekoppala M, Grainger M, Dluzewski AR, Gunaratne RS, ScottFinnigan TJ, Ogun SA, Ling IT, Bannister LH, Taylor HM, Mitchell GH, Holder AA. Extensive proteolytic processing of the malaria parasite merozoite surface protein 7 during biosynthesis and parasite release from erythrocytes. Mol Biochem Parasitol. 2007;151(1):59-69.

Patarroyo ME, Amador R, Clavijo P, Moreno A, Guzman F, Romero P, Tascon R, Franco A, Murillo LA, Ponton G, Trujillo G. A synthetic vaccine protects humans against challenge with asexual blood stages of Plasmodium falciparum malaria. Nature. 1988;332(6160):158-161.

Pearce JA, Triglia T, Hodder AN, Jackson DC, Cowman AF, Anders RF. Plasmodium falciparum merozoite surface protein 6 is a dimorphic antigen. Infect Immun. 2004;72(4):2321-2328.

Perkins SL, Schall JJ. A molecular phylogeny of malarial parasites recovered from cytochrome b gene sequences. J Parasitol. 2002;88(5):972-978.

Polley SD, Weedall GD, Thomas AW, Golightly LM, Conway DJ. Orthologous gene sequences of merozoite surface protein 1 (MSP1) from Plasmodium reichenowi and $P$. gallinaceum confirm an ancient divergence of $P$. falciparum alleles. Mol Biochem Parasitol. 2005;142(1):25-31

Polley SD, Tetteh KK, Lloyd JM, Akpogheneta OJ, Greenwood BM, Bojang KA, Conway DJ. Plasmodium falciparum merozoite surface protein 3 is a target of allelespecific immunity and alleles are maintained by natural selection. J Infect Dis. 2007;195(2):279-287.

Prajapati SK, Verma A, Adak T, Yadav RS, Kumar A, Eapen A, Das MK, Singh N, Sharma SK, Rizvi MA, Dash AP, Joshi H. Allelic dimorphism of Plasmodium vivax gam-1 in the Indian subcontinent. Malar J. 2006;5:90

Rich SM, Licht MC, Hudson RR, Ayala FJ. Malaria's Eve: evidence of a recent population bottleneck throughout the world populations of Plasmodium falciparum. Proc Natl Acad Sci U S A. 1998;95(8):4425-4430.

Rich SM, Ayala FJ. Population structure and recent evolution of Plasmpodium falciparum. Proc Natl Acad Sci U S A. 2000;97(13):6994-7001.

Rich SM, Ayala FJ. Progress in malaria research: the case for phylogenetics. Adv Parasitol. 2003;54: 255-280. 
Richman A. Evolution of balanced genetic polymorfhism. Mol Ecol. 2000;9(12):19531963.

Roy SW, Ferreira MU, Hartl DL. Evolution of allelic dimorphism in malarial surface antigens. Heredity. 2008;100(2):103-110.

Rozas J, Sanchez-Delbarrio JC, Messeguer X, Rozas R. DnaSP, DNA polymorphism analyses by the coalescent and other methods. Bioinformatics. 2003;19(18):24962497.

Saitou N, Nei M. The neighbour-joining method: a new method for reconstructing phylogenetic trees. Mol Biol Evol. 1987;4(4):406-425.

Schofield L, Grau GE. Immunological processes in malaria pathogenesis. Nat Rev Immunol. 2005;5(9):722-735 .

Silva NS, Silveira La, Machado RL, Povoa MM, Ferreira MU. Temporal and spatial distribution of the variants of merozoite surface protein-1 (MSP-1) in Plasmodium falciparum populations in Brazil. Ann Trop Med Parasitol. 2000;94(7):675-688.

Sinden RE, Gilles HM. The malaria parasites. In: Warrell DA, Gilles HM, editors. Essential Malariology. $4^{\text {th }}$. Ed. New York: Arnold Publishers; 2002. p. 8-34.

Singh S, Soe S, Roussilhon C, Corradin G, Druilhe P. Plasmodium falciparum merozoite surface protein 6 displays multiple targets for naturally occurring antibodies that mediate monocyte-dependent parasite killing. Infect Immun. 2005;73(2):12351238.

Smythe JA, Coppel RL, Day KP, Martin RK, Oduola AM, Kemp DJ, Anders RF. Structural diversity in the Plasmodium falciparum merozoite surface antigen 2. Proc Natl Acad Sci U S A. 1991;88(5):1751-1755.

Snewin VA, Herrera M, Sanchez G, Scherf A, Langsley G, Herrera S. Polymorphism of the alleles of the merozoite surface antigens MSA1 and MSA2 in Plasmodium falciparum wild isolates from Colombia. Mol Biochem Parasitol. 1991;49(2):265-275.

Snow RW, Guerra CA, Noor AM, Myint HY, Hay SI. The global distribution of clinical episodes of Plasmodium falciparum malaria. Nature. 2005;434(7030):214-217. 
Sturm A, Amino R, van de Sand C, Regen T, Retzlaff S, Rennenberg A, Krueger A, Pollok JM, Menard R, Heussler VT. Manipulation of host hepatocytes by the malaria parasite for delivery into liver sinusoids. Science. 2006;313(5791):1287-1290.

Tamura K, Dudley J, Nei M, Kumar S. MEGA4: Molecular Evolutionary Genetics Analysis (MEGA) software version 4.0. Mol Biol Evol. 2007;24(8):1596-1599.

Tanabe K, Mackay M, Goman M, Scaife JG. Allelic dimorphism in a surface antigen gene of the malaria parasite Plasmodium falciparum. J Mol Biol. 1987;195(2):273287.

Tanabe K, Sakihama N, Hattori T, Ranford-Cartwright L, Goldman I, Escalante AA, Lal AA. Genetic distance in housekeeping genes between Plasmodium falciparum and Plasmodium reichenowi and within P. falciparum. J Mol Evol. 2004;59(5):687-94.

Tanabe K, Sakihama N, Walliker D, Babiker H, Abdel-Muhsin Am, Bakote'e B, Ohmae H, Arisue N, Horii T, Rooth I, Färnert A, Björkman A, Ranford-Cartwright L. Allelic dimorphism-associated restriction of recombination in Plasmodium falciparum msp1. Gene. 2007a;397(1-2):153-160

Tanabe K, Escalante A, Sakihama N, Honda M, Arisue N, Horii T, Culleton R, Hayakawa T, Hashimoto T, Longacre S, Pathirana S, Handunnetti S, Kishino H. Recent independent evolution of msp1 polymorphism in Plasmodium vivax and related simian malaria parasites. Mol Biochem Parasitol. 2007b;156(1):74-9.

Taylor WR. The classification of amino acid conservation. J Theor Biol. 1986;119(2): 205-218.

Troye-Blomberg M, Weidanz WP, Van Der Heyde $\mathrm{H}$. The role of $\mathrm{T}$ cells in immunity to malaria and the pathogenesis of disease. In: Wahlgren $M$, Perlmann $P$, editors. Malaria: Molecular and Clinical Aspects. Amsterdam: Harwood Academic Publishers; 1999. p. 403-438.

Trucco C, Fernandez-Reyes D, Howell S, Stafford WH, Scott-Finnigan TJ, Grainger M, Ogun SA, Taylor WR, Holder AA. The merozoite surface protein 6 gene codes for a $36 \mathrm{kDa}$ protein associated with the Plasmodium falciparum merozoite surface protein-1 complex. Mol Biochem Parasitol. 2001;112(1):91-101.

Tsuji M, Rodrigues EG, Nussenzweig S. Progress toward a malaria vaccine: efficient induction of protective anti-malaria immunity. Biol Chem. 2001;382(4):553-70 
Volkman SK, Sabeti PC, DeCaprio D, Neafsey DE, Schaffner SF, Milner DA Jr, Daily JP, Sarr O, Ndiaye D, Ndir O, Mboup S, Duraisingh MT, Lukens A, Derr A, StangeThomann N, Waggoner S, Onofrio R, Ziaugra L, Mauceli E, Gnerre S, Jaffe DB, Zainoun J, Wiegand RC, Birren BW, Hartl DL, Galagan JE, Lander ES, Wirth DF. A genome-wide map of diversity in Plasmodium falciparum. Nat Genet. 2007;39(1):113-9.

Wahlgreen $M$, Barragan A, Chen $Q$, Fernandez V, Hagblon $P$, Heddini $A$, Schlichtherle M, Scholander C, Sundströn A, Treutiger CJ, Von Euler, Carlson J. Rosetting of malaria infected erythrocytes: ligands, host receptors and the involvment of serum proteins. In: Sherman IW, editor. Malaria: Parasite biology, pathogenesis and protection. Washington, D.C.: ASM Press; 1998. p. 387-398.

Wang L, Crouch L, Richie TL, Nhan DH, Coppel RL. Naturally acquired antibody responses to the components of the Plasmodium falciparum merozoite surface protein 1 complex. Parasite Immunol. 2003;25(8-9):403-12.

Warrel DA. Clinical features of malaria. In: Warrell DA, Gilles HM, editors. Essential Malariology. $4^{\text {th }}$. Ed. New York: Arnold Publishers; 2002. p. 191-205.

Waters AP, Higgins DG, Mccutchan TF. Plasmodium falciparum appears to have arisen as a result of lateral transfer between avian and human hosts. Proc Natl Acad Sci USA. 1991;88(8): 3140-3144.

Weedall G. Applications of molecular evolutionary analyses of Plasmodium genomes to detect genes under natural selection [Ph D Thesis (Biology)]. London: Department of Infectious and Tropical Diseases; London School of Hygiene and Tropical Medicine; 2008.

Zavala F, Tam JP, Hollingdale MR, Cochrane AH, Quakyi I, Nussenzweig RS, Nussenzweig $\mathrm{V}$. Rationale for development of a synthetic vaccine against Plasmodium falciparum malaria. Science. 1985;228(4706):1436-1440 


\title{
ANEXO A - ALINHAMENTO DAS SEQÜÊNCIAS DE msp-6
}

\author{
As seqüências acima da linha tracejada são do tipo 3D7, e as abaixo \\ são do tipo K1. Os sítios dimórficos, com exceção dos indels, estão marcados \\ em vermelho claro. A origem das amostras está indicada no Quadro 4, com \\ exceção das amostras 106, 54 e ICBIII, que são provenientes de Rondônia.
}

\begin{tabular}{|c|c|}
\hline 3D7 & TGAATAAGATTTATAATATTACTTTTCTTTTCATTCTTTTAAACTTATATATAAATGAA \\
\hline D10 & ATGAATAAGATTTATAATATTACTTTTCTTTTCATTCTTTTAAACTTATATATAAATGAA \\
\hline $\mathrm{NHC}-1$ & ATGAATAAGATTTATAATATTACTTTTCTTTTCATTCTTTTAAACTTATATATAAATGAA \\
\hline IT & ATGAATAAGATTTATAATATTACTTTTCTTTTCATTCTTTTAAACTTATATATAAATGAA \\
\hline NF7 & ATGAATAAGATTTATAATATTACTTTTCTTTTCATTCTTTTAAACTTATATATAAATGAA \\
\hline T9/96 & ATGAATAAGATTTATAATATTACTTTTCTTTTCATTCTTTTAAACTTATATATAAATGAA \\
\hline 32 & ATGAATAAGATTTATAATATTACTTTTCTTTTCATTCTTTTAAACTTATATATAAATGAA \\
\hline B3 & ATGAATAAGATTTATAATATTACTTTTCTTTTCATTCTTTTAAACTTATATATAAATGAA \\
\hline DE28 & ATGAATAAGATTTATAATATTACTTTTCTTTTCATTCTTTTAAACTTATATATAAATGAA \\
\hline HB3 & ATGAATAAGATTTATAATATTACTTTTCTTTTCATTCTTTTAAACTTATATATAAATGAA \\
\hline 04 & ATGAATAAGATTTATAATATTACTTTTCTTTTCATTCTTTTAAACTTATATATAAATGAA \\
\hline $7 \mathrm{G} 8$ & ATGAATAAGATTTATAATATTACTTTTCTTTTCATTCTTTTAAACTTATATATAAATGAA \\
\hline 42 & ATGAATAAGATTTATAATATTACTTTTCTTTTCATTCTTTTAAACTTATATATAAATGAA \\
\hline BA2 4 & ATGAATAAGATTTATAATATTACTTTTCTTTTCATTCTTTTAAACTTATATATAAATGAA \\
\hline PC17 & ATGAATAAGATTTATAATATTACTTTTCTTTTCATTCTTTTAAACTTATATATAAATGAA \\
\hline B1 & ATGAATAAGATTTATAATATTACTTTTCTTTTCATTCTTTTAAACTTATATATAAATGAA \\
\hline 106 & ATGAATAAGATTTATAATATTACTTTTCTTTTCATTCTTTTAAАСTTATATATAAATGAA \\
\hline 59 & ATGAATAAGATTTATAATATTACTTTTCTTTTCATTCTTTTAAACTTATATATAAATGAA \\
\hline 54 & ATGAATAAGATTTATAATATTACTTTTCTTTTCATTCTTTTAAACTTATATATAAATGAA \\
\hline 45 & ATGAATAAGATTTATAATATTACTTTTCTTTTCATTCTTTTAAACTTATATATAAATGAA \\
\hline 27 & 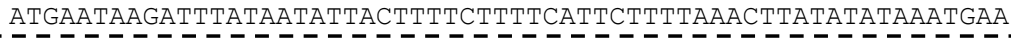 \\
\hline 06 & ATGAATAAGATTTATAATATTACTTTTCTTTTCATTCTTTTAAAСTTATATATAAATGAA \\
\hline 20 & ATGAATAAGATTTATAATATTACTTTTCTTTTCATTCTTTTAAACTTATATATAAATGAA \\
\hline 134 & ATGAATAAGATTTATAATATTACTTTTCTTTTCATTCTTTTAAACTTATATATAAATGAA \\
\hline 608 & ATGAATAAGATTTATAATATTACTTTTCTTTTCATTCTTTTAAACTTATATATAAATGAA \\
\hline MC & ATGAATAAGATTTATAATATTACTTTTCTTTTCATTCTTTTAAACTTATATATAAATGAA \\
\hline D2 & ATGAATAAGATTTATAATATTACTTTTCTTTTCATTCTTTTAAACTTATATATAAATGAA \\
\hline 62 & ATGAATAAGATTTATAATATTACTTTTCTTTTCATTCTTTTAAACTTATATATAAATGAA \\
\hline W2mef & ATGAATAAGATTTATAATATTACTTTTCTTTTCATTCTTTTAAACTTATATATAAATGAA \\
\hline B2 & ATGAATAAGATTTATAATATTACTTTTCTTTTCATTCTTTTAAACTTATATATAAATGAA \\
\hline B7 & ATGAATAAGATTTATAATATTACTTTTCTTTTCATTCTTTTAAACTTATATATAAATGAA \\
\hline ICBIII & ATGAATAAGATTTATAATATTACTTTTCTTTTCATTCTTTTAAACTTATATATAAATGAA \\
\hline K1 & ATGAATAAGATTTATAATATTACTTTTCTTTTCATTCTTTTAAACTTATATATAAATGAA \\
\hline IC & ATGAATAAGATTTATAATATTACTTTTCTTTTCATTCTTTTAAACTTATATATAAATGAA \\
\hline Dd2 & ATGAATAAGATTTATAATATTACTTTTCTTTTCATTCTTTTAAACTTATATATAAATGAA \\
\hline
\end{tabular}


3D7

D10

NHC-1

IT

NF7

T9/96

32

B3

DE28

HB 3

04

$7 \mathrm{G} 8$

42

BA2 4

PC1 7

B1

106

59

54

45

27

06

20

134

608

$\mathrm{MC}$

D2

62

W2mef

B2

B7

ICBIII

K1

IC

Dd2

AATAACTTTATCAGAAATGAACTTATAAACGAAAAAAACCATAATTTAAGAAATGGTTCA 120 AATAACTTTATCAGAAATGAACTTATAAACGAAAAAAACCATAATTTAAGAAATGGTTCA 120 AATAACTTTATCAGAAATGAACTTATAAACGAAAAAAACCATAATTTAAGAAATGGTTCA 120 AATAACTTTATCAGAAATGAACTTATAAACGAAAAAAACCATAATTTAAGAAATGGTTCA 120 AATAACTTTATCAGAAATGAACTTATAAACGAAAAAAACCATAATTTAAGAAATGGTTCA 120 AATAACTTTATCAGAAATGAACTTATAAACGAAAAAAACCATAATTTAAGAAATGGTTCA 120 AATAACTTTATCAGAAATGAACTTATAAACGAAAAAAACCATAATTTAAGAAATGGTTCA 120 AATAACTTTATCAGAAATGAACTTATAAACGAAAAAAACCATAATTTAAGAAATGGTTCA 120 AATAACTTTATCAGAAATGAACTTATAAACGAAAAAAACCATAATTTAAGAAATGGTTCA 120 AATAACTTTATCAGAAATGAACTTATAAACGAAAAAAACCATAATTTAAGAAATGGTTCA 120 AATAACTTTATCAGAAATGAACTTATAAACGAAAAAAACCATAATTTAAGAAATGGTTCA 120 AATAACTTTATCAGAAATGAACTTATAAACGAAAAAAACCATAATTTAAGAAATGGTTCA 120 AATAACTTTATCAGAAATGAACTTATAAACGAAAAAAACCATAATTTAAGAAATGGTTCA 120 AATAACTTTATCAGAAATGAACTTATAAACGAAAAAAACCATAATTTAAGAAATGGTTCA 120 AATAACTTTATCAGAAATGAACTTATAAACGAAAAAAACCATAATTTAAGAAATGGTTCA 120 AATAACTTTATCAGAAATGAACTTATAAACGAAAAAAACCATAATTTAAGAAATGGTTCA 120 AATAACTTTATCAGAAATGAACTTATAAACGAAAAAAACCATAATTTAAGAAATGGTTCA 120 AATAACTTTATCAGAAATGAACTTATAAACGAAAAAAACCATAATTTAAGAAATGGTTCA 120 AATAACTTTATCAGAAATGAACTTATAAACGAAAAAAACCATAATTTAAGAAATGGTTCA 120 AATAACTTTATCAGAAATGAACTTATAAACGAAAAAAACCATAATTTAAGAAATGGTTCA 120 AATAACTTTATCAGAAATGAACTTATAAACGAAAAAAACCATAATTTAAGAAATGGTTCA 120.

AATAACTTTATCAGAAATGAACTTATAAACGAAAAAACTATAATTTAAGAAATGGTTCA 120 AATAACTTTATCAGAAATGAACTTATAAACGAAAAAAACTATAATTTAAGAAATGGTTCA 120 AATAACTTTATCAGAAATGAACTTATAAACGAAAAAAACTATAATTTAAGAAATGGTTCA 120 AATAACTTTATCAGAAATGAACTTATAAACGAAAAAAACTATAATTTAAGAAATGGTTCA 120 AATAACTTTATCAGAAATGAACTTATAAACGAAAAAAACCATAATTTAAGAAATGGTTCA 120 AATAACTTTATCAGAAATGAACTTATAAACGAAAAAAACCATAATTTAAGAAATGGTTCA 120 AATAACTTTATCAGAAATGAACTTATAAACGAAAAAAACCATAATTTAAGAAATGGTTCA 120 AATAACTTTATCAGAAATGAACTTATAAACGAAAAAAACCATAATTTAAGAAATGGTTCA 120 AATAACTTTATCAGAAATGAACTTATAAACGAAAAAAACCATAATTTAAGAAATGGTTCA 120 AATAACTTTATCAGAAATGAACTTATAAACGAAAAAAACCATAATTTAAGAAATGGTTCA 120 AATAACTTTATCAGAAATGAACTTATAAACGAAAAAAACCATAATTTAAGAAATGGTTCA 120 AATAACTTTATCAGAAATGAACTTATAAACGAAAAAAACCATAATTTAAGAAATGGTTCA 120 AATAACTTTATCAGAAATGAACTTATAAACGAAAAAAACCATAATTTAAGAAATGGTTCA 120 AATAACTTTATCAGAAATGAACTTATAAACGAAAAAAACCATAATTTAAGAAATGGTTCA 120

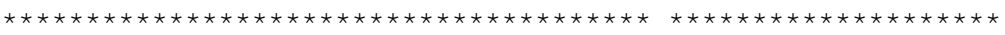

$3 \mathrm{D} 7$

D10

$\mathrm{NHC}-1$

$\mathrm{IT}$

NF7

T9/96

32

B3

DE28

HB3

04

$7 \mathrm{G} 8$

42

BA2 4

PC1 7

B1

106

59

54

45

27

$0 \overline{6}$

20

134

608

$\mathrm{MC}$

D2

62

W2mef

B2

B7

ICBIII

$\mathrm{K} 1$

IC

$\operatorname{Dd} 2$

ATGTATAATAACGATAAAATATAAGTAAAAATGAAGTAGATACTAATATAGAAAGTAAC 180 ATGTATAATAACGATAAAATATTAAGTAAAAATGAAGTAGATACTAATATAGAAAGTAAC 180 ATGTATAATAACGATAAAATATTAAGTAAAAATGAAGTAGATACTAATATAGAAAGTAAC 180 ATGTATAATAACGATAAAATATTAAGTAAAAATGAAGTAGATACTAATATAGAAAGTAAC 180 ATGTATAATAACGATAAAATATTAAGTAAAAATGAAGTAGATACTAATATAGAAAGTAAC 180 ATGTATAATAACGATAAAATATTAAGTAAAAATGAAGTAGATACTAATATAGAAAGTAAC 180 ATGTATAATAACGATAAAATATTAAGTAAAAATGAAGTAGATACTAATATAGAAAGTAAC 180 ATGTATAATAACGATAAAATATTAAGTAAAAATGAAGTAGATACTAATATAGAAAGTAAC 180 ATGTATAATAACGATAAAATATTAAGTAAAAATGAAGTAGATACTAATATAGAAAGTAAC 180 ATGTATAATAACGATAAAATATTAAGTAAAAATGAAGTAGATACTAATATAGAAAGTAAC 180 ATGTATAATAACGATAAAATATTAAGTAAAAATGAAGTAGATACTAATATAGAAAGTAAC 180 ATGTATAATAACGATAAAATATTAAGTAAAAATGAAGTAGATACTAATATAGAAAGTAAC 180 ATGTATAATAACGATAAAATATTAAGTAAAAATGAAGTAGATACTAATATAGAAAGTAAC 180 ATGTATAATAACGATAAAATATTAAGTAAAAATGAAGTAGATACTAATATAGAAAGTAAC 180 ATGTATAATAACGATAAAATATTAAGTAAAAATGAAGTAGATACTAATATAGAAAGTAAC 180 ATGTATAATAACGATAAAATATTAAGTAAAAATGAAGTAGATACTAATATAGAAAGTAAC 180 ATGTATAATAACGATAAATATTAAGTAAAAATGAAGTAGATACTAATATAGAAAGTAAC 180 ATGTATAATAACGATAAAATATTAAGTAAAAATGAAGTAGATACTAATATAGAAAGTAAC 180 ATGTATAATAACGATAAAATATTAAGTAAAAATGAAGTAGATACTAATATAGAAAGTAAC 180 ATGTATAATAACGATAAAATATTAAGTAAAAATGAAGTAGATACTAATATAGAAAGTAAC 180 ATGTATAATAACGATAAAATATTAAGTAAAAATGAAGTAGATACTAATATAGAAAGTAAC 180 ATGTATAATAACGATAAAATTTAAGTAAAATGAAGTAGATACTAATATAGAAAGTÄ 180 ATGTATAATAACGATAAAATATTAAGTAAAAATGAAGTAGATACTAATATAGAAAGTAAC 180 ATGTATAATAACGATAAAATATTAAGTAAAAATGAAGTAGATACTAATATAGAAAGTAAC 180 ATGTATAATAACGATAAAATATTAAGTAAAAATGAAGTAGATACTAATATAGAAAGTAAC 180 ATGTATAATAACGATAAAATATTAAGTAAAAATGAAGTAGATACTAATATAGAAAGTAAC 180 ATGTATAATAACGATAAAATATTAAGTAAAAATGAAGTAGATACTAATATAGAAAGTAAC 180 ATGTATAATAACGATAAAATATTAAGTAAAAATGAAGTAGATACTAATATAGAAAGTAAC 180 ATGTATAATAACGATAAAATATTAAGTAAAAATGAAGTAGATACTAATATAGAAAGTAAC 180 ATGTATAATAACGATAAAATATAAGTAAAAATGAAGTAGATACTAATATAGAAAGTAAC 180 ATGTATAATAACGATAAAATATTAAGTAAAAATGAAGTAGATACTAATATAGAAAGTAAC 180 ATGTATAATAACGATAAAATATTAAGTAAAAATGAAGTAGATACTAATATAGAAAGTAAC 180 ATGTATAATAACGATAAAATATTAAGTAAAAATGAAGTAGATACTAATATAGAAAGTAAC 180 ATGTATAATAACGATAAAATATTAAGTAAAAATGAAGTAGATACTAATATAGAAAGTAAC 180 ATGTATAATAACGATAAAATTAAGTAAAAATGAAgTAGATACTAATATAGAAAgTAAC 180

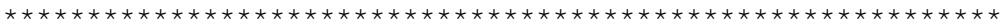


3D7

D10

NHC-1

IT

NF7

T9/96

32

B3

DE2 8

HB 3

04

$7 \mathrm{G} 8$

42

BA2 4

PC1 7

B1

106

59

54

45

27

06

20

134

608

$\mathrm{MC}$

D2

62

W2mef

B2

B7

ICBIII

K1

$\mathrm{IC}$

Dd2

GAAAATAGTATTCACGAATCTGGACATAAGATTGATGGGGAAGAAGTTTTAAAAGCTAAT 240

GAAAATAGTATTCACGAATCTGGACATAAGATTGATGGGGAAGAAGTTTTAAAAGCTAAT 240

GAAAATAGTATTCACGAATCTGGACATAAGATTGATGGGGAAGAAGTTTTAAAAGCTAAT 240 GAAAATAGTATTCACGAATCTGGACATAAGATTGATGGGGAAGAAGTTTTAAAAGCTAAT 240 GAAAATAGTATTCACGAATCTGGACATAAGATTGATGGGGAAGAAGTTTTAAAAGCTAAT 240 GAAAATAGTATTCACGAATCTGGACATAAGATTGATGGGGAAGAAGTTTTAAAAGCTAAT 240 GAAAATAGTATTCACGAATCTGGACATAAGATTGATGGGGAAGAAGTTTTAAAAGCTAAT 240 GAAAATAGTATTCACGAATCTGGACATAAGATTGATGGGGAAGAAGTTTTAAAAGCTAAT 240 GAAAATAGTATTCACGAATCTGGACATAAGATTGATGGGGAAGAAGTTTTAAAAGCTAAT 240 GAAAATAGTATTCACGAATCTGGACATAAGATTGATGGGGAAGAAGTTTTAAAAGCTAAT 240 GAAAATAGTATTCACGAATCTGGACATAAGATTGATGGGGAAGAAGTTTTAAAAGCTAAT 240 GAAAATAGTATTCACGAATCTGGACATAAGATTGATGGGGAAGAAGTTTTAAAAGCTAAT 240 GAAAATAGTATTCACGAATCTGGACATAAGATTGATGGGGAAGAAGTTTTAAAAGCTAAT 240 GAAAATAGTATTCACGAATCTGGACATAAGATTGATGGGGAAGAAGTTTTAAAAGCTAAT 240 GAAAATAGTATTCACGAATCTGGACATAAGATTGATGGGGAAGAAGTTTTAAAAGCTAAT 240 GAAAATAGTATTCACGAATCTGGACATAAGATTGATGGGGAAGAAGTTTTAAAAGCTAAT 240 GAAAATAGTATTCACGAATCTGGACATAAGATTGATGGGGAAGAAGTTTTAAAAGCTAAT 240 GAAAATAGTATTCACGAATCTGGACATAAGATTGATGGGGAAGAAGTTTTAAAAGCTAAT 240 GAAAATAGTATTCACGAATCTGGACATAAGATTGATGGGGAAGAAGTTTTAAAAGCTAAT 240 GAAAATAGTATTCACGAATCTGGACATAAGATTGATGGGGAAGAAGTTTTAAAAGCTAAT 240 GAAAATAGTATTCACGAATCTGGACATAAGATTGATGGGGAAGAAGTTTTAAAAGCTAAT 240

GAAAATAGTATTCACGAATCTGGACATAAGATTGATGGGAAGAAGTTTTAAAAGCTAAT 240 GAAAATAGTATTCACGAATCTGGACATAAGATTGATGGGGAAGAAGTTTTAAAAGCTAAT 240 GAAAATAGTATTCACGAATCTGGACATAAGATTGATGGGGAAGAAGTTTTAAAAGCTAAT 240 GAAAATAGTATTCACGAATCTGGACATAAGATTGATGGGGAAGAAGTTTTAAAAGCTAAT 240 GAAAATAGTATTCACGAATCTGGACATAAGATTGATGGGGAAGAAGTTTTAAAAGCTAAT 240 GAAAATAGTATTCACGAATCTGGACATAAGATTGATGGGGAAGAAGTTTTAAAAGCTAAT 240 GAAAATAGTATTCACGAATCTGGACATAAGATTGATGGGGAAGAAGTTTTAAAAGCTAAT 240 GAAAATAGTATTCACGAATCTGGACATAAGATTGATGGGGAAGAAGTTTTAAAAGCTAAT 240 GAAAATAGTATTCACGAATCTGGACATAAGATTGATGGGGAAGAAGTTTTAAAAGCTAAT 240 GAAAATAGTATTCACGAATCTGGACATAAGATTGATGGGGAAGAAGTTTTAAAAGCTAAT 240 GAAAATAGTATTCACGAATCTGGACATAAGATTGATGGGGAAGAAGTTTTAAAAGCTAAT 240 GAAAATAGTATTCACGAATCTGGACATAAGATTGATGGGGAAGAAGTTTTAAAAGCTAAT 240 GAAAATAGTATTCACGAATCTGGACATAAGATTGATGGGGAAGAAGTTTTAAAAGCTAAT 240 GAAAATAGTATTCACGAATCTGGACATAAGATTGATGGGGAAGAAGTTTTAAAAGCTAAT 240

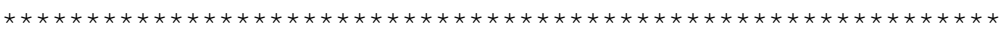

\begin{tabular}{|c|c|}
\hline $3 \mathrm{D} 7$ & -------------GTAGA $\mathrm{W}$ GATAAACATACAAAAAAAAAAATGTTGATGATTCAGAA \\
\hline D10 & 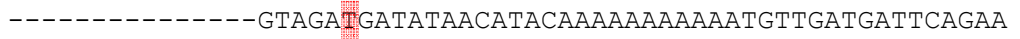 \\
\hline $\mathrm{NHC}-1$ & -------------GTAGATGATATAACATACAAAAAAAAAAATGTTGATGATTCAGAA \\
\hline IT & 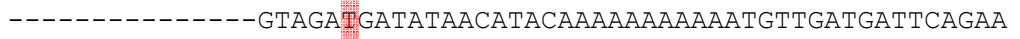 \\
\hline NF7 & $--------------G T A G A$ TATATAACATACAAAAAAAAAAATGTTGATGATTCAGAA \\
\hline $\mathrm{T} 9 / 96$ & -------------GTAGA I GATATAACATACAAAAAAAAAAATGTTGATGATTCAGAA \\
\hline 32 & -------------GTAGA ${ }^{2}$ GATATAACATACAAAAAAAAAAATGTTGATGATTCAGAA \\
\hline B3 & -------------GTAGA1 GATATAACATACAAAAAAAAAAATGTTGATGATTCAGAA \\
\hline DE28 & -------------GTAGAITATATAACATACAAAAAAAAAAATGTTGATGATTCAGAA \\
\hline HB3 & $--------------G T A G A$ GATATAACATACAAAAAAAAAAATGTTGATGATTCAGAA \\
\hline 04 & $--------------G T A G A$ GATATAACATACAAAAAAAAAAATGTTGATGATTCAGAA \\
\hline $7 \mathrm{G} 8$ & -------------GTAGA $\operatorname{GATATAACATACAAAAAAAAAAATGTTGATGATTCAGAA~}$ \\
\hline 42 & -------------GTAGA TITATAACATACAAAAAAAAAAATGTTGATGATTCAGAA \\
\hline BA24 & --------------GTAGAT GATATAACATACAAAAAAAAAAATGTTGATGATTCAGAA \\
\hline PC17 & $--------------G T A G A$ GATATAACATACAAAAAAAAAAATGTTGATGATTCAGAA \\
\hline B1 & -------------GTAGA稿GATATAACATACAAAAAAAAAAATGTTGATGATTCAGAA \\
\hline 106 & --------------GTAGATGATATAACATACAAAAAAAAAAATGTTGATGATTCAGAA \\
\hline 59 & -------------GTAGA TATATAACATACAAAAAAAAAAATGTTGATGATTCAGAA \\
\hline 54 & -------------GTAGATGATATAACATACAAAAAAAAAAATGTTGATGATTCAGAA \\
\hline 45 & --------------GTAGA GATATAACATACAAAAAAAAAAATGTTGATGATTCAGAA \\
\hline 27 & ------------- GTAGA GATATAACATACAAAAAAAAAAATGTTGATGATTCAGAA \\
\hline & CAAGAACAAGCTAATGTAGAAGATAAACATACAAAAAAAAAAATGTTATGATTCAGAA \\
\hline 20 & CAAGAACAAGCTAATGTAGAAGATATAACATACAAAAAAAAAAATGTTGATGATTCAGAA \\
\hline 134 & CAAGAACAAGCTAATGTAGAÄGATATAACATACAAAAAAAAAAATGTTGATGATTCAGAA \\
\hline 608 & CAAGAACAAGCTAATGTAGAAGATATAACATACAAAAAAAAAAATGTTGATGATTCAGAA \\
\hline $\mathrm{MC}$ & CAAGAACAAGCTAATGTAGAAGATATAACATACAAAAAAAAAAATGTTGATGATTCAGAA \\
\hline D2 & CAAGAACAAGCTAATGTAGAAGATATAACATACAAAAAAAAAAATGTTGATGATTCAGAA \\
\hline 62 & CAAGAACAAGCTAATGTAGAAGATATAACATACAAAAAAAAAAATGTTGATGATTCAGAA \\
\hline W2mef & CAAGAACAAGCTAATGTAGAAGATATAACATACAAAAAAAAAAATGTTGATGATTCAAAA \\
\hline B2 & CAAGAACAAGCTAATGTAGAAGATATAACATACAAAAAAAAAAATGTTGATGATTCAGAA \\
\hline B7 & CAAGAACAAGCTAATGTAGAZGATATAACATACAAAAAAAAAAATGTTGATGATTCAGAA \\
\hline ICBIII & CAAGAACAAGCTAATGTAGAAGATATAACATACAAAAAAAAAAATGTTGATGATTCAGAA \\
\hline K1 & CAAGAACAAGCTAATGTAGAAGATATAACATACAAAAAAAAAAATGTTGATGATTCAGAA \\
\hline IC & CAAGAACAAGCTAATGTAGAAGATATAACATACAAAAAAAAAAATGTTGATGATTCAGAA \\
\hline $\mathrm{Dd} 2$ & CAAGAACAAGCTAATGTAGA A GATATAACATACAAAAAAAAAAATGTTGATGATTCAGAA \\
\hline
\end{tabular}


3D7

D10

NHC-1

IT

NF 7

T9/96

32

B3

DE2 8

HB3

04

$7 \mathrm{G} 8$

42

BA2 4

PC1 7

B1

106

59

54

45

27

$-\overline{6}$

20

134

608

$\mathrm{MC}$

D2

62

W2mef

B2

B7

ICBIII

K1

IC

Dd2

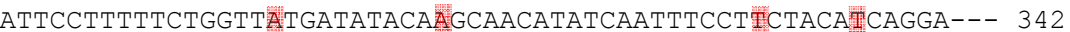

АTTCCTTTTTCTGGTTATGATATACAAGCAACATATCAATTTCCTTCTACATCAGGA--- 342

ATTCCTTTTTCTGGTTATGATATACAAGCAACATATCAATTTCCTTCTACA ITAGAA--- 342 ATTCCTTTTTCTGGTTATGATATACAAGCAACATATCAATTTCCTTCTACATCAGGA--- 342 AтTCCTTTTTCTGGTTATGATATACAAGCAACATATCAATTTCCTTCTACATCAGGA--- 342 АTTCCTTTTTCTGGTTATGATATACA ACAACATATCAATTTCCTTCTACATCAGGA--- 342 ATTCCTTTTTCTGGTTATGATATACA ACAACATATCAATTTCCTWCTACATCAGGA--- 342 ATTCCTTTTTCTGGTTATGATATACAAGCAACATATCAATTTCCTICTACATCAGGA--- 342 ATTCCTTTTTCTGGTTATGATATACAAGCAACATATCAATTTCCTTCTACAICAGGA--- 342 АтTCCTTTTTCTGGTTATGATATACA AMCAACATATCAATTTCCTTCTACAICAGGA--- 342 ATtCCTTTTTCTGGTTATGATATACA AGCAACATATCAATTTCCTITCTACAMCAGGA--- 342 АTTCCTTTTTCTGGTTATGATATACAAGCAACATATCAATTTCCTTCTACAICAGGA--- 342

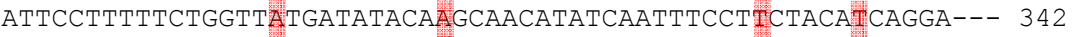
ATTCCTTTTTCTGGTTATGATATACAAGCAACATATCAATTTCCTTCTACATCAGGA--- 342 ATTCCTTTTTCTGGTTATGATATACAAGCAACATATCAATTTCCTTCTACATCAGGA--- 342 ATTCCTTTTTCTGGTTATGATATACAAGCAACATATCAATTTCCTTCTACATCAGGA--- 342 ATTCCTTTTTCTGGTTATGATATACAAGCAACATATCAATTTCCTTCTACAICAGGA--- 342 АTTCCTTTTTCTGGTTATGATATACA AGCAACATATCAATTTCCTMCTACATCAGGA--- 342 ATTCCTTTTTCTGGTT ATGATATACAAGCAACATATCAATTTCCTTCTACA АTTCCTTTTTCTGGTTATGATATACAAGCAACATATCAATTTCCTTCTACATCAGGA--- 342 ATTCCTTTTTCTGGTTATGATATACAAGCAACATATCAATTCCTTCTACA:CAGGA-- 342 ATTCCTTTTTCTGGTTCTGATATACA GCAACATATCAATTTCCTCCTACACCAGGAAGA 360 ATTCCTTTTTCTGGTTCTGATATACACGCAACATATCAATTTCCTCCTACACCAGGAAGA 360 ATTCCTTTTTCTGGTTCTGATATACAGGCAACATATCAATTTCCTCCTACACCAGGAAGA 360 ATTCCTTTTTCTGGTTCTGATATACAEGCAACATATCAATTTCCTCCTACACCAGGAAGA 360 ATTCCTTTTTCTGGTTCTGATATACAGGCAACATATCAATTTCCTCCTACACCAGGAAGA 360 AтTCстTTTTCTGGTTCTGATATACACGCAACATATCAATTTCCTCCTACACCAGGAAGA 360 ATTCCTTTTTCTGGTTCTGATATACAGGCAACATATCAATTTCCTCCTACACCAGGAAGA 360 ATTCCTTTTTCTGGTTCTGATATACAGGCAACATATCAATTTCCTCCTACACCAGGAAGA 360 ATTCCTTTTTCTGGTTCTGATATACA GCAACATATCAATTTCCTCCTACACCAGGAAGA 360 ATTCCTTTTTCTGGTTCTGATATACAGGCAACATATCAATTTCCTCCTACACCAGGAAGA 360 AтTсCтTTTTCTGGTTCTGATATACA GCAACATATCAATTTCCTCCTACACCAGGAAGA 360 ATTCCTTTTCTGGTTCTGATATACA GCAACATATCAATTTCCTCCTACACCAGGAAGA 360 ATTCCTTTTTCTGGTTCTGATATACAGGCAACATATCAATTTCCTCCTACACCAGGAAGA 360 ATTCCTTTTTCTGGTTCTGATATACAGGCAACATATCAATTTCCTCCTACACCAGGAAGA 360

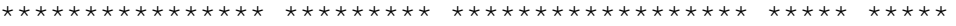

$3 \mathrm{D} 7$

D10

$\mathrm{NHC}-1$

$\mathrm{IT}$

NF7

T9/96

32

B3

DE2 8

HB3

04

$7 \mathrm{G} 8$

42

BA2 4

PC1 7

B1

106

59

54

45

27

06

20

134

608

$\mathrm{MC}$

D2

62

W2mef

B2

B 7

ICBIII

$\mathrm{K} 1$

IC

Dd2

----------------GGAAATATGTAATTCCACTTCCTATAAAAAA----- 375

------------------GGAAATAATGTAATTCCACTTCCTATAAAACAA------ 375

------------------GGAAATAATGTAATTCCACTTCCTATAAAACAA------ 375

------------------GGAAATAATGTAATTCCACTTCCTATAAAACAA------ 375

-----------------GGAAATAATGTAATTCCACWTCCTATAAAACAA------ 375

------------------GGAAATAATGTAATTCCACTTCCTATAAAACAA------ 375

-----------------GGAAATAATGTAATTCCACTTCCTA TAAAACAA------ 375

-----------------GGAAATAATGTAATTCCACTTCCTA AAAACAA----- 375

-----------------GGAAATAATGTAATTCCACPTCCTATAAAACAA------ 375

-----------------GGAAATAATGTAATTCCACETCCTA TAAAACAA------ 375

-----------------GGAAATAATGTAATTCCACTTCCTA AAAACAA------ 375

$---------------G G A A A T A A T G T A A T T C C A C C C C C T A T A A A A C A A-----375$

-----------------GGAAATAATGTAATTCCACTTCCTATAAAACAA------ 375

------------------GGAAATAATGTAATCCACTTCCTATAAAACAA------ 375

-----------------GGAAATAATGTAATTCCACTTCCTATAAAACAA------ 375

-----------------GGAAATAATGTAATTCCACTTCCTATAAAACAA------ 375

-----------------GGAAATAATGTAATTCCACTTCCTA TAAAACAA------ 375

------------------GGAAATAATGTAATTCCACTTCCTAIAAAACAA------ 375

-----------------GGAAATAATGTAATTCCACTTCCTATAAAACAA------ 375

------------------GGAAATAATGTAATTCCACTTCCTATAAAACAA------ 375

$-------------G G A A A T A A T G T A A T T C C A C T$ TCCTA TAAAACAA----- 375

ATTATAAATCCTCGTACTGGAGGAAATACTGTAATTCACCTCCTAGAAGACAAGTGGA 420 ATTATAAATCCTCGTACTGGAGGAAATACTGTAATTCCACGTCCTAGAAGACTAAGTGG 420 ATTATAAATCCTCGTACTGGAGGAAATACTGTAATTCCACCTCCTAGAAGAC ATTATAAATCCTCGTACTGGAGGAAATACTGTAATTCCACCTCCTAGAAGACTAAGTGGA 420 ATTATAAATCCTCGTACTGGAGGAAATACTGTAATTCACCTCCTAGAAGAC: ATTATAAATCCTCGTACTGGAGGAAATACTGTAATTCCACCTCCTAGAAGACAAGTGGA 420 ATTATAAATCCTCGTACTGGAGGAAATACTGTAATCCACCTCCTAGAAGACAAGTGGA 420 ATTATAAATCCTCGTACTGGAGGAAATACTGTAATTCCACCTCCTAGAACACWAAGTGGA 420 ATTATAAATCCTCGTACTGGAGGAAATACTGTAATTCCACCTCCTAGAAGACAAGTGGA 420 ATTATAAATCCTCGTACTGGAGGAAATACTGTAATTCCACCTCCTAGAACACTAAGTGG 420 ATTATAAATCCTCGTACTGGAGGAAATACTGTAATTCCACCTCCTAGAAGACTAAGTGG 420 ATTATAAATCCTCGTACTGGAGGAAATACTGTAATTCCACETCCTAGAAGACAAagTGgA 420 ATTATAAATCCTCGTACTGGAGGAAATACTGTAATTCACCTCCTAGAAGACTAAGTGGA 420 ATTATAAATCCTCGTACTGGAGGAAATACTGTAATTCCACCTCCTAGAAGACTAAGT--- 417

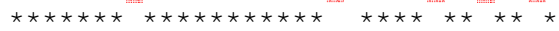




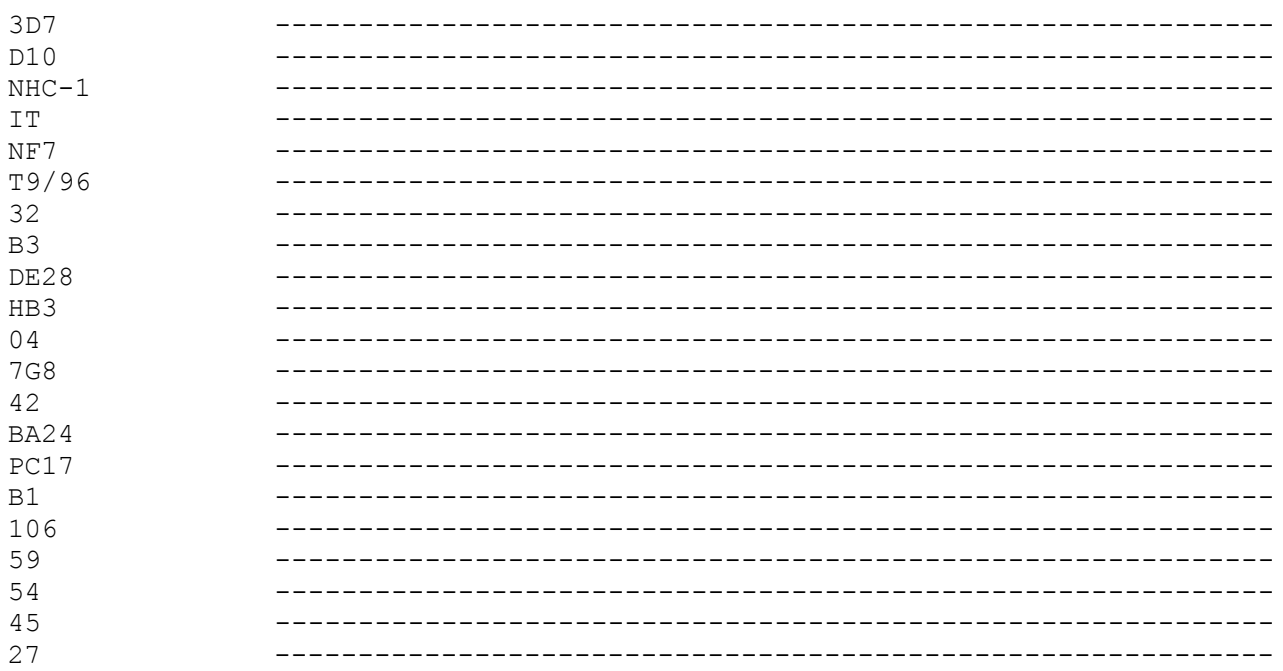

CTAGAAGTGTTTCTATCCACATGTATTTACATCTTCTAATCAATCACATCCTCAAAGA 480 20 134 608

$\mathrm{D} 2$

62

W2mef

B2

B7

ICBIII

K1

IC

CTAGAAGGTGTTTCTTATCCACATGTATTTACATCTTCTAATCAATCACATCCTCAAAGA 480 CTAGAAGGTGTTTCTTATCCACATGTATTTACATCTTCTAATCAATCACATCCTCAAAGA 480 CTAGAAGGTGTTTCTTATCCACATGTATTTACATCTTCTAATCAATCACATCCTCAAAGA 480 CTAGAAGGTGTTTCTTATCCACATGTATTTACATCTTCTAATCAATCACATCCTCAAAGA 480 CTAGAAGGTGTTTCTTATCCACATGTATTTACATCTTCTAATCAATCACATCCTCAAAGA 480 CTAGAAGGTGTTTCTTATCCACATGTATTTACATCTTCTAATCAATCACATCCTCAAAGA 480 CTAGAAGGTGTTTCTTATCCACATGTATTTACATCTTCTAATCAATCACATCCTCAAAGA 480 CTAGAAGGTGTTTCTTATCCACATGTATTTACATCTTCTAATCAATCACATCCTCAAAGA 480 CTAGAAGGTGTTTCTTATCCACATGTATTTACATCTTCTAATCAATCACATCCTCAAAGA 480 CTAGAAGGTGTTTCTTATCCACATGTATTTACATCTTCTAATCAATCACATCCTCAAAGA 480 CTAGAAGGTGTTTCTTATCCACATGTATTTACATCTTCTAATCAATCACATCCTCAAAGA 480 CTAGAAGGTGTTTCTTATCCACATGTATTTACATCTTCTAATCAATCACATCCTCAAAGA 480

\begin{tabular}{l} 
3D7 \\
D10 \\
NHC-1 \\
IT \\
NF7 \\
T9/96 \\
32 \\
B3 \\
DE28 \\
HB3 \\
04 \\
7 G8 \\
42 \\
BA24 \\
PC17 \\
B1 \\
106 \\
59 \\
54 \\
45 \\
27 \\
\hline 06 \\
20 \\
134 \\
608 \\
MC - - - \\
D2 \\
62 \\
W2mef \\
B2 \\
B7 \\
ICBIII \\
K1 \\
IC \\
Dd2 \\
\end{tabular}

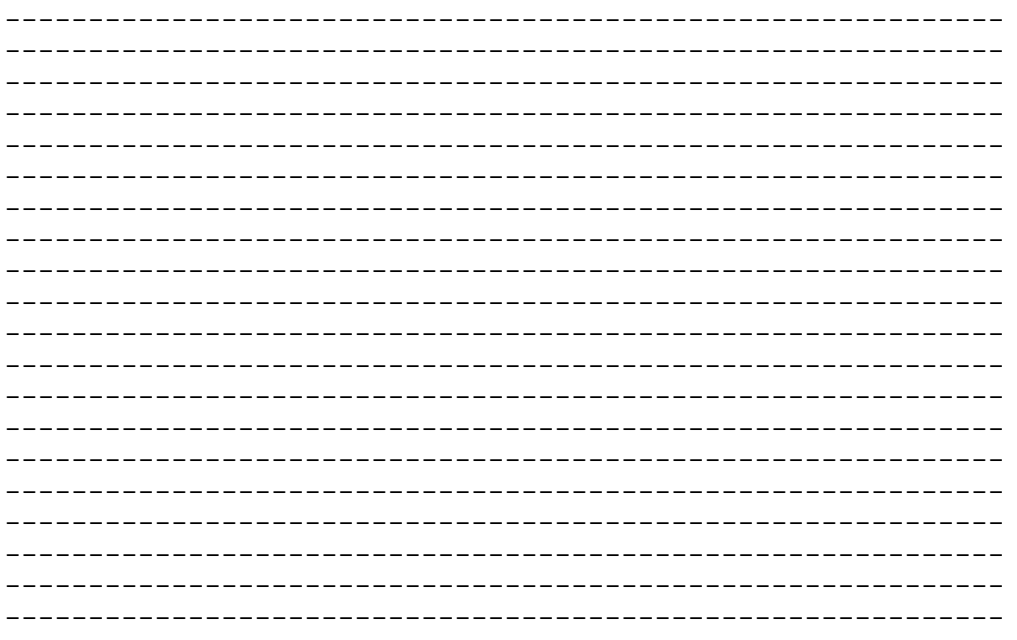

GCCAACATCGGAGGAATATCCCATTTATCAGGGACACGTGGATTCATACTTATTCAGGT 540 GCCAACATCGGAGGAATATCCCATTTATCAGGGACACGTGGAATTCATACTTATTCAGGT 540 GCCAACATCGGAGGAATATCCCATTTATCAGGGACACGTGGAATTCATACTTATTCAGGT 540 GCCAACATCGGAGGAATATCCCATTTATCAGGGACACGTGGAATTCATACTTATTCAGGT 540 GCCAACATCGGAGGAATATCCCATTTATCAGGGACACGTGGAATTCATACTTATTCAGGT 540 GCCAACATCGGAGGAATATCCCATTTATCAGGGACACGTGGAATTCATACTTATTCAGGT 540 GCCAACATCGGAGGAATATCCCATTTATCAGGGACACGTGGAATTCATACTTATTCAGGT 540 GCCAACATCGGAGGAATATCCCATTTATCAGGGACACGTGGAATTCATACTTATTCAGGT 540 GCCAACATCGGAGGAATATCCCATTTATCAGGGACACGTGGAATTCATACTTATTCAGGT 540 GCCAACATCGGAGGAATATCCCATTTATCAGGGACACGTGGAATTCATACTTATTCAGGT 540 GCCAACATCGGAGGAATATCCCATTTATCAGGGACACGTGGAATTCATACTTATTCAGGT 540 GCCAACATCGGAGGAATATCCCATTTATCAGGGACACGTGGAATTCATACTTATTCAGGT 540 GCCAACATCGGAGGAATATCCCATTTATCAGGGACACGTGGAATTCATACTTATTCAGGT 540 
3D7

D10

NHC-1

IT

NF 7

T9/96

32

B3

DE28

HB 3

04

$7 \mathrm{G} 8$

42

BA2 4

PC1 7

B1

106

59

54

45

27

06

20

134

608

$\mathrm{MC}$

D2

62

W2mef

B2

B7

ICBIII

K1

IC

Dd2

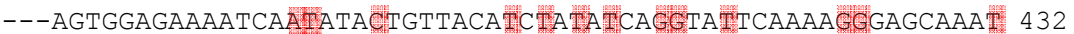

---AGTGGAGAAAATCAATATACTGGTACA CTATA TIAGGTATTCAAAAGGGAGCAAA 432

---AGTGGAGAAAATCAATATACTGTTACATCWATA TAGGTATTCAAAAGGGAGCAAA 432

---AGTGGAGAAAATCAATATACTGTTACATCTATATCAGGTATTCAAAAGGGAGCAAA 432

---AGTGGAGAAAATCAATATACTGTTACA CTA TA:CAGGTATTCAAAAGGGAGCAAA 432

---AGTGGAGAAAATCAATATACTGTTACATCTATATCAGGTATTCAAAAGGGAGCAAAT 432

---AGTGGAGAAAATCAATATACTGTTACATCTATATCAGGTATTCAAAAGGGAGCAAA 432

---AGTGGAGAAAATCAATATACTGTTACATCTATATCAGGTATTCAAAAGGGAGCAAAT 432

---AGTGGAGAAAATCAAIATACTGTTACATCTATA TAGGTATTCAAAAGGGAGCAAAT 432

---AGTGGAGAAAATCAATATACTGTTACA TI:TA TAGGTATTCAAAAGGGAGCAAA 432

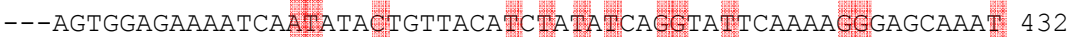

---AGTGGAGAAAATCAATATACTGTTACATCTATATCAGGTATTCAAAAGGGAGCAAA 432

---AGTGGAGAAAATCAATATACTGTTACA CTATATCAGETATTCAAAAGGGAGCAAAT 432

---AGTGGAGAAAATCAATATACTGTTACA CTATATCAGGTATTCAAAAGSGAGCAAAT 432

---AGTGGAGAAAATCAATATA TGTTACATCTATATCA G CTATTCAAAA GGGAGCAAAT 432

---AGTGGAGAAAATCAATATA CTGTTACA CTATA CAGGTATTCAAAAGGGAGCAAA 432

---AGTGGAGAAAATCAAIATACTGTTACATCTATATCAGGTATTCAAAAGGGAGCAAAT 432

---AGTGGAGAAAATCAATATACTGTTACATCTATA TIAGGTATCAAAAGGGAGCAAA 432

---AGTGGAGAAAATCAATATACTGTTACATCATATCAGCTATTCAAAAGGGAGCAAA 432

---AGTGGAGAAAATCAATATACTGTTACATCATATCAGGTATTCAAAAGGGAGCAAAT 432 - AGTGGAGAAAATCAATATACTGTTACA TEATATCAGGTATTCAAAAGGGAGCAAA 432

GAAAGTGGAGAAATCACCATATTGTACAACAGACCAAATACTCAAAACCGAGCAAAA 600 GAAAGTGGAGAAAATCACCATATTGTTACAACCAGACCAANTACTCAAAACCGAGCAAAA 600 GAAAGTGGAGAAAATCACCATATTGTTACAACCAGACCAANTACTCAAAACCGAGCAAA 600 GAAAGTGGAGAAAATCACCATATTGTTACAACCAGACCAANTACTCAAAACCGAGCAAAA 600 GAAAGTGGAGAAAATCACCATATTGTTACAACCAGACCAANTACTCAAAACCGAGCAAAA 600 GAAAGTGGAGAAAATCACCATATTGTTACAACCAGACCAAATACTCAAAACCGAGCAAA 600 GAAAGTGGAGAAAATCACCATATTGTTACAACCAGACCANATACTCAAAACCGAGCAAAA 600 GAAAGTGGAGAAAATCACCATATTGTTACAACCAGACCAANTACTCAAAACCGAGCAAAA 600 GAAAGTGGAGAAAATCACCATATTGTTACAACAGACCAANTACTCAAAACEGAGCAAA 600 GAAAGTGGAGAAAATCACCATATTGTTACAACCAGACCAANTACTCAAAACCGAGCAAAA 600 GAAAGTGGAGAAAATCACCATATTGTTACAACCAGACCAANTACTCAAAACCGAGCAAAA 600 GAAAGTGGAGAAAATCACCATATTGTTACARCCAGACCAANTACTCAAAACCGAGCAAA 600 GAAAGTGGAGAAAATCACCATATTGTTACAACCAGACCAAATACTCAAAACCGAGCAAAA 600 GAAAGTGGAGAAAATCACCATATTGTTACAACCAGACCAAATACTCAAAACCGAGCAAAA 477

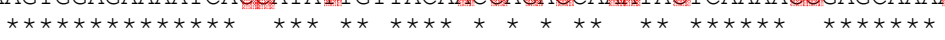

GGTTTAACTGGTGCAACAGAAAATATTACACAAGTGTACAAGCAAACTCTGAAACAAAT 492 GGTTTAACTGGTGCAACAGAAAATATTACACAAGTTMTCAAGCAAACTCTGAAACAAAT 492 GGTTTAACTGGTGCAACAGAAAA GGTTTAACTGGTGCAACAGAAAATATTACACAAGTTGTACAAGCAAACTCTGAAACAAAT 492 GGTTTAACTGGTGCAACAGAAAATATACACAAGTTIACAAGCAAACTCTGAAACAAAT 492 GGTTTAACTGGTGCAACAGAAAATATTACACAAGTGTACAAGCAAACTCTGAAACAAAT 492 GGTTTAACTGGTGCAACAGAAAATATTACACAÄGTGTACAAGCAAACTCTGAAACAAAT 492 GGTTTAACTGGTGCAACAGAAAATATTACACAAGTTTACAAGCAAACTCTGAAACAAAT 492 GGTTTAACTGGTGCAACAGAAAA TATTACACAAGTITACAAGCAAACTCTGAAACAAAT 492 GGTTTAACTGGTGCAACAGAAAATATTACACAAGTTGTACAAGCAAACTCTGAAACAAAT 492 GGTTTAACTGGTGCAACAGAAAATATTACACAAGTTGTACAAGAAACTCTGAAACAAAT 492 GGTTTAACTGGTGCAACAGAAAATATTACACAAGTGTACAAGCAAACTCTGAAACAAAT 492 GGTTTAACTGGTGCAACAGAAAA TATTACACAAGTTGACAAGCAAACTCTGAAACAAAT 492 GGTTTAACTGGTGCAACAGAAAATATTACACAAGTGTACAAGCAAACTCTGAAACAAAT 492 GGTTTAACTGGTGCAACAGAAAATATTACACAAGTTGTACAAGCAAACTCTGAAACAAAT 492 GGTTTAACTGGTGCAACAGAAAATATTACACAAGTTGACAAGCAAACTCTGAAACAAAT 492 GGTTTAACTGGTGCAACAGAAAA ITTACACAAGTITACAAGCAAACTCTGAAACAAAT 492 GGTTTAACTGGTGCAACAGAAAA IATACACAAGTTGTACAAGCAAACTCTGAAACAAAT 492 GGTTTAACTGGTGCAACAGAAAATATTACACAAGTGTACAAGCAAACTCTGAAACAAAT 492 GGTTTAACTGGTGCAACAGAAAATATTACACAAGTTGTACAAGCAAACTCTGAAACAAAT 492 GGTTTAACTGGTGCAACAGAAAATATTACACAAGTTGTACAAGCAAACTCTGAAACAAAT 492 GGTTTAACTGGTGCAACAGAAAAATTACACACGGTGCAGAAGAAACTCTGAAACAAAT 660 GGTTTAACTGGTGCAACAGAAAAAATTACACACGCTGCAGAGAAAACTCTGAAACAAAT 660 GGTTTAACTGGTGCAACAGAAAAAATTACACA CGGTGCAGAAGAAAACTCTGAAACAAAT 660 GGTTTAACTGGTGCAACAGAAAAAATTACACACGGTGCAGAAGAAAACTCTGAAACAAAT 660 GGTTTAACTGGTGCAACAGAAAAAATACACACGGTGCAGAAGAAAACTCTGAAACAAAT 660 GGTTTAACTGGTGCAACAGAAAAAATACACACGGTGCAGAAGAAAATCTGAAACAAAT 660 GGTTTAACTGGTGCAACAGAAAAAATTACACA GGTGCAGAAGAAAACTCTGAAACAAAT 660 GGTTTAACTGGTGCAACAGAAAARATTACACACGGTGCAGAAGAAAACTCTGAAACAAAT 660 GGTTTAACTGGTGCAACAGAAAAAATACACACGGTGCAGAAGAAAATCTGAAACAAAT 660 GGTTTAACTGGTGCAACAGAAAAAATTACACACGGTGCAGAAGAAACTCTGAAACAAAT 660 GGTTTAACTGGTGCAACAGAAAAAATTACACACGGTGCAGAAGAAAACTCTGAAACAAAT 660 GGTTTAACTGGTGCAACAGAAAAAATACACACGGTGCAGAGAAAACTCTGAAACAAAT 660 GGTTTAACTGGTGCAACAGAAAAAATTACACACGGTGCAGAAGAAAACTCTGAAACAAAT 660 GGTTTAACTGGTGCAACAGAAAAAATACACACGGTGCAGAAGAAACTCTGAAACAAAT 537

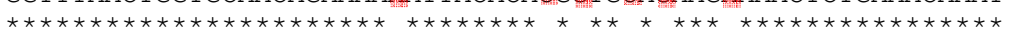


3D7

D10

NHC-1

IT

NF7

T9/96

32

B3

DE2 8

HB 3

04

$7 \mathrm{G} 8$

42

BA2 4

PC1 7

B1

106

59

54

45

27

06

20
134
608

608

$\mathrm{MC}$

D2

62

W2mef

B2

B7

ICBIII

K1

IC

Dd2

AAAAATCCTACTTCTCATAGTAATAGTACTACAACTTCTCTGAATAATAATATACTTGGA 552 AAAAATCCTACTTCTCATAGTAA:AGTACTACAACTTCTCTGAATAATAATATACTTGGA 552 AAAAATCCTACT TCTCATAGTAA TAGTACTACAACTTCTCTGAATAATAATATACTTGGA 552 AAAAATCCTACTTCTCATAGTAATAGTACTACAACTTCTCTGAATAATAATATACTTGGA 552 AAAAATCCTACTTCTCATAGTAATAGTACTACAACTTCTCTGAATAATAATATACTTGGA 552 AAAAATCCTACTTCTCATAGTAATAGTACTACAACTTCTCTGAATAATAATATACTTGGA 552 AAAAATCCTACTTCTCATAGTAATAGTACTACAACTTCTCTGAATAATAATATACTTGGA 552 AAAAATCCTACTTCTCATAGTAATAGTACTACAACTTCTCTGAATAATAATATACTTGGA 552 AAAAATCCTACTTCTCATAGTAATAGTACTACAACTTCTCTGAATAATAATATACTTGGA 552 AAAAATCCTACTTCTCATAGTAATAGTACTACAACTTCTCTGAATAATAATATACTTGGA 552 AAAAATCCTACT TCTCATAGTAA AAAAATCCTACTTCTCATAGTAATAGTACTACAACTTCTCTGAATAATAATATACTTGGA 552 AAAAATCCTACTTCTCATAGTAATAGTACTACAACTTCTCTGAATAATAATATACTTGGA 552 AAAAATCCTACT TCTCATAGTAA:AGTACTACAACTTCTCTGAATAATAATATACTTGGA 552 AAAAATCCTACTTCTCATAGTAA ATACTACAACTTCTCTGAATAATAATATACTTGGA 552 AAAAATCCTACT TCTCATAGTAATAGTACTACAACTTCTCTGAATAATAATATACTTGGA 552 AAAAATCCTACTTCTCATAGTAATAGTACTACAACTTCTCTGAATAATAATATACTTGGA 552 AAAAATCCTACTTCTCATAGTAATAGTACTACAACTTCTCTGAATAATAATATACTTGGA 552 AAAAATCCTACTTCTCATAGTAATAGTACTACAACTTCTCTGAATAATAATATACTTGGA 552 AAAAATCCTACTICTCATAGTAANAGTACTACAACTTCTCTGAATAATAATATACTTGGA 552 AAAAATCCTACT:CTCATAGTAATAGTACTACAACTTCTCTGAATAATAATATACTTGGA 552 AAAAATCCTACTCCTGGTAGTAAAAGTACTACAACTTCTCTGAATAATAATATACTTGGA 720 AAAAATCCTACTCCTGGTAGTAAAAGTACTACAACTTCTCTGAATAATAATATACTTGGA 720 AAAAATCCTACTCCTGGTAGTAAAAGTACTACAACTTCTCTGAATAATAATATACTTGGA 720 AAAAATCCTACTCCTGGTAGTAAAAGTACTACAACTTCTCTGAATAATAATATACTTGGA 720 AAAAATCCTACTCCTGGTAGTAAAAGTACTACAACTTCTCTGAATAATAATATACTTGGA 720 AAAAATCCTACTCCTGGTAGTAAAAGTACTACAACTTCTCTGAATAATAATATACTTGGA 720 AAAAATCCTACTCCTGGTAGTAAAAGTACTACAACTTCTCTGAATAATAATATACTTGGA 720 AAAAATCCTACTCCTGGTAGTAAAAGTACTACAACTTCTCTGAATAATAATATACTTGGA 720 AAAAATCCTACTCCTGGTAGTAAAAGTACTACAACTTCTCTGAATAATAATATACTTGGA 720 AAAAATCCTACTCCTCGTAGTAAAAGTACTACAACTTCTCTGAATAATAATATACTTGGA 720 AAAAATCCTACTCСTGGTAGTAARAGTACTACAACTTCTCTGAATAATAATATACTTGGA 720 AAAAATCCTACTCCTGGTAGTAAAAGTACTACAACTTCTCTGAATAATAATATACTTGGA 720 AAAAATCCTACTCCTGGTAGTAAAAGTACTACAACTTCTCTGAATAATAATATACTTGGA 720 AAAAATCCTACTCCTGGTAGTAAAAGTACTACAACTTCTCTGAATAATAATATACTTGGA 597

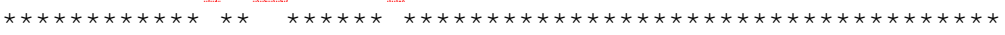

TGGGAATTTGGAGGAGGTGCTCCTCAAAATGGAGCTGCAGAAGATAAAAAGACAGAATAT 612 TGGGAATTTGGAGGAGGTGCTCCTCAAAATGGAGCTGCAGAAGATAAAAAGACAGAATAT 612 TGGGAATTTGGAGGAGGTGCTCCTCAAAATGGAGCTGCAGAAGATAAAAAGACAGAATAT 612 TGGGAATTTGGAGGAGGTGCTCCTCAAAATGGAGCTGCAGAAGATAAAAAGACAGAATAT 612 TGGGAATTTGGAGGAGGTGCTCCTCAAAATGGAGCTGCAGAAGATAAAAAGACAGAATAT 612 TGGGAATTTGGAGGAGGTGCTCCTCAAAATGGAGCTGCAGAAGATAAAAAGACAGAATAT 612 TGGGAATTTGGAGGAGGTGCTCCTCAAAATGGAGCTGCAGAAGATAAAAAGACAGAATAT 612 TGGGAATTTGGAGGAGGTGCTCCTCAAAATGGAGCTGCAGAAGATAAAAAGACAGAATAT 612 TGGGAATTTGGAGGAGGTGCTCCTCAAAATGGAGCTGCAGAAGATAAAAAGACAGAATAT 612 TGGGAATTTGGAGGAGGTGCTCCTCAAAATGGAGCTGCAGAAGATAAAAAGACAGAATAT 612 TGGGAATTTGGAGGAGGTGCTCCTCAAAATGGAGCTGCAGAAGATAAAAAGACAGAATAT 612 TGGGAATTTGGAGGAGGTGCTCCTCAAAATGGAGCTGCAGAAGATAAAAAGACAGAATAT 612 TGGGAATTTGGAGGAGGTGCTCCTCAAAATGGAGCTGCAGAAGATAAAAAGACAGAATAT 612 TGGGAATTTGGAGGAGGTGCTCCTCAAAATGGAGCTGCAGAAGATAAAAAGACAGAATAT 612 TGGGAATTTGGAGGAGGTGCTCCTCAAAATGGAGCTGCAGAAGATAAAAAGACAGAATAT 612 TGGGAATTTGGAGGAGGTGCTCCTCAAAATGGAGCTGCAGAAGATAAAAAGACAGAATAT 612 TGGGAATTTGGAGGAGGTGCTCCTCAAAATGGAGCTGCAGAAGATAAAAAGACAGAATAT 612 TGGGAATTTGGAGGAGGTGCTCCTCAAAATGGAGCTGCAGAAGATAAAAAGACAGAATAT 612 TGGGAATTTGGAGGAGGTGCTCCTCAAAATGGAGCTGCAGAAGATAAAAAGACAGAATAT 612 TGGGAATTTGGAGGAGGTGCTCCTCAAAATGGAGCTGCAGAAGATAAAAAGACAGAATAT 612 TGGGAATTTGGAGGAGGTGCTCCTCAAAATGGAGCTGCAGAAGATAAAAAGACAGAATAT 612 TGGGAATTTGGAGGAGGTGCTCTCAAAATGGAGCTGCAGAAGATAAAAAGACAGAATAT 780 TGGGAATTTGGAGGAGGTGCTCCTCAAAATGGAGCTGCAGAAGATAAAAAGACAGAATAT 780 TGGGAATTTGGAGGAGGTGCTCCTCAAAATGGAGCTGCAGAAGATAAAAAGACAGAATAT 780 TGGGAATTTGGAGGAGGTGCTCCTCAAAATGGAGCTGCAGAAGATAAAAAGACAGAATAT 780 TGGGAATTTGGAGGAGGTGCTCCTCAAAATGGAGCTGCAGAAGATAAAAAGACAGAATAT 780 TGGGAATTTGGAGGAGGTGCTCCTCAAAATGGAGCTGCAGAAGATAAAAAGACAGAATAT 780 TGGGAATTTGGAGGAGGTGCTCCTCAAAATGGAGCTGCAGAAGATAAAAAGACAGAATAT 780 TGGGAATTTGGAGGAGGTGCTCCTCAAAATGGAGCTGCAGAAGATAAAAAGACAGAATAT 780 TGGGAATTTGGAGGAGGTGCTCCTCAAAATGGAGCTGCAGAAGATAAAAAGACAGAATAT 780 TGGGAATTTGGAGGAGGTGCTCCTCAAAATGGAGCTGCAGAAGATAAAAAGACAGAATAT 780 TGGGAATTTGGAGGAGGTGCTCCTCAAAATGGAGCTGCAGAAGATAAAAAGACAGAATAT 780 TGGGAATTTGGAGGAGGTGCTCCTCAAAATGGAGCTGCAGAAGATAAAAAGACAGAATAT 780 TGGGAATTTGGAGGAGGTGCTCCTCAAAATGGAGCTGCAGAAGATAAAAAGACAGAATAT 780 TGGGAATTTGGAGGAGGTGCTCCTCAAAATGGAGCTGCAGAAGATAAAAAGACAGAATAT 657

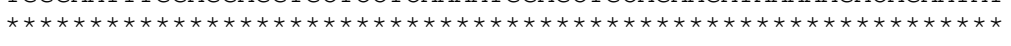


3D7

D10

NHC-1

IT

NF7

T9/96

32

B3

DE2 8

HB 3

04

$7 \mathrm{G} 8$

42

BA2 4

PC1 7

B1

106

59

54

45

27

06

20

134

608

$\mathrm{MC}$

D2

62

W2mef

B2

B7

ICBIII

K1

IC

Dd2

TTACTAGAACAAATAAAAATTCCATCATGGGATAGAAATAACATCCCCGATGAGAATGAA 672 TTACTAGAACAAATAAAAATTCCATCATGGGATAGAAATAACATCCCCGATGAGAATGAA 672 TTACTAGAACAAATAAAAATTCCATCATGGGATAGAAATAACATCCCCGATGAGAATGAA 672 TTACTAGAACAAATAAAAATTCCATCATGGGATAGAAATAACATCCCCGATGAGAATGAA 672 TTACTAGAACAAATAAAAATTCCATCATGGGATAGAAATAACATCCCCGATGAGAATGAA 672 TTACTAGAACAAATAAAAATTCCATCATGGGATAGAAATAACATCCCCGATGAGAATGAA 672 TTACTAGAACAAATAAAAATTCCATCATGGGATAGAAATAACATCCCCGATGAGAATGAA 672 TTACTAGAACAAATAAAAATTCCATCATGGGATAGAAATAACATCCCCGATGAGAATGAA 672 TTACTAGAACAAATAAAAATTCCATCATGGGATAGAAATAACATCCCCGATGAGAATGAA 672 TTACTAGAACAAATAAAAATTCCATCATGGGATAGAAATAACATCCCCGATGAGAATGAA 672 TTACTAGAACAAATAAAAATTCCATCATGGGATAGAAATAACATCCCCGATGAGAATGAA 672 TTACTAGAACAAATAAAAATTCCATCATGGGATAGAAATAACATCCCCGATGAGAATGAA 672 TTACTAGAACAAATAAAAATTCCATCATGGGATAGAAATAACATCCCCGATGAGAATGAA 672 TTACTAGAACAAATAAAAATTCCATCATGGGATAGAAATAACATCCCCGATGAGAATGAA 672 TTACTAGAACAAATAAAAATTCCATCATGGGATAGAAATAACATCCCCGATGAGAATGAA 672 TTACTAGAACAAATAAAAATTCCATCATGGGATAGAAATAACATCCCCGATGAGAATGAA 672 TTACTAGAACAAATAAAAATTCCATCATGGGATAGAAATAACATCCCCGATGAGAATGAA 672 TTACTAGAACAAATAAAAATTCCATCATGGGATAGAAATAACATCCCCGATGAGAATGAA 672 TTACTAGAACAAATAAAAATTCCATCATGGGATAGAAATAACATCCCCGATGAGAATGAA 672 TTACTAGAACAAATAAAAATTCCATCATGGGATAGAAATAACATCCCCGATGAGAATGAA 672 TTACTAGAACAAATAAAAATTCCATCATGGGATAGAAATAACATCCCCGATGAGAATGAA 672

TTACTAGAACAAATAAAAATTCATCATGGGATAGAAATAACATCCCCGATGAGAATGAA 840 TTACTAGAACAAATAAAAATTCCATCATGGGATAGAAATAACATCCCCGATGAGAATGAA 840 TTACTAGAACAAATAAAAATCCATCATGGGATAGAAATAACATCCCCGATGAGAATGAA 840 TTACTAGAACAAATAAAAATTCCATCATGGGATAGAAATAACATCCCCGATGAGAATGAA 840 TTACTAGAACAAATAAAAATTCCATCATGGGATAGAAATAACATCCCCGATGAGAATGAA 840 TTACTAGAACAAATAAAAATTCCATCATGGGATAGAAATAACATCCCCGATGAGAATGAA 840 TTACTAGAACAAATAAAAATTCCATCATGGGATAGAAATAACATCCCCGATGAGAATGAA 840 TTACTAGAACAAATAAAAATTCCATCATGGGATAGAAATAACATCCCCGATGAGAATGAA 840 TTACTAGAACAAATAAAAATTCCATCATGGGATAGAAATAACATCCCCGATGAGAATGAA 840 TTACTAGAACAAATAAAAATTCCATCATGGGATAGAAATAACATCCCCGATGAGAATGAA 840 TTACTAGAACAAATAAAAATTCCATCATGGGATAGAAATAACATCCCCGATGAGAATGAA 840 TTACTAGAACAAATAAAAATTCCATCATGGGATAGAAATAACATCCCCGATGAGAATGAA 840 TTACTAGAACAAATAAAAATTCCATCATGGGATAGAAATAACATCCCCGATGAGAATGAA 840 TTACTAGAACAAATAAAAATCCATCATGGGATAGAAATAACATCCCCGATGAGAATGAA 717

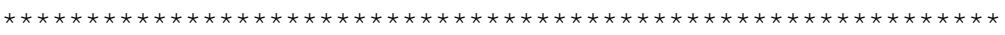

\begin{tabular}{l}
$3 \mathrm{D} 7$ \\
D10 \\
NHC-1 \\
IT \\
NF7 \\
T9/96 \\
32 \\
B3 \\
DE28 \\
HB3 \\
04 \\
7 G8 \\
42 \\
BA24 \\
PC17 \\
B1 \\
106 \\
59 \\
54 \\
45 \\
27 \\
\hline $06-------8 A$ \\
20 \\
134 \\
608 \\
MC \\
D2 \\
62 \\
W2mef \\
B2 \\
B7 \\
ICBIII \\
K1 \\
IC \\
Dd2
\end{tabular}

CAAGTAATAGAGGACCCTCAAGAAGATAATAAAGATGAAGATGAAGATGAAGAA------ 726 CAAGTAATAGAgGACCCTCAAGAAGATAATAAAGATGAAGATGAAGATGAAGAA------ 726 CAAGTAATAGAGGACCCTCAAGAAGATAATAAAGATGAAGATGAAGATGAAGAA------ 726 CAAGTAATAGAGGACCCTCAAGAAGATAATAAAGATGAAGATGAAGATGAAGAA------ 726 CAAGTAATAGAGGACCCTCAAGAAGATAATAAAGATGAAGATGAAGATGAAGAA------ 726 CAAGTAATAGAGGACCCTCAAGAAGATAATAAAGATGAAGATGAAGATGAAGAA------ 726 CAAGTAAAAGAGGACCCTCAAGAAGATAATAAAGATGAAGATGAAGATGAAGAA-- - - - 726 CAAGTAAAAGAGGACCCTCAAGAAGATAATAAAGATGAAGATGAAGATGAAGAA------ 726 CAAGTAAAAGAGGACCCTCAAGAAGATAATAAAGATGAAGATGAAGATGAAGAA------ 726 CAAGTAAAAGAGGACCCTCAAGAAGATAATAAAGATGAAGATGAAGATGAAGAA------ 726 CAAGTAAAAGAGGACCCTCAAGAAGATAATAAAGATGAAGATGAAGATGAAGAA------ 726 CAAGTAAAAGAGGACCCTCAAGAAGATAATAAAGATGAAGATGAAGATGAAGAA------ 726 CAAGTAAAAGAGGACCCTCAAGAAGATAATAAAGATGAAGATGAAGATGAAGAA------ 726 CAAGTAAAAGAGGACCCTCAAGAAGATAATAAAGATGAAGATGAAGATGAAGAA------ 726 CAAGTAAAAGAGGACCCTCAAGAAGATAATAAAGATGAAGATGAAGATGAAGAA------ 726 CAAGTAAAAGAGGACCCTCAAGAAGATAATAAAGATGAAGATGAAGATGAAGAA------ 726 CAAGTAAAAGAGGACCCTCAAGAAGATAATAAAGATGAAGATGAAGATGAAGAA------ 726 CAAGTAAAAGAGGACCCTCAAGAAGATAATAAAGATGAAGATGAAGATGAAGAA----- 726 CAAGTAAAAGAGGACCCTCAAGAAGATAATAAAGATGAAGATGAAGATGAAGAA-- - - - 726 CAAGTAAAAGAGGACCCTCAAGAAGATAATAAAGATGAAGATGAAGATGAAGAA------ 726 CAAGTAAAAGAGGACCCTCAAGAAGATAATAAAGATGAAGATGAAGATGAAGAA------ 726

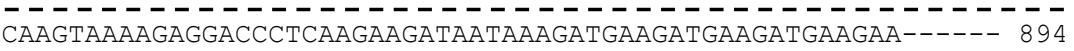
CAAGTAAAAGAGGACCCTCAAGAAGATAATAAAGATGAAGATGAAGATGAAGAA------ 894 CAAGTAAAAGAGGACCCTCAAGAAGATAATAAAGATGAAGATGAAGATGAAGAA----- 894 CAAGTAAAAGAGGACCCTCAAGAAGATAATAAAGATGAAGATGAAGATGAAGAA------ 894 CAAGTAAAAGAGGACCCTCAAGAAGATAATAAAGATGAAGATGAAGATGAAGATGAAGAA 900 CAAGTAAAAGAGGACCCTCAAGAAGATAATAAAGATGAAGATGAAGATGAAGAA------ 894 CAAGTAAAAGAGGACCCTCAAGAAGATAATAAAGATGAAGATGAAGATGAAGAA------ 894 CAAGTAAAAGAGGACCCTCAAGAAGATAATAAAGATGAAGATGAAGATGAAGAA------ 894 CAAGTAAAAGAGGACCCTCAAGAAGATAATAAAGATGAAGATGAAGATGAAGAA------ 894 CAAGTAAAAGAGGACCCTCAAGAAGATAATAAAGATGAAGATGAAGATGAAGAA----- 894 CAAGTAAAAGAGGACCCTCAAGAAGATAATAAAGATGAAGATGAAGATGAAGAA----- 894 CAAGTAAAAGAGGACCCTCAAGAAGATAATAAAGATGAAGATGAAGATGAAGAA------ 894 CAAGTAAAAGAGGACCCTCAAGAAGATAATAAAGATGAAGATGAAGATGAAGAA- - - - - 894 CAAGTAAAAGAGGACCCTCAAGAAGATAATAAAGATGAAGATGAAGATGAAGAA------ 771

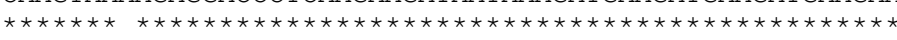


3D7

D10

NHC-1

IT

NF7

T9/96

32

B3

DE2 8

HB 3

04

$7 \mathrm{G} 8$

42

BA2 4

PC1 7

B1

106

59

54

45

27

06

20

134

608

$\mathrm{MC}$

D2

62

W2mef

B2

B7

ICBIII

K1

$\mathrm{IC}$

Dd2

ACAGAAACAGAAAATTTGGAAACAGAAGATGATAATAATGAAGAGATAGAAGAAAATGAA 786 ACAGAAACAGAAAATTTGGAAACAGAAGATGATAATAATGAAGAGATAGAAGAAAATGAA 786 ACAGAAACAGAAAATTGGAAACAGAAGATGATAATAATGAAGAGATAGAAGAAAATGAA 786 ACAGAAACAGAAAATTTGGAAACAGAAGATGATAATAATGAAGAGATAGAAGAAAATGAA 786 ACAGAAACAGAAAATTGGAAACAGAAGATGATAATAATGAAGAGATAGAAGAAAATGAA 786 ACAGAAACAGAAAATTTGGAAACAGAAGATGATAATAATGAAGAGATAGAAGAAAATGAA 786 ACAGAAACAGAAAATTTGGAAACAGAAGATGATAATAATGAAGAGATAGAAGAAAATGAA 786 ACAGAAACAGAAAATTTGGAAACAGAAGATGATAATAATGAAGAGATAGAAGAAAATGAA 786 ACAGAAACAGAAAATTTGGAAACAGAAGATGATAATAATGAAGAGATAGAAGAAAATGAA 786 ACAGAAACAGAAAATTTGGAAAAGAAGATGATAATAATGAAGAGATAGAAGAAAATGAA 786 ACAGAAACAGAAAATTTGGAAACAGAAGATGATAATAATGAAGAGATAGAAGAAAATGAA 786 ACAGAAACAGAAAATTTGGAACAGAAGATGATAATAATGAAGAGATAGAAGAAAATGAA 786 ACAGAAACAGAAAATTTGGAAACAGAAGATGATAATAATGAAGAGATAGAAGAAAATGAA 786 ACAGAAACAGAAAATTTGGAAACAGAAGATGATAATAATGAAGAGATAGAAGAAAATGAA 786 ACAGAAACAGAAAATTTGGAAACAGAAGATGATAATAATGAAGAGATAGAAGAAAATGAA 786 ACAGAAACAGAAAATTTGGAAACAGAAGATGATAATAATGAAGAGATAGAAGAAAATGAA 786 ACAGAAACAGAAAATTTGGAAACAGAAGATGATAATAATGAAGAGATAGAAGAAAATGAA 786 ACAGAAACAGAAAATTTGGAAACAGAAGATGATAATAATGAAGAGATAGAAGAAAATGAA 786 ACAGAAACAGAAAATTTGGAAAAGAAGATGATAATAATGAAGAGATAGAAGAAAATGAA 786 ACAGAAACAGAAAATTTGGAAACAGAAGATGATAATAATGAAGAGATAGAAGAAAATGAA 786 ACAGAAACAGAAAATTTGGAAAAGAAGATGATAATAATGAAGAGATAGAAGAAAATGAA 786

ACAGAAACAGAAAATTGGAAACAGAAGATGATAATATGAAGAGATAGAAGAAAATGAA 954 ACAGAAACAGAAAATTTGGAAACAGAAGATGATAATAATGAAGAGATAGAAGAAAATGAA 954 ACAGAAACAGAAAATTTGGAAACAGAAGATGATAATAATGAAGAGATAGAAGAAAATGAA 954 ACAGAAACAGAAAATTTGGAAACAGAAGATGATAATAATGAAGAGATAGAAGAAAATGAA 954 ACAGAAACAGAAAATTTGGAAACAGAAGATGATAATAATGAAGAGATAGAAGAAAATGAA 960 ACAGAAACAGAAAATTTGAAACAGAAGATGATAATAATGAAGAGATAGAAGAAAATGAA 954 ACAGAAACAGAAAATTTGGAAACAGAAGATGATAATAATGAAGAGATAGAAGAAAATGAA 954 ACAGAAACAGAAAATTGGAAACAGAAGATGATAATAATGAAGAGATAGAAGAAAATGAA 954 ACAGAAACAGAAAATTTGGAAACAGAAGATGATAATAATGAAGAGATAGAAGAAAATGAA 954 ACAGAAACAGAAAATTTGGAAACAGAAGATGATAATAATGAAGAGATAGAAGAAAATGAA 954 ACAGAAACAGAAAATTTGGAAACAGAAGATGATAATAATGAAGAGATAGAAGAAAATGAA 954 ACAGAAACAGAAAATTTGGAAACAGAAGATGATAATAATGAAGAGATAGAAGAAAATGAA 954 ACAGAAACAGAAAATTTGGAAACAGAAGATGATAATAATGAAGAGATAGAAGAAAATGAA 954 ACAGAAACAGAAAATTGGAAACAGAAGATGATAATAATGAAGAGATAGAAGAAAATGAA 831

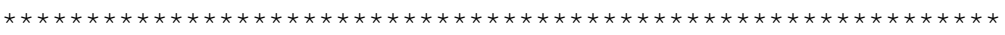

$3 \mathrm{D} 7$

110

$\mathrm{NHC}-1$

IT

NF7

T9/96

32

B3

DE2 8

HB3

04

$7 \mathrm{G} 8$

42

BA2 4

PC17

$\mathrm{B} 1$

106

59

59
54

45

27

06

06
20

134

608

$\mathrm{MC}$

D2

62

W2mef

B2

B7

ICBIII

K1

IC

Dd2

GAAGATGACATAGATGAAGAAAGTGTAGAAGAAAAGGAAGAAGAGGAAGAAAAAAAGGAA 846 GAAGATGACATAGATGAAGAAAGTGTAGAAGAAAAGGAAGAAGAGGAAGAAAAAAAGGAA 846 GAAGATGACATAGATGAAGAAAGTGTAGAAGAAAAGGAAGAAGAGGAAGAAAAAAAGGAA 846 GAAGATGACATAGATGAAGAAAGTGTAGAAGAAAAGGAAGAAGAGGAAGAAAAAAAGGAA 846 GAAGATGACATAGATGAAGAAAGTGTAGAAGAAAAGGAAGAAGAGGAAGAAAAAAAGGAA 846 GAAGATGACATAGATGAAGAAAGTGTAGAAGAAAAGGAAGAAGAGGAAGAAAAAAAGGAA 846 GAAGATGACATAGATGAAGAAAGTGTAGAAGAAAAGGAAGAAGAGGAAGAAAAAAAGGAA 846 GAAGATGACATAGATGAAGAAAGTGTAGAAGAAAAGGAAGAAGAGGAAGAAAAAAAGGAA 846 GAAGATGACATAGATGAAGAAAGTGTAGAAGAAAAGGAAGAAGAGGAAGAAAAAAAGGAA 846 GAAGATGACATAGATGAAGAAAGTGTAGAAGAAAAGGAAGAAGAGGAAGAAAAAAAGGAA 846 GAAGATGACATAGATGAAGAAAGTGTAGAAGAAAAGGAAGAAGAGGAAGAAAAAAAGGAA 846 GAAGATGACATAGATGAAGAAAGTGTAGAAGAAAAGGAAGAAGAGGAAGAAAAAAAGGAA 846 GAAGATGACATAGATGAAGAAAGTGTAGAAGAAAAGGAAGAAGAGGAAGAAAAAAAGGAA 846 GAAGATGACATAGATGAAGAAAGTGTAGAAGAAAAGGAAGAAGAGGAAGAAAAAAAGGAA 846 GAAGATGACATAGATGAAGAAAGTGTAGAAGAAAAGGAAGAAGAGGAAGAAAAAAAGGAA 846 GAAGATGACATAGATGAAGAAAGTGTAGAAGAAAAGGAAGAAGAGGAAGAAAAAAAGGAA 846 GAAGATGACATAGATGAAGAAAGTGTAGAAGAAAAGGAAGAAGAGGAAGAAAAAAAGGAA 846 GAAGATGACATAGATGAAGAAAGTGTAGAAGAAAAGGAAGAAGAGGAAGAAAAAAAGGAA 846 GAAGATGACATAGATGAAGAAAGTGTAGAAGAAAAGGAAGAAGAGGAAGAAAAAAAGGAA 846 GAAGATGACATAGATGAAGAAAGTGTAGAAGAAAAGGAAGAAGAGGAAGAAAAAAAGGAA 846 GAAGATGACATAGATGAAGAAAGTGTAGAAGAAAAGGAAGAAGAGGAAGAAAAAAAGGAA 846 GAAGATGACATAGATGAAGAAGTGTAGAAAAAAGGÄGAAGAGGÄAAAAAAAGGA 1014 GAAGATGACATAGATGAAGAAAGTGTAGAAGAAAAGGAAGAAGAGGAAGAAAAAAAGGAA 1014 GAAGATGACATAGATGAAGAAAGTGTAGAAGAAAAGGAAGAAGAGGAAGAAAAAAAGGAA 1014 GAAGATGACATAGATGAAGAAAGTGTAGAAGAAAAGGAAGAAGAGGAAGAAAAAAAGGAA 1014 GAAGATGACATAGATGAAGAAAGTGTAGAAGAAAAGGAAGAAGAGGAAGAAAAAAAGGAA 1020 GAAGATGACATAGATGAAGAAAGTGTAGAAGAAAAGGAAGAAGAGGAAGAAAAAAAGGAA 1014 GAAGATGACATAGATGAAGAAAGTGTAGAAGAAAAGGAAGAAGAGGAAGAAAAAAAGGAA 1014 GAAGATGACATAGATGAAGAAAGTGTAGAAGAAAAGGAAGAAGAGGAAGAAAAAAAGGAA 1014 GAAGATGACATAGATGAAGAAAGTGTAGAAGAAAAGGAAGAAGAGGAAGAAAAAAAGGAA 1014 GAAGATGACATAGATGAAGAAAGTGTAGAAGAAAAGGAAGAAGAGGAAGAAAAAAAGGAA 1014 GAAGATGACATAGATGAAGAAAGTGTAGAAGAAAAGGAAGAAGAGGAAGAAAAAAAGGAA 1014 GAAGATGACATAGATGAAGAAAGTGTAGAAGAAAAGGAAGAAGAGGAAGAAAAAAAGGAA 1014 GAAGATGACATAGATGAAGAAAGTGTAGAAGAAAAGGAAGAAGAGGAAGAAAAAAAGGAA 1014 GAAGATGACATAGATGAAGAAAGTGTAGAAGAAAAGGAAGAAGAGGAAGAAAAAAAGGAA 891

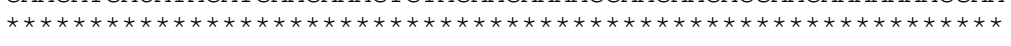


GAAGAAGAAAAAAAGGAAGAAAAAAAAGAAGAAAAAAAACCAGACAATGAAATTACAAAT 906 GAAGAAGAAAAAAAGGAAGAAAAAAAAGAAGAAAAAAAACCAGACAATGAAATTACAAAT 906 GAAGAAGAAAAAAAGGAAGAAAAAAAAGAAGAAAAAAAACCAGACAATGAAATTACAAAT 906 GAAGAAGAAAAAAAGGAAGAAAAAAAAGAAGAAAAAAAACCAGACAATGAAATTACAAAT 906 GAAGAAGAAAAAAAGGAAGAAAAAAAAGAAGAAAAAAAACCAGACAATGAAATTACAAAT 906 GAAGAAGAAAAAAAGGAAGAAAAAAAAGAAGAAAAAAAACCAGACAATGAAATTACAAAT 906 GAAGAAGAAAAAAAGGAAGAAAAAAAAGAAGAAAAAAAACCAGACAATGAAATTACAAAT 906 GAAGAAGAAAAAAAGGAAGAAAAAAAAGAAGAAAAAAAACCAGACAATGAAATTACAAAT 906 GAAGAAGAAAAAAAGGAAGAAAAAAAAGAAGAAAAAAAACCAGACAATGAAATTACAAAT 906 GAAGAAGAAAAAAAGGAAGAAAAAAAAGAAGAAAAAAAACCAGACAATGAAATTACAAAT 906 GAAGAAGAAAAAAAGGAAGAAAAAAAAGAAGAAAAAAAACCAGACAATGAAATTACAAAT 906 GAAGAAGAAAAAAAGGAAGAAAAAAAAGAAGAAAAAAAACCAGACAATGAAATTACAAAT 906 GAAGAAGAAAAAAAGGAAGAAAAAAAAGAAGAAAAAAAACCAGACAATGAAATTACAAAT 906 GAAGAAGAAAAAAAGGAAGAAAAAAAAGAAGAAAAAAAACCAGACAATGAAATTACAAAT 906 GAAGAAGAAAAAAAGGAAGAAAAAAAAGAAGAAAAAAAACCAGACAATGAAATTACAAAT 906 GAAGAAGAAAAAAAGGAAGAAAAAAAAGAAGAAAAAAAACCAGACAATGAAATTACAAAT 906 GAAGAAGAAAAAAAGGAAGAAAAAAAAGAAGAAAAAAAACCAGACAATGAAATTACAAAT 906 GAAGAAGAAAAAAAGGAAGAAAAAAAAGAAGAAAAAAAACCAGACAATGAAATTACAAAT 906 GAAGAAGAAAAAAAGGAAGAAAAAAAAGAAGAAAAAAAACCAGACAATGAAATTACAAAT 906 GAAGAAGAAAAAAAGGAAGAAAAAAAAGAAGAAAAAAAACCAGACAATGAAATTACAAAT 906 GAAGAAGAAAAAAGGAAGAAAAAAAGAAGAAAAAAACCAGACAATGAAATTACAAAT 906 GAAGAAGAAAAAAGGAAGAAAAAAAGAAGAAAAAAACCAGACATGAAATTACAAAT 1074 GAAGAAGAAAAAAAGGAAGAAAAAAAAGAAGAAAAAAAACCAGACAATGAAATTACAAAT 1074 GAAGAAGAAAAAAAGGAAGAAAAAAAAGAAGAAAAAAAACCAGACAATGAAATTACAAAT 1074 GAAGAAGAAAAAAAGGAAGAAAAAAAAGAAGAAAAAAAACCAGACAATGAAATTACAAAT 1074 GAAGAAGAAAAAAAGGAAGAAAAAAAAGAAGAAAAAAAACCAGACAATGAAATTACAAAT 1080 GAAGAAGAAAAAAAGGAAGAAAAAAAAGAAGAAAAAAAACCAGACAATGAAATTACAAAT 1074 GAAGAAGAAAAAAAGGAAGAAAAAAAAGAAGAAAAAAAACCAGACAATGAAATTACAAAT 1074 GAAGAAGAAAAAAAGGAAGAAAAAAAAGAAGAAAAAAAACCAGACAATGAAATTACAAAT 1074 GAAGAAGAAAAAAAGGAAGAAAAAAAAGAAGAAAAAAAACCAGACAATGAAATTACAAAT 1074 GAAGAAGAAAAAAAGGAAGAAAAAAAAGAAGAAAAAAAACCAGACAATGAAATTACAAAT 1074 GAAGAAGAAAAAAAGGAAGAAAAAAAAGAAGAAAAAAAACCAGACAATGAAATTACAAAT 1074 GAAGAAGAAAAAAAGGAAGAAAAAAAAGAAGAAAAAAAACCAGACAATGAAATTACAAAT 1074 GAAGAAGAAAAAAAGGAAGAAAAAAAAGAAGAAAAAAAACCAGACAATGAAATTACAAAT 1074 GAAGAAGAAAAAAAGGAAGAAAAAAAGAAGAAAAAAAACCAGACAATGAAATTACAAAT 951

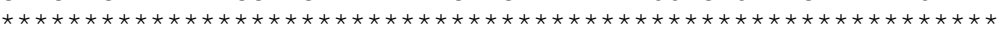

GAAGTTAAAGAGGAACAAAAATATAGTTCACCAAGTGATATAAATGCCCAAAATTTAATT 966 GAAGTTAAAGAGGAACAAAAATATAGTTCACCAAGTGATATAAATGCCCAAAATTTAATT 966 GAAGTTAAAGAGGAACAAAAATATAGTTCACCAAGTGATATAAATGCCCAAAATTTAATT 966 GAAGTTAAAGAGGAACAAAAATATAGTTCACCAAGTGATATAAATGCCCAAAATTTAATT 966 GAAGTTAAAGAGGAACAAAAATATAGTTCACCAAGTGATATAAATGCCCAAAATTTAATT 966 GAAGTTAAAGAGGAACAAAAATATAGTTCACCAAGTGATATAAATGCCCAAAATTTAATT 966 GAAGTTAAAGAGGAACAAAAATATAGTTCACCAAGTGATATAAATGCCCAAAATTTAATT 966 GAAGTTAAAGAGGAACAAAAATATAGTTCACCAAGTGATATAAATGCCCAAAATTTAATT 966 GAAGTTAAAGAGGAACAAAAATATAGTTCACCAAGTGATATAAATGCCCAAAATTTAATT 966 GAAGTTAAAGAGGAACAAAAATATAGTTCACCAAGTGATATAAATGCCCAAAATTTAATT 966 GAAGTTAAAGAGGAACAAAAATATAGTTCACCAAGTGATATAAATGCCCAAAATTTAATT 966 GAAGTTAAAGAGGAACAAAAATATAGTTCACCAAGTGATATAAATGCCCAAAATTTAATT 966 GAAGTTAAAGAGGAACAAAAATATAGTTCACCAAGTGATATAAATGCCCAAAATTTAATT 966 GAAGTTAAAGAGGAACAAAAATATAGTTCACCAAGTGATATAAATGCCCAAAATTTAATT 966 GAAGTTAAAGAGGAACAAAAATATAGTTCACCAAGTGATATAAATGCCCAAAATTTAATT 966 GAAGTTAAAGAGGAACAAAAATATAGTTCACCAAGTGATATAAATGCCCAAAATTTAATT 966 GAAGTTAAAGAGGAACAAAAATATAGTTCACCAAGTGATATAAATGCCCAAAATTTAATT 966 GAAGTTAAAGAGGAACAAAAATATAGTTCACCAAGTGATATAAATGCCCAAAATTTAATT 966 GAAGTTAAAGAGGAACAAAAATATAGTTCACCAAGTGATATAAATGCCCAAAATTTAATT 966 GAAGTTAAAGAGGAACAAAAATATAGTTCACCAAGTGATATAAATGCCCAAAATTTAATT 966 GAAGTTAAAGAGGAACAAAAATATAGTTCACCAAGTGATATAAATGCCCAAAATTTAATT 966 GAAGTTAAAGAGGACAAAAATAAGTTCACCAAGTGATATAATGCCCAAAATTAATT 1134 GAAGTTAAAGAGGAACAAAAATATAGTTCACCAAGTGATATAAATGCCCAAAATTTAATT 1134 GAAGTTAAAGAGGAACAAAAATATAGTTCACCAAGTGATATAAATGCCCAAAATTTAATT 1134 GAAGTTAAAGAGGAACAAAAATATAGTTCACCAAGTGATATAAATGCCCAAAATTTAATT 1134 GAAGTTAAAGAGGAACAAAAATATAGTTCACCAAGTGATATAAATGCCCAAAATTTAATT 1140 GAAGTTAAAGAGGAACAAAAATATAGTTCACCAAGTGATATAAATGCCCAAAATTTAATT 1134 GAAGTTAAAGAGGAACAAAAATATAGTTCACCAAGTGATATAAATGCCCAAAATTTAATT 1134 GAAGTTAAAGAGGAACAAAAATATAGTTCACCAAGTGATATAAATGCCCAAAATTTAATT 1134 GAAGTTAAAGAGGAACAAAAATATAGTTCACCAAGTGATATAAATGCCCAAAATTTAATT 1134 GAAGTTAAAGAGGAACAAAAATATAGTTCACCAAGTGATATAAATGCCCAAAATTTAATT 1134 GAAGTTAAAGAGGAACAAAAATATAGTTCACCAAGTGATATAAATGCCCAAAATTTAATT 1134 GAAGTTAAAGAGGAACAAAAATATAGTTCACCAAGTGATATAAATGCCCAAAATTTAATT 1134 GAAGTTAAAGAGGAACAAAAATATAGTTCACCAAGTGATATAAATGCCCAAAATTTAATT 1134 GAAGTTAAAGAGGAACAAAAATATAGTTCACCAAGTGATATAAATGCCCAAAATTTAATT 1011

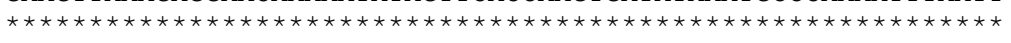


3D7

D10

NHC-1

IT

NF7

T9/96

32

B3

DE2 8

HB 3

04

$7 \mathrm{G} 8$

42

BA2 4

PC1 7

B1

106

59

54

45

27

06

20

134

608

$\mathrm{MC}$

D2

62

W2mef

B2

B7

ICBIII

K1

IC

Dd2

TCTAATAAGAATAAAAAGAATGATGAAACAAAAAAGACTGCTGAAAATATAGTTAAAACA 1026 TCTAATAAGAATAAAAAGAATGATGAAACAAAAAAGACTGCTGAAAATATAGTTAAAACA 1026 TCTAATAAGAATAAAAAGAATGATGAAACAAAAAAGACTGCTGAAAATATAGTTAAAACA 1026 TCTAATAAGAATAAAAAGAATGATGAAACAAAAAAGACTGCTGAAAATATAGTTAAAACA 1026 TCTAATAAGAATAAAAAGAATGATGAAACAAAAAAGACTGCTGAAAATATAGTTAAAACA 1026 TCTAATAAGAATAAAAAGAATGATGAAACAAAAAAGACTGCTGAAAATATAGTTAAAACA 1026 TCTAATAAGAATAAAAAGAATGATGAAACAAAAAAGACTGCTGAAAATATAGTTAAAACA 1026 TCTAATAAGAATAAAAAGAATGATGAAACAAAAAAGACTGCTGAAAATATAGTTAAAACA 1026 TCTAATAAGAATAAAAAGAATGATGAAACAAAAAAGACTGCTGAAAATATAGTTAAAACA 1026 TCTAATAAGAATAAAAAGAATGATGAAACAAAAAAGACTGCTGAAAATATAGTTAAAACA 1026 TCTAATAAGAATAAAAAGAATGATGAAACAAAAAAGACTGCTGAAAATATAGTTAAAACA 1026 TCTAATAAGAATAAAAAGAATGATGAAACAAAAAAGACTGCTGAAAATATAGTTAAAACA 1026 TCTAATAAGAATAAAAAGAATGATGAAACAAAAAAGACTGCTGAAAATATAGTTAAAACA 1026 TCTAATAAGAATAAAAAGAATGATGAAACAAAAAAGACTGCTGAAAATATAGTTAAAACA 1026 TCTAATAAGAATAAAAAGAATGATGAAACAAAAAAGACTGCTGAAAATATAGTTAAAACA 1026 TCTAATAAGAATAAAAAGAATGATGAAACAAAAAAGACTGCTGAAAATATAGTTAAAACA 1026 TCTAATAAGAATAAAAAGAATGATGAAACAAAAAAGACTGCTGAAAATATAGTTAAAACA 1026 TCTAATAAGAATAAAAAGAATGATGAAACAAAAAAGACTGCTGAAAATATAGTTAAAACA 1026 TCTAATAAGAATAAAAAGAATGATGAAACAAAAAAGACTGCTGAAAATATAGTTAAAACA 1026 TCTAATAAGAATAAAAAGAATGATGAAACAAAAAAGACTGCTGAAAATATAGTTAAAACA 1026 TCTAATAAGAATAAAAAGAATGATGAAACAAAAAAGACTGCTGAAAATATAGTTAAAACA 1026 TCTAATAAGAATAAAAAGATGATGAAACAAAAAAGACTGCTGAAAATATAGTTAAAACA 1194 TCTAATAAGAATAAAAAGAATGATGAAACAAAAAAGACTGCTGAAAATATAGTTAAAACA 1194 TCTAATAAGAATAAAAAGAATGATGAAACAAAAAAGACTGCTGAAAATATAGTTAAAACA 1194 TCTAATAAGAATAAAAAGAATGATGAAACAAAAAAGACTGCTGAAAATATAGTTAAAACA 1194 TCTAATAAGAATAAAAAGAATGATGAAACAAAAAAGACTGCTGAAAATATAGTTAAAACA 1200 TCTAATAAGAATAAAAAGAATGATGAAACAAAAAAGACTGCTGAAAATATAGTTAAAACA 1194 TCTAATAAGAATAAAAAGAATGATGAAACAAAAAAGACTGCTGAAAATATAGTTAAAACA 1194 TCTAATAAGAATAAAAAGAATGATGAAACAAAAAAGACTGCTGAAAATATAGTTAAAACA 1194 TCTAATAAGAATAAAAAGAATGATGAAACAAAAAAGACTGCTGAAAATATAGTTAAAACA 1194 TCTAATAAGAATAAAAAGAATGATGAAACAAAAAAGACTGCTGAAAATATAGTTAAAACA 1194 TCTAATAAGAATAAAAAGAATGATGAAACAAAAAAGACTGCTGAAAATATAGTTAAAACA 1194 TCTAATAAGAATAAAAAGAATGATGAAACAAAAAAGACTGCTGAAAATATAGTTAAAACA 1194 TCTAATAAGAATAAAAAGAATGATGAAACAAAAAAGACTGCTGAAAATATAGTTAAAACA 1194 TCTAATAAGAATAAAAAGAATGATGAAACAAAAAAGACTGCTGAAAATATAGTTAAAACA 1071

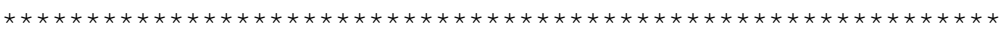

$3 \mathrm{D} 7$

D10

$\mathrm{NHC}-1$

IT

NF7

T9/96

32

32

B3
DE2 8

HB3

04

$7 \mathrm{G} 8$

42

BA2 4

PC17

$\mathrm{PC} 1$
$\mathrm{~B} 1$

106

59

59
54

45

27

06

06
20

20

134

608

$\mathrm{MC}$

D2

62

W2mef

B2

B7

ICBIII

K1

IC

Dd2

TTGGTTGGATTATTTAATGAAAAAAATGAGATAGATTCTACTATAAATAATTTAGTACAA 1086 TTGGTTGGATTATTTAATGAAAAAAATGAGATAGATTCTACTATAAATAATTTAGTACAA 1086 TTGGTTGGATTATTTAATGAAAAAAATGAGATAGATTCTACTATAAATAATTTAGTACAA 1086 TTGGTTGGATTATTTAATGAAAAAAATGAGATAGATTCTACTATAAATAATTTAGTACAA 1086 TTGGTTGGATTATTTAATGAAAAAAATGAGATAGATTCTACTATAAATAATTTAGTACAA 1086 TTGGTTGGATTATTTAATGAAAAAAATGAGATAGATTCTACTATAAATAATTTAGTACAA 1086 TTGGTTGGATTATTTAATGAAAAAAATGAGATAGATTCTACTATAAATAATTTAGTACAA 1086 TTGGTTGGATTATTTAATGAAAAAAATGAGATAGATTCTACTATAAATAATTTAGTACAA 1086 TTGGTTGGATTATTTAATGAAAAAAATGAGATAGATTCTACTATAAATAATTTAGTACAA 1086 TTGGTTGGATTATTTAATGAAAAAAATGAGATAGATTCTACTATAAATAATTTAGTACAA 1086 TTGGTTGGATTATTTAATGAAAAAAATGAGATAGATTCTACTATAAATAATTTAGTACAA 1086 TTGGTTGGATTATTTAATGAAAAAAATGAGATAGATTCTACTATAAATAATTTAGTACAA 1086 TTGGTTGGATTATTTAATGAAAAAAATGAGATAGATTCTACTATAAATAATTTAGTACAA 1086 TTGGTTGGATTATTTAATGAAAAAAATGAGATAGATTCTACTATAAATAATTTAGTACAA 1086 TTGGTTGGATTATTTAATGAAAAAAATGAGATAGATTCTACTATAAATAATTTAGTACAA 1086 TTGGTTGGATTATTTAATGAAAAAAATGAGATAGATTCTACTATAAATAATTTAGTACAA 1086 TTGGTTGGATTATTTAATGAAAAAAATGAGATAGATTCTACTATAAATAATTTAGTACAA 1086 TTGGTTGGATTATTTAATGAAAAAAATGAGATAGATTCTACTATAAATAATTTAGTACAA 1086 TTGGTTGGATTATTTAATGAAAAAAATGAGATAGATTCTACTATAAATAATTTAGTACAA 1086 TTGGTTGGATTATTTAATGAAAAAAATGAGATAGATTCTACTATAAATAATTTAGTACAA 1086 TTGGTTGGATTATTTAATGAAAAAAATGAGATAGATTCTACTATAAATAATTTAGTACAA 1086 TTGGTTGGATTATTTAATGAAAAAATGAGATAGATTCTACTATAAATAATTTAGTACAA 1254 TTGGTTGGATTATTTAATGAAAAAAATGAGATAGATTCTACTATAAATAATTTAGTACAA 1254 TTGGTTGGATTATTTAATGAAAAAAATGAGATAGATTCTACTATAAATAATTTAGTACAA 1254 TTGGTTGGATTATTTAATGAAAAAAATGAGATAGATTCTACTATAAATAATTTAGTACAA 1254 TTGGTTGGATTATTTAATGAAAAAAATGAGATAGATTCTACTATAAATAATTTAGTACAA 1260 TTGGTTGGATTATTTAATGAAAAAAATGAGATAGATTCTACTATAAATAATTTAGTACAA 1254 TTGGTTGGATTATTTAATGAAAAAAATGAGATAGATTCTACTATAAATAATTTAGTACAA 1254 TTGGTTGGATTATTTAATGAAAAAAATGAGATAGATTCTACTATAAATAATTTAGTACAA 1254 TTGGTTGGATTATTTAATGAAAAAAATGAGATAGATTCTACTATAAATAATTTAGTACAA 1254 TTGGTTGGATTATTTAATGAAAAAAATGAGATAGATTCTACTATAAATAATTTAGTACAA 1254 TTGGTTGGATTATTTAATGAAAAAAATGAGATAGATTCTACTATAAATAATTTAGTACAA 1254 TTGGTTGGATTATTTAATGAAAAAAATGAGATAGATTCTACTATAAATAATTTAGTACAA 1254 TTGGTTGGATTATTTAATGAAAAAAATGAGATAGATTCTACTATAAATAATTTAGTACAA 1254 TTGGTTGGATTATTTAATGAAAAAAATGAGATAGATCTACTATAAATAATTTAGTACAA 1131

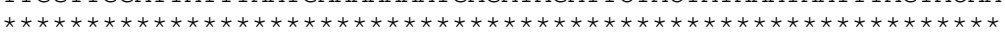




\begin{tabular}{|c|c|c|}
\hline 3D7 & GAAATGATCCATCTATTTAGTAATAAT & 1113 \\
\hline D10 & GAAATGATCCATCTATTTAGTAATAAT & 1113 \\
\hline $\mathrm{NHC}-1$ & GAAATGATCCATCTATTTAGTAATAAT & 1113 \\
\hline IT & GAAATGATCCATCTATTTAGTAATAAT & 1113 \\
\hline NF7 & GAAATGATCCATCTATTTAGTAATAAT & 1113 \\
\hline T9/96 & GAAATGATCCATCTATTTAGTAATAAT & 1113 \\
\hline 32 & GAAATGATCCATCTATTTAGTAATAAT & 1113 \\
\hline B3 & GAAATGATCCATCTATTTAGTAATAAT & 1113 \\
\hline DE28 & GAAATGATCCATCTATTTAGTAATAAT & 1113 \\
\hline HB3 & GAAATGATCCATCTATTTAGTAATAAT & 1113 \\
\hline 04 & GAAATGATCCATCTATTTAGTAATAAT & 1113 \\
\hline $7 \mathrm{G} 8$ & GAAATGATCCATCTATTTAGTAATAAT & 1113 \\
\hline 42 & GAAATGATCCATCTATTTAGTAATAAT & 1113 \\
\hline BA2 4 & GAAATGATCCATCTATTTAGTAATAAT & 1113 \\
\hline PC17 & GAAATGATCCATCTATTTAGTAATAAT & 1113 \\
\hline B1 & GAAATGATCCATCTATTTAGTAATAAT & 1113 \\
\hline 106 & GAAATGATCCATCTATTTAGTAATAAT & 1113 \\
\hline 59 & GAAATGATCCATCTATTTAGTAATAAT & 1113 \\
\hline 54 & GAAATGATCCATCTATTTAGTAATAAT & 1113 \\
\hline 45 & GAAATGATCCATCTATTTAGTAATAAT & 1113 \\
\hline 27 & GAAATGATCCATCTATTTAGTAATAAT & 1113 \\
\hline 06 & GAAATGATCCATCTATTTAGTAATAAT & 1281 \\
\hline 20 & GAAATGATCCATCTATTTAGTAATAAT & 1281 \\
\hline 134 & GAAATGATCCATCTATTTAGTAATAAT & 1281 \\
\hline 608 & GAAATGATCCATCTATTTAGTAATAAT & 1281 \\
\hline MC & GAAATGATCCATCTATTTAGTAATAAT & 1287 \\
\hline D2 & GAAATGATCTATCTATTTAGTAATAAT & 1281 \\
\hline 62 & GAAATGATCCATCTATTTAGTAATAAT & 1281 \\
\hline W2mef & GAAATGATCCATCTATTTAGTAATAAT & 1281 \\
\hline B2 & GAAATGATCCATCTATTTAGTAATAAT & 1281 \\
\hline B7 & GAAATGATCCATCTATTTAGTAATAAT & 1281 \\
\hline ICBIII & GAAATGATCCATCTATTTAGTAATAAT & 1281 \\
\hline & GAAATGATCCATCTATTTAGTAATAAT & 1281 \\
\hline IC & GAAATGATCCATCTATTTAGTAATAAT & 1281 \\
\hline D & GAAATGATCCATCTATTTAGTAATAAT & 1158 \\
\hline
\end{tabular}




\section{ANEXO B - ALINHAMENTO DAS SEQÜÊNCIAS REPRESENTATIVAS DOS ALELOS DE $m s p-6$ DE $P$. falciparum COM O GENE ORTÓLOGO EM $P$. reichenowi}

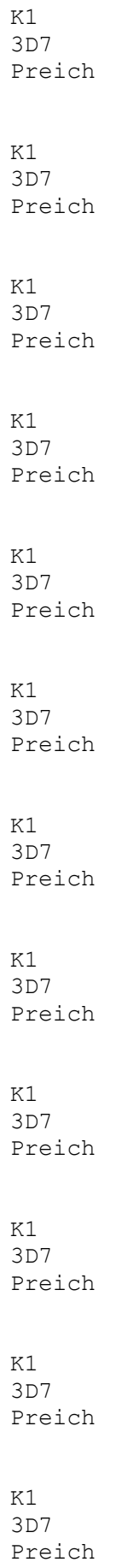

ATGAAтAAGATTATAATATTAстTTTCTTTTCATTCTTTTAAACTTATATATAAATGAA 60 ATGAATAAGATTTATAATATTACTTTTCTTTTCATTCTTTTAAACTTATATATAAATGAA 60 ATGAATAAgATTATAATATTACTTTTCTTTTCATTCTTTTAAACTTATATATAAATGAA 60

AATAACTTTATCAGAAATGAACTTATAAACGAAAAAAACCATAATTTAAGAAATGGTTCA 120 AATAACTTTATCAGAAATGAACTTATAAACGAAAAAAACCATAATTTAAGAAATGGTTCA 120

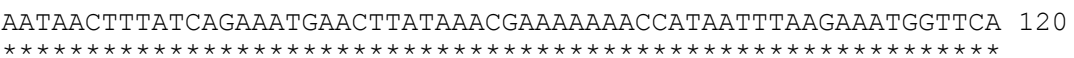

ATGTATAATAACGATAAAATATAAGTAAAAATGAAGTAGATACTAATATAGAAAGTAAC 180 ATGTATAATAACGATAAAATATTAAGTAAAAATGAAGTAGATACTAATATAGAAAGTAAC 180 ATATATAATAACGATAAAATATTAAGTAAAAATGAAGTAGATACTAATATAGAAAGTAAT 180

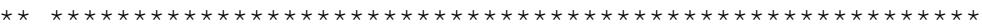

GAAAATAGTATTCACGAATCTGGACATAAGATTGATGGGGAAGAAGTTTTAAAAGCTAAT 240 GAAAATAGTATTCACGAATCTGGACATAAGATTGATGGGGAAGAAGTTTTAAAAGCTAAT 240 GAAAATAGTATTCACGAATCTGGACATAAGATTGAGGGGGAAGAAGTTTCAAAAGCTAAT 240

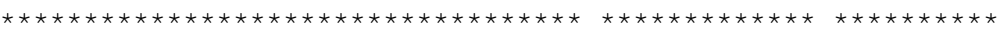

CAAGAACAAGCTAATGTAGAAGATATAACATACAAAAAAAAAAATGTGATGATTCAGAA 300 -------n---GTAGATGATATAACATACAAAAAAAAAAATGTTGATGATTCAGAA 285 CAAGAACAACCTAATGTAGAAGATATAACATACAAAAAAAAAGATGTTGTGATTCAGAA 300

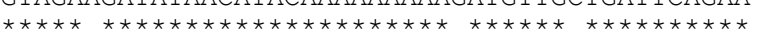

АтTсCтTTTTCTGGTTCTGATATACAGGCAACATATCAATTTCCTCCTACACCAGGAAGA 360 ATTCCTTTTCTGGTTATGATATACAAGCAACATATCAATTTCCTTCTACATCAGGA--- 342 ATTCCTTTTTCTGGTTCTGATATACAGGGAACATATCAATTTCCTCGTAAACCAGGAAGA 360

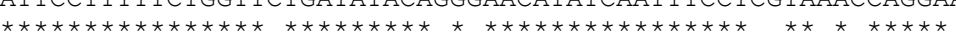

ATTATAAATCCTCGTACTGGAGGAAATACTGTAATTCCACCTCCTAGAAGACTAAGTGGA 420 ------------------GGAAATAATGTAATTCCACTTCCTATAAAAC------- 373 ATTACAAATCCTCGTACTGGAgGAAATACTATAATTCCACCTCCTAGTAGACTAAGTGGA 420

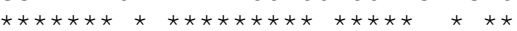

CTAGAAgGTGTTTCTTATCCACATGTATTTACATCTTCTAATCAATCACATCCTCAAAGA 480 CTAGAAgGTGTTCTTATCCATTTGTAтAтACATCTTCTAATCAACCACGTCCTCAAAgA 480

GCCAACATCGGAGGAATATCCCATTTATCAGGGACACGTGGAATTCATACTTATTCAGGT 540 GCCAACATCGGAGGCATATCCCATTTATCAGGGATACGTGGAATTCATACTTATTCAGGT 540

GAAAGTGGAGAAAATCACCATATTGTTACAACCAGACCAAATACTCAAAACCGAGCAAAA 600 -AAAGTGGAGAAAATCAATATACTGTTACATCTATATCAGGTATTCAAAAGGGAGCAAAT 432 GAAAGTGGAGAAAATCAACATATTGTTACATCCAGATCAAATACTCAAAACGGAGCAAAT 600

GGTTTAACTGGTGCAACAGAAAAAATTACACACGGTGCAGAAGAAAACTCTGAAACAAAT 660 GGTTTAACTGGTGCAACAGAAAATATTACACAAGTTGTACAAGCAAACTCTGAAACAAAT 492 GATTTAACTGGTACAACACAAGAAATTACACAAGGTGAACAAGCAAGCTCTGAAACAAAT 660

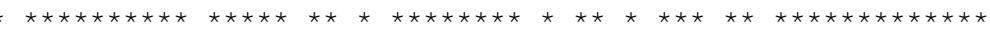

AAAAATCCTACTCCTGGTAGTAAAAGTACTACAACTTCTCTGAATAATAATATACTTGGA 720 AAAAATCCTACTTCTCATAGTAATAGTACTACAACTTCTCTGAATAATAATATACTTGGA 552 AGAAATCCTACTTCTGGTAGTAATAGTACTACAACTTCTCTGAATAATAATATACTTGGC 720 
K1

3D7

Preich

K1

3D7

Preich

K1

3D 7

Preich

K1

3D7

Preich

K1

3D7

Preich

K1

3D7

Preich

K1

3D 7

Preich

K1

3D7

Preich

K1

3D 7

Preich

K1

3D7

Preich
TGGGAATTTGGAGGAGGTGCTCCTCAAAATGGAGCTGCAGAAGATAAAAAGACAGAATAT 780 TGGGAATTTGGAGGAGGTGCTCCTCAAAATGGAGCTGCAGAAGATAAAAAGACAGAATAT 612 TGGGAATTTGGAGGAGGTGCTCCTCAAAATGGAGCTGCAGAAGATAAAAAGACAAATCAT 780

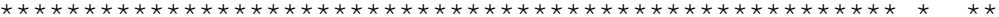

TTACTAGAACAAATAAAAATTCCATCATGGGATAGAAATAACATCCCCGATGAGAATGAA 840 TTACTAGAACAAATAAAAATCCATCATGGGATAGAAATAACATCCCCGATGAGAATGAA 672 TTACTAGAACAAATAAAAATCCATCATGGGATAGAGATAACATCCCCGATGAGAATGAA 840

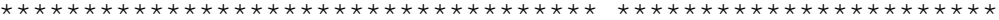

CAAGTAAAAGAGGACCCTCAAGAAGATAATAAAGATGAAGATGAAGATGAAGAAACAGAA 900 CAAGTAATAGAGGACCCTCAAGAAGATAATAAAGATGAAGATGAAGATGAAGAAACAGAA 732 CAAGTAATAGAGGACCCTCAAGAAGATAATAAAAATGACGAGGAAGAAACAGAAACAGAA 900

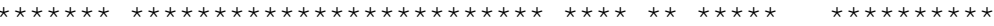

ACAGAAAATTTGGAAACAGAAGATGATAATAATGAAGAGATAGAAGAAAATGAAGAAGAT 960 ACAGAAAATTTGGAAACAGAAGATGATAATAATGAAGAGATAGAAGAAAATGAAGAAGAT 792 ACAGAAAATTGGAAACTGAAGAGGATAATAATGAAGAGATAGAAGAAAATGAAGAAGAT 960

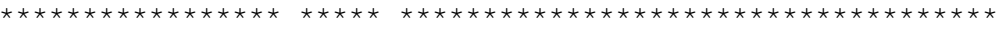

GACATAGATGAAGAAAGTGAGAAGAAAAGGAAGAAGAGGAAGAAAAAAAGGAAGAAGAA 1020 GACATAGATGAAGAAAGTGTAGAAGAAAAGGAAGAAGAGGAAGAAAAAAAGGAAGAAGAA 852 GATATAGATGAAGAAATGTAGAAGAAAACGAAGAAGATGACATAAATGATGAAAGTGTA 1020

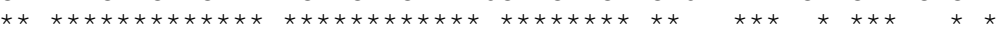

GAAAAAAAGGAAGAAAAAAAAGAAGAAAAAAACCAGACAATGAAATTACAAATGAAGTT 1080 GAAAAAAAGGAAGAAAAAAAAGAGAAAAAAAACCAGACAATGAAATTACAAATGAAGTT 912 GAAGAAAAGGAAGAAAAAACAGAAGAAAAAA---CAGAAAATAAAATTACAAATGAAGGT 1077

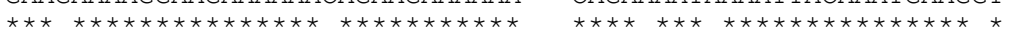

AAAGAGGAACAAAAATATAGTTCACCAAGTGATATAAATGCCCAAAATTTAATTTCTAAT 1140 AAAGAGGAACAAAAATATAGTTCACCAAGTGATATAAATGCCCAAAATTTAATTTCTAAT 972 AAAGAGGAACAAAAGAATAATTCACCAAGTGATATAAATGCCCAAAATTTAATTTCTAAT 1137

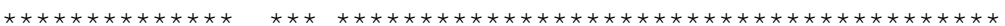

AAGAATAAAAAGAATGATGAAACAAAAAAGACTGCTGAAAATATAGTTAAAACATTGGTT 1200 AAGAATAAAAAGAATGATGAAACAAAAAAGACTGCTGAAAATATAGTTAAAACATTGGTT 1032 AAGCATAAAAAGAATGATGAAACAAAAAAGACTGCTGAAAATATAGTTAAAACATTGGTT 1197

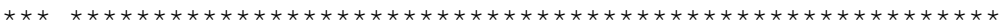

GGATTATTTAATGAAAAAAATGAGATAGATTCTACTATAAATAATTTAGTACAAGAAATG 1260 GGATTATTTAATGAAAAAAATGAGATAGATTCTACTATAAATAATTTAGTACAAGAAATG 1092 GGATTATTCAGTGAAAAAAATCAGATAGATTCTACTATAAATAATTTAGTACAAGAAATG 1257

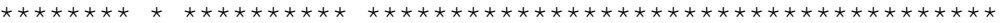

ATCCATCTATTTAGTAATAAT 1281

ATCCATCTATTTAGTAATAAT 1113

ATCCATCTATTTAGTAATAAT 1278

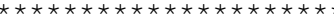

